\title{
Young Adults in the Workplace: A Multisite Initiative of Substance Use Prevention Programs
}

Edited by Jeremy W. Bray, Deborah M. Galvin, and Laurie A. Cluff
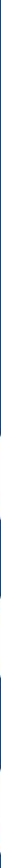



\title{
Young Adults in the Workplace: A Multisite Initiative of Substance Use Prevention Programs
}

\author{
Edited by \\ Jeremy W. Bray, Deborah M. Galvin, and Laurie A. Cluff
}

March 2011 
C2011 Research Triangle Institute. RTI International is a registered trademark and a trade name of Research Triangle Institute. The RTI logo is a registered trademark of Research Triangle Institute.

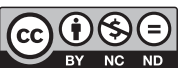

This work is distributed under the terms of a Creative Commons

Attribution-NonCommercial-NoDerivatives 4.0 license (CC BY-NC-ND), a copy of which is available at https://creativecommons.org/licenses/ by-nc-nd/4.0/legalcode.

ISBN 978-1-934831-03-8

RTI Press Publication No. BK-0005-1103

https://doi.org/10.3768/rtipress.2011.bk.0005.1103 www.rti.org/rtipress

The project described was supported by the Steering Committee of the Young Adults in the Workplace (YIW) cooperative agreement, a program funded through Substance Abuse and Mental Health Services Administration (SAMHSA), U.S. Department of Health and Human Services (HHS). The YIW Steering Committee, composed of SAMHSA, the RTI cross-site evaluation contract (HHSS28320070002I/ HHSS28300002T), and the YIW Phase 2 grants (ISA Associates: SP11128-03; National Health Promotion Associates: SP11134-03; Organizational Wellness and Learning Systems: SP11129-02; Peer Assistance Services \& OMNI Institute: SP11121-02; Pacific Institutes for Research and Evaluation: SP11140-01; RMC Research Corporation: SP11137-01) all assisted in the writing of the book. The views, policies, and opinions expressed are those of the authors and do not necessarily reflect those of SAMHSA or HHS.
The RTI Press mission is to disseminate information about RTI research, analytic tools, and technical expertise to a national and international audience. RTI Press publications are peer-reviewed by at least two independent substantive experts and one or more Press editors.

RTI International is an independent, nonprofit research institute dedicated to improving the human condition. We combine scientific rigor and technical expertise in social and laboratory sciences, engineering, and international development to deliver solutions to the critical needs of clients worldwide.

This publication is part of the RTI Press Book series.

RTI International

3040 Cornwallis Road, PO Box 12194, Research Triangle Park, NC 27709-2194 USA

rtipress@rti.org

www.rti.org 


\section{Contents}

About the Editors iv

Acknowledgments $\mathrm{V}$

Chapter 1. The Young Adults in the Workplace Initiative: An Introduction

Deborah M. Galvin, William Schlenger, and Johannes Norling

Chapter 2. Healthy WorkLife for Young Adults: Implementing

Health Promotion and Substance Abuse Prevention in a

Health Care Setting

Rebekah K. Hersch, Royer F. Cook, Daniel Hughes,

Samantha L. Leaf, and Douglas W. Billings

Chapter 3. Substance Abuse Prevention for the Young Workforce in the Railroad Industry: An Adaptation of the PREVENT

Program

Rebecca Spicer, Ted Miller, and Eduard Zaloshnja

Chapter 4. Team Resilience: Health Promotion for Young

Restaurant Workers

Joel B. Bennett and Charles C. Aden

Chapter 5. Substance Abuse Prevention in the Electrical Industry:

The NECA-IBEW Team Awareness and Team Vigilance

Programs

Eric Einspruch, Chris O'Neill, Kelly Jarvis, Kelly Vander Ley, and

Paméla Raya-Carlton

Chapter 6. Adapted Team Awareness for Youth and

Conservation Corps

Jean Denious, Chandra Ring, Nick Reese, Jennifer Hooks,

Caitlin Kozicki, Cori Stott, and Brie Reimann

Chapter 7. LifeSkills Training Wellness Program: An Application

for Young Adults in Supermarkets

Christopher Williams, Jessica Samuolis, Kenneth W. Griffin, and Gilbert J. Botvin

Chapter 8. The Young Adults in the Workplace Initiative:

Cross-Site Evaluation Methods

Georgia T. Karuntzos, Jeremy Bray, Laurie Cluff, and

Deborah M. Galvin

Contributors 


\section{About the Editors}

Jeremy W. Bray, PhD, RTI Fellow in Health Economics, received his doctorate in economics from the University of North Carolina at Chapel Hill in December 2000. He is the cross-site evaluation director for the Young Adults in the Workplace initiative and the principal investigator of the Data and Methods Coordinating Center for Phase II of the NICHD-funded Work, Family, and Health Network (WFHN). Dr. Bray also serves as the project director of the Cross-Site Evaluation of the SAMHSA Screening, Brief Intervention, Referral, and Treatment (SBIRT) Program. He was a co-investigator on a National Institute on Alcohol Abuse and Alcoholism (NIAAA)-funded cost-effectiveness study of COMBINE, a multisite trial testing the efficacy of naltrexone, acamprosate, and behavioral therapies, both alone and in combination, for the treatment of alcohol dependence. Dr. Bray is an adjunct associate professor of economics at the University of North Carolina at Greensboro and an assistant editor for Addiction.
Deborah M. Galvin, PhD, is the Workplace Prevention Research Manager for the Division of Workplace Programs at the Substance Abuse and Mental Health Services Administration's Center for Substance Abuse Prevention. She received her doctorate in sociology/ criminology from the University of Pennsylvania, has over 20 years experience in social science research, and is widely published at the national and international levels. Dr. Galvin has been responsible at SAMHSA for the Young Adults in the Workplace program, Workplace Managed Care, and a variety of programs related to prevention of substance abuse and related concerns including comorbidity, violence, and the integration of emotional, behavioral, and physical health issues along with related methodological and research issues. She also is an adjunct professor at George Washington University and the University of Maryland.

Laurie A. Cluff, $\mathrm{PhD}$, is a research psychologist at RTI International. She received her doctorate in industrial and organizational psychology from North Carolina State University. Her work includes occupational analysis and research focused on employees' health, well-being, and safety and the organizational factors that affect these outcomes. Dr. Cluff is the Associate Project Director for the Young Adults in the Workplace cross-site evaluation. 


\section{Acknowledgments}

The results and analyses discussed in this book are based on research supported by the Young Adults in the Workplace (YIW) initiative, funded by the Substance Abuse and Mental Health Services Administration (SAMHSA). A great number of colleagues, researchers, and federal staff were invaluable in the development and implementation of our work. We are indebted to our YIW workplace partners, who implemented the programs described in these chapters, and to the grantees who contributed the framework, evaluation, and positive energy to explore with us new methods in substance abuse prevention for a younger workforce. Organizational leaders and frontline managers provided the critical support needed to obtain employee participation and worked to frame and implement the new ideas through health/wellness and traditional drug-free workplace programs. Special thanks goes to the YIW Steering Committee, reviewers, and production staff who contributed a great deal to the content, organization, and readability of the book. 



\title{
The Young Adults in the Workplace Initiative: An Introduction
}

\author{
Deborah M. Galvin, ${ }^{2}$ William Schlenger, ${ }^{2}$ and Johannes Norling ${ }^{3}$ \\ 1Substance Abuse and Mental Health Services Administration, RockVille, MD; \\ 2abt Associates, Durham, NC; ${ }^{3}$ University of Michigan, Ann Arbor, MI
}

At the turn of the 21st century, American workplaces began to recognize some important sociodemographic changes in the workforce. As the initial wave of the post-World War II baby boom (i.e., Americans born between 1945 and 1964) advanced toward retirement, it became clear that the workforce was becoming younger and more diverse, that this trend would continue for decades, and that these changes posed challenges to workplaces more accustomed to an older workforce.

Although higher rates of substance use among young adults aged 16 to 24 are well-established (OAS, 2010), existing workplace substance use prevention and early intervention programs primarily target older workers. These data suggest that workplaces need substance abuse prevention and early intervention programs that are proven to be efficacious with young working adults. Research has also shown that young adults are at high risk for other potentially unhealthy behaviors that frequently co-occur with substance abuse and that these behaviors can be addressed by workplace prevention and early intervention programs (Corrado et al., 2003; Ludwig et al., 1999; McFarlane et al., 2002).

To address this critical need in American workplaces, in 2004 the Substance Abuse and Mental Health Services Administration (SAMHSA) announced its Young Adults in the Workplace initiative (originally entitled Youth in the Workplace [YIW]) (SAMHSA, 2004). The YIW initiative was designed as a two-phase collaborative effort among SAMHSA investigators, multiple grantees, and a coordinating center. It was conceived as a mechanism to test the efficacy of workplace substance use prevention or early intervention programs for young working adults aged 16 to 24 .

In Phase I, SAMHSA required grantees to develop workplace programs by starting with interventions shown to be efficacious either for adults in 
workplace settings or for young adults in non-workplace settings and to modify these programs specifically for use with young adult workers. In Phase II, SAMHSA funded a subset of the Phase I grantees to implement the workplace programs and to participate in a cross-site evaluation of the YIW initiative conducted by the Coordinating Center. Based on a peer-review process, SAMHSA funded 13 Phase I grantees and 6 Phase II grantee teams (including workplace partners).

This book briefly describes the background and rationale for the YIW initiative (this chapter), presents the interventions implemented by the six YIW grantees (Chapters 2 through 7), and provides an overview of the methods and design of the cross-site evaluation (Chapter 8). The remainder of this introductory chapter provides an overview of some important issues that must be addressed in developing interventions to prevent or reduce substance use among young adults and in testing those interventions in workplace settings. First, we provide a justification for YIW's focus on young adults aged 16 to 24. Next, we discuss substance use patterns and related issues among this population. Finally, we discuss issues relevant to the evaluation of workplace interventions.

\section{Defining Young Adults for the YIW InItiative}

Although social and psychological research suggests a variety of other definitions for young adults, the need to address workplace issues guided the decision to define young adults as individuals aged 16 to 24 because this is the age range when most people enter the workforce. Nonetheless, other conceptualizations of young adulthood inform the YIW initiative and provide useful guidance on the numerous issues that might be encountered by YIW grantees as they develop workplace substance use prevention programs for young adults.

The transition from adolescence to adulthood has long been viewed as an important developmental stage. For example, the Tibetan Book of the Dead describes circular life states and asserts that young adulthood occurs between the ages of 20 and 35 (translated, Thurman, 1993). Plato's Republic alludes to the specific transition of young adulthood and notes the increased corruption of youth as they transfer into adulthood (Ferrari, 2007). G. Stanley Hall, who was the first psychologist to focus on human development and life course, held the heavily biological view that human child development recapitulated human evolution (1904). Subsequently, Erik Erikson's psychosocial theory analyzed 
the human life span in terms of a predictable, sequential set of stages. Erikson (1982) noted that at each stage, the individual reaches a balance or healthy ratio, achieving fundamental strengths before moving on to the next stage.

Galvin (1978) noted that, historically, most of the conceptualizations of human development focused on the young child and assumed that development is completed by the end of the second decade of life. In contrast, she theorized that transitions representing both developmental advancement and regression are possible, especially in adulthood. Galvin suggested that young adult and adult behavior and decision making should be studied according to these fluid transitions. Levinson (1986), Elder (1998), and Dannefer (1984) also discussed young adult and adult transitions and life cycles. Levinson noted that "in social and psychological terms, early adulthood is the season for forming and pursuing youthful aspirations, establishing a niche in society, raising a family, and as the era ends, reaching a more 'senior' position in the adult world" (p. 5).

Recent research, however, identifies two important trends that have extended the transition period from adolescence to adulthood in the United States and other industrialized countries over the 20th century. First, the median age at menarche-an indication of the biological transition to adulthood-dropped in industrialized nations from approximately 15 years at the beginning of the century to about 12.5 years by 1970 ; it has since leveled off (Arnett, 2000). Second, the typical length of time in school—an important marker of continued dependence on parents or other family members-has increased substantially. In 1900, 10 percent of youth aged 14 to 17 were enrolled in school. By 2004, the proportion rose to 96.5 percent, and the rates of high school graduation and enrollment in higher education also increased (Arnett \& Tabor, 1994; US Census Bureau, 1975, 2008). A result of these two trends is that the time has increased between the end of biological childhood and the start of social adulthood.

Arnett $(1999,2000)$ proposed the term "emerging adulthood" for this transition period because it reflects a period of identity exploration and experimentation. He defined emerging adults as individuals who have recently completed school, although many are in this stage through their twenties. Arnett contends that emerging adults differ from adolescents and older adults across a variety of dimensions, including demographic diversity and proclivity to engage in a variety of risky behaviors, such as substance use. 
Furthermore, Arnett (1998) documented that emerging adults have a different view of what it means to be an adult. For example, when asked to identify markers of adulthood, emerging adults pointed to accepting responsibility for oneself, making independent decisions, and becoming financially independent, rather than to more traditional indicators expressed by older adults, such as finishing education, beginning a career, getting married, or having children.

Interest in issues related to the transition to adulthood is not limited to professional and scientific journals, as these issues are also discussed and debated in the popular press. For example, in 2005, a Time magazine article reviewed some new labels being used to identify the stage of life between adolescence and adulthood (youthhood and adultescense) and for the 18- to 25-year-old age group (twixters, kidults, and thresholders) (Grossman, 2005). The proliferation of popular slang terms for individuals transitioning from youth to adulthood highlights the importance of young adults in modern American society.

\section{Substance Use Among Young Adults}

Recent studies suggest that rates of substance use are highest among young adults. For example, SAMHSA's National Household Survey on Drug Use and Health (NSDUH) (OAS, 2010), which defines young adults as individuals aged 18 to 25 when reporting the prevalence of illicit drug use, clearly shows an increased risk of illicit drug use among young adults. In 2008, 19.6 percent of young adults used illicit drugs in the past month, compared with 9.3 percent of youth aged 12 to 17 and 5.9 percent of adults aged 26 or older. For alcohol use, NSDUH reports prevalence rates in more detailed age increments. In 2008, prevalence of past month alcohol use increased dramatically with age, from 26.2 percent of 16 - to 18 -year-olds to 69.5 percent of 21 - to 25 -year-olds.

In addition to higher rates of substance use, young adulthood is also associated with an increased risk of initiation for many substances. According to NSDUH estimates (OAS, 2010), in 2008, the average age at first use of alcohol was 17 years, and the average age at first use of marijuana was just under 18 years. The average age of individuals initiating drug use in 2008 was between the ages of 16 and 24 for LSD, cocaine, ecstasy, pain relievers, stimulants, sedatives, and heroin. Beyond the cross-sectional NSDUH, longitudinal studies have identified the late teen years and early twenties as the ages when individuals, particularly those entering the labor force, are most 
susceptible to alcohol, marijuana, and other illegal drug use (Chen \& Kandel, 1995; Kandel, 1984; Kaplan \& Liu, 1994; Kandel et al., 1986).

However, age alone does not tell the full story of the risk faced by young adults in regard to substance use. Young adults' risk of substance use increases as they face numerous stressors, such as low pay, job change, and unemployment, and as they begin to make choices about where and with whom to live; what type of occupation or studies to pursue; when, how, and with whom to enter into long-term interpersonal relationships; and whether and/or when to have children (Glantz \& Leshner, 2000; Hawkins et al., 1992; Kirisci et al., 2005; Steinhausen et al., 2007). Recent research supports the expectation of increased substance use initiation as youth age and encounter more life stressors, with substance use rates peaking in young adulthood. Advances in neurobiology based on evidence from both animal and human models have broadened substantially the understanding of substance use disorders and their frequent comorbidities (Charney, 2004; Heimer, 2003; McEwen, 1998; Rodrigues et al., 2009) and further highlighted young adulthood as a time of increased susceptibility to and harm from substance use.

Epidemiologic research also documents several important risk and protective factors for young adult substance use and abuse. For example, being a college student is an independent risk factor for problem alcohol use and marijuana use, whereas being married and becoming a parent are associated with reductions in alcohol and illicit drug use, especially for women. Having a job is another independent risk factor for substance use, particularly binge drinking, among adolescents aged 12 to 17 (Wu et al., 2003). Studies indicate that, relative to their peers who work fewer than 20 hours per week, young adults who work more than 20 hours per week have a higher chance of using alcohol and other drugs, missing more school, experiencing negative relationships with family, and experiencing health problems (Bachman \& Schulenburg, 1993; Resnick et al., 1997; Wu et al., 2003). Some research suggests that more hours spent working increase environmental and social risks for substance use, including interactions with older coworkers, less parental monitoring, and additional personal income (Godley et al., 2006). 


\section{Workforce Issues}

In 1996, 21.2 million individuals aged 16 to 24 were in the civilian labor force; by 2006, 22.4 million were in the labor force (Bureau of Labor Statistics, 2008). In 2006, 44 percent of individuals aged 16 to 19 and 75 percent of individuals aged 20 to 24 participated in the labor force (US Department of Labor, 2007). Furthermore, in 2004, 21 percent of full-time high school students and 50 percent of college students were employed (US Census Bureau, 2008). Therefore, the workplace is often the venue and context in which youth make the transition from adolescence to young adulthood.

A number of sociological studies support the argument that certain variables, such as gender and social class, have lost their power to explain young adult transitions and the role of substance use. Because of the rate of social change, the weakening of class identity, and the increased individualization of lifestyles, it is hypothesized that these variables no longer have the same impact or constraints as in previous decades (Pavis et al., 1998). Some studies point to the change in friendships and lifestyle choices during this period as an important influence on substance use or abuse (Pavis et al., 1998; Plant, 1992). Other researchers (e.g., Farkas et al., 2000) have noted that the culture itself and its behavioral norms are the strongest indicator of young adults' future substance use.

The population-level pattern of escalating substance use as youth age and enter the workplace creates challenges for employers. A growing body of literature documents the association of substance use with a variety of negative workplace outcomes, including absenteeism, turnover, performance, and medical costs (Mangione et al., 1999; Trudeau et al., 2002). In addition, the stigma associated with substance use has been identified as a barrier to the development and implementation of substance abuse prevention programs in the workplace (Cook et al., 1996; Hersch et al., 2000). These and other findings make a compelling case that the workplace is a critical venue for psychosocial interventions aimed at preventing and reducing substance use.

\section{Studying Workplace-Based Interventions}

The pioneering work conducted by industrial sociologist Elton Mayo and colleagues at the Western Electric Company's Hawthorne plant (Mayo 1933, 1945 ) in the 1920s and 1930s formed the empirical basis for the human relations school of management. In the decades since the seminal work by Mayo and others, a substantial body of workplace-based intervention 
research has accumulated. In the 1940s and 1950s, for instance, the industrial alcoholism program movement developed (Trice \& Roman, 1972), spurred in part by recognition of the consequences of worker drinking on productivity and worker health. Subsequently, the drug-free workplace movement, stimulated by the Drug-Free Workplace Act of 1988, resulted in widespread pre-employment and other drug testing and subsequent drug-free workplace programs (Cook \& Schlenger, 2002). By the end of the 20th century, more than half of US workers in companies employing 50 or more people had access to an employee assistance program (EAP) that provided behavioral health care screening and referral services to employees and their family members (Hartwell et al., 1996).

Bennett and Lehman (2003) provide a comprehensive textbook of workplace-based substance use prevention and early intervention efforts, including drug testing, EAPs, and self-report alcoholism screening assessments, such as the $\mathrm{CAGE}^{\star}$ screening instrument and the Alcohol Use Disorders Identification Test (AUDIT), as well as health promotion programs embedded in these more traditional drug-free workplace components. Bennett, Cook, and Pelletier (2003) noted that variability across worksites in substance use or other health problems underscores the need for a broad set of prevention and early intervention programs to fully address the needs of each specific workplace.

To date, the specific approaches to workplace intervention that have been tested are diverse. These include stress- and coping-based interventions (Snow, 1996; Snow \& Kline, 1995), peer-to-peer approaches that use prevention and early intervention messages designed to reduce substance abuse problems (Bacharach et al., 1996; Miller et al., 2007), and substance use prevention nested in a comprehensive health promotion program (Cook \& Youngblood, 1990; Heirich \& Sieck, 2003). In addition to these approaches, the use of workplace-based health promotion and disease prevention programs has increased substantially in recent decades.

CAGE is an acronym based on key words in the instrument's four questions: $\mathrm{C}=$ Have you ever felt the need to cut down on your drinking?; A = Have you ever felt annoyed by someone criticizing your drinking?; $\mathrm{G}=$ Have you ever felt guilty about your drinking?; and $\mathrm{E}=$ Have you ever had to drink in the morning to quiet your nerves or relieve a hangover (eye-opener)? 


\section{Summary}

In response to a combination of well-established epidemiologic findings concerning substance use and well-documented sociodemographic shifts in the American workforce, SAMHSA created the YIW multisite collaborative to examine whether modified versions of evidence-based substance use prevention or intervention programs would be efficacious when tailored to the needs and expectations of working young adults. SAMHSA investigators, six grantee teams that included workplace partners, and a coordinating center team worked together to design, adapt, and implement the selected interventions.

The chapters that follow provide details about the six YIW grantees, the adaptations they made to their interventions, the target populations, and process findings related to implementation. The final chapter in this monograph describes the design and methods of the YIW cross-site evaluation.

\section{References}

Arnett, J. J. (1998). Learning to stand alone: The contemporary American transition to adulthood in cultural and historical context. Human Development, 41(5-6), 295-315.

Arnett, J. J. (1999). Adolescent storm and stress, reconsidered. American Psychologist, 54(5), 317-326.

Arnett, J. J. (2000). Emerging adulthood. A theory of development from the late teens through the twenties. American Psychologist, 55(5), 469-480.

Arnett, J. J., \& Tabor, S. (1994). Adolescence terminable and interminable: When does adolescence end? Journal of Youth \& Adolescence, 23(5), 517-537.

Bacharach, S. B., Bamberger, P. A., \& Sonnenstuhl, W. J. (1996). MAPs: Laborbased peer assistance in the workplace. Industrial Relations, 35(2), 261-275.

Bachman, J. G., \& Schulenberg, J. (1993). How part-time work intensity relates to drug use, problem behavior, time use, and satisfaction among high school seniors: Are these consequences or merely correlates? Developmental Psychology, 29(2), 220-235. 
Bennett, J. B., Cook, R. F., \& Pelletier, K. R. (2003). Toward an integrated framework for comprehensive organizational wellness: Concepts, practices, and research in workplace health promotion. In J. C. Quick \& L. E. Tetrick (Eds.), Handbook of occupational health psychology (pp. 69-95). Washington, DC: American Psychological Association.

Bennett, J. B., \& Lehman, W. E. K. (2003). Preventing workplace substance abuse: Beyond drug testing to wellness. Washington, DC: American Psychological Association.

Bureau of Labor Statistics. (2008). Civilian labor force by sex, age, race, and ethnicity. Retrieved September 19, 2008, from http://www.bls.gov/emp/ emplab06.htm

Charney, D. S. (2004). Psychobiological mechanisms of resilience and vulnerability: Implications for the successful adaptation to extreme stress. American Journal of Psychiatry, 161, 195-216.

Chen, K., \& Kandel, D. B. (1995). The natural history of drug use from adolescence to the mid-thirties in a general population sample. American Journal of Public Health, 85(1), 41-47.

Cook, R. F., \& Schlenger, W. (2002). Prevention of substance abuse in the workplace: Review of research on the delivery of services. The Journal of Primary Prevention, 23(1), 115-142.

Cook, R. F., Back, A., \& Trudeau, J. (1996). Substance abuse prevention in the workplace: Recent findings and an expanded conceptual model. The Journal of Primary Prevention, 16(3), 319-339.

Cook, R. F., \& Youngblood, A. (1990). Preventing substance abuse as an integral part of worksite health promotion. Occupational Medicine, 5(4), $725-738$.

Corrado, D., Basso, C., Rizzoli, G., Schiavon, M., \& Thiene, G. (2003). Does sports activity enhance the risk of sudden death in adolescents and young adults? Journal of the American College of Cardiology, 42(11), 1959-1963.

Dannefer, D. (1984). Adult development and social theory: A paradigmatic reappraisal. American Sociological Review, 49(1), 100-116.

Elder, G. H. (1998). The life course as developmental theory. Child Development, 69, 1-12.

Erikson, E. H. (1982). The life cycle completed: A review. New York: Norton. 
Farkas, A. J., Gilpin, E. A., White, M. M., \& Pierce, J. P. (2000). Association between household and workplace smoking restrictions and adolescent smoking. Journal of the American Medical Association, 284(6), 717-722.

Ferrari, G. R. F. (Ed.). (2007). The Cambridge companion to Plato's Republic. London: Cambridge University Press.

Galvin, D. (1978). Crime severity discrimination development in youth. (Unpublished doctoral dissertation). University of Pennsylvania, Philadelphia, PA.

Glantz, M. D., \& Leshner, A. I. (2000). Drug abuse and developmental psychopathology. Development and Psychopathology, 12(4), 795-814.

Godley, S. H., Passetti, L. L., \& White, M. K. (2006). Employment and adolescent alcohol and drug treatment and recovery: An exploratory study. The American Journal on Addictions, 15, 137-143.

Grossman, L. (2005, January 16). Grow up? Not so fast. Time. Retrieved September 22, 2008, from http://www.time.com/time/magazine /article/0,9171,1018089,00.html

Hall, G. S. (1904). Adolescence: Its psychology and its relations to physiology, anthropology, sociology, sex, crime, religion, and education. 2 vols. New York: Appleton.

Hartwell, T. D., Steele, P. D., French, M. T., \& Rodman, N. F. (1996). Prevalence of drug testing in the workplace. Monthly Labor Review, 119(11), 35-42.

Hawkins, J. D., Catalano, R. F., \& Miller, J. Y. (1992). Risk and protective factors for alcohol and other drug problems in adolescence and early adulthood: Implications for substance abuse prevention. Psychological Bulletin, 112(1), 64-105.

Heimer, L. (2003). A new anatomical framework for neuropsychiatric disorders and drug abuse. American Journal of Psychiatry, 160(10), 1726-1739.

Heirich, M., \& Sieck, C. J. (2003). Helping at-risk drinkers reduce their drinking: Cardiovascular wellness outreach at work. In J. B. Bennett \& W. E. K. Lehman (Eds.), Preventing workplace substance abuse: Beyond drug testing to wellness (pp. 135-164). Washington, DC: American Psychological Association. 
Hersch, R. K., Cook, R. F., Deitz, D. K., \& Trudeau, J. V. (2000). Methodological issues in workplace substance abuse prevention research. The Journal of Behavioral Health Services and Research, 27(2), 144-151.

Kandel, D. B. (1984). Marijuana users in young adulthood. Archives of General Psychiatry, 41(2), 200-209.

Kandel, D. B., Davies, M., Karus, D., \& Yamaguchi, K. (1986). The consequences in young adulthood of adolescent drug involvement. An overview. Archives of General Psychiatry, 43(8), 746-754.

Kaplan, H. B., \& Liu, X. (1994). A longitudinal analysis of mediating variables in the drug use-dropping out relationship. Criminology, 32(3), 415-439.

Kirisci, L., Vanyukov, M., \& Tarter, R. (2005). Detection of youth at high risk for substance use disorders: A longitudinal study. Psychology of Addictive Behaviors, 19(3), 243-252.

Levinson, D. J. (1986). A conception of adult development. American Psychologist, 41(1), 3-13.

Ludwig, D. S., Pereira, M. A., Kroenke, C. H., Hilner, J. E., Van Horn, L., Slattery, M. L., et al. (1999). Dietary fiber weight gain, and cardiovascular disease risk factors in young adults. Journal of the American Medical Association, 282, 1539-1546.

Mangione, T. W., Howland, J., Amick, B., Cote, J., Lee, M., Bell, N., et al. (1999). Employee drinking practices and work performance. Journal of Studies on Alcohol, 60(2), 261-270.

Mayo, E. (1933). The human problems of an industrial civilization. New York: Macmillan.

Mayo, E. (1945). The social problems of an industrial civilization. Boston: Harvard University, Graduate School of Business Administration.

McEwen, B. S. (1998). Protective and damaging effects of stress mediators. New England Journal of Medicine, 338, 171-179.

McFarlane, M., Bull, S. S., \& Rietmeijer, C. A. (2002). Young adults on the Internet: Risk behaviors for sexually transmitted diseases and HIV1. Journal of Adolescent Health, 31(1), 11-16.

Miller, T. R., Zaloshnja, E., \& Spicer, R. S. (2007). Effectiveness and benefit-cost of peer-based workplace substance abuse prevention coupled with random testing. Accident Analysis and Prevention, 39(3), 565-573. 
Office of Applied Studies [OAS] (2010). SAMHSA's National Survey on Drug Use and Health. Retrieved March 12, 2010, from http://www.oas. samhsa.gov/nsduhLatest.htm

Pavis, S., Cunningham-Burley, S., \& Amos, A. (1998, November). Health related behavioural change in context: Young people in transition. Social Science and Medicine, 47(10), 1407-1418.

Plant, M.A. (1992). Introduction. Substance Use and Misuse, 27(2), vii-viii.

Resnick, M. D., Bearman, P. S., Blum, R. W., Bauman, K. E., Harris, K. M., Jones, J., et al. (1997). Protecting adolescents from harm. Findings from the National Longitudinal Study on Adolescent Health. Journal of the American Medical Association, 278(10), 823-832.

Rodrigues, S. M., LeDoux, J. E., \& Sapolsky, R. M. (2009). The influence of stress hormones on fear circuitry. Annual Review of Neuroscience, 32, 289-313.

Snow, D. (1996, April). A workplace intervention to address work and family stressors: Effects on coping and alcohol use. Paper presented at Conference on Research on Alcohol Problems in the Worksite: Moving toward Prevention Research, Washington, DC.

Snow, D. L., \& Kline, M. L. (1995). Preventive interventions in the workplace to reduce negative psychiatric consequences of work and family stress. In C. M. Mazure (Ed.), Does stress cause psychiatric illness? (pp. 221-270). Washington, DC: American Psychiatric Press.

Steinhausen, H.-C., Eschmann, S., \& Metzke, C. W. (2007). Continuity, psychosocial correlates, and outcome of problematic substance use from adolescence to young adulthood in a community sample. Child Adolescent Psychiatry and Mental Health, 1(1), 12.

Substance Abuse and Mental Health Services Administration (SAMHSA). (2004). Funding opportunity title: Youth Transition Into the Workplace grants (short title: YIW grants). Federal Register, 69(56), 13548-13553.

Thurman, R. A. F. (1993). The Tibetan book of the dead. New York: Bantam Books.

Trice, H. M., \& Roman, P. M. (1972). Spirits and demons at work: Alcohol and other drugs on the job. Industrial and Labor Relations Review, 28(1), $171-172$. 
Trudeau, J. V., Deitz, D. K., \& Cook, R. F. (2002). Utilization and cost of behavioral health services: Employee characteristics and workplace health promotion. Journal of Behavioral Health Services \& Research, 29(1), 61-74.

US Census Bureau. (1975). Bicentennial edition: Historical statistics of the United States, colonial times to 1970, Part 1. Retrieved September 19, 2008, from http://www2.census.gov/prod2/statcomp/documents /CT1970p1-01.pdf

US Census Bureau. (2008). School enrollment-social and economic characteristics of students: October 2004. Retrieved December 20, 2008, from http://www.census.gov/population/www/socdemo/school /cps2004.html

US Department of Labor, Bureau of Labor Statistics, Office of Employment and Unemployment Statistics. (2007). Labor force participation rates and employment to population ratios of persons 16 to 64 years old, by highest level of education, age, sex, and race/ethnicity: 2006. Unpublished 2006 annual average data from the Current Population Survey (CPS). Retrieved October 18, 2008, from http://nces.ed.gov/programs/digest/d07/tables /dt07_368.asp

Wu, L.-T., Schlenger, W. E., \& Galvin, D. M. (2003). The relationship between employment and substance use among students aged 12 to 17. Journal of Adolescent Health, 32(1), 5-15. 



\title{
Healthy WorkLife for Young Adults: Implementing Health Promotion and Substance Abuse Prevention in a Health Care Setting
}

\author{
Rebekah K. Hersch, ${ }^{1}$ Royer F. Cook, ${ }^{1}$ Daniel Hughes, ${ }^{2}$ \\ Samantha L. Leaf, ${ }^{1}$ and Douglas W. Billings ${ }^{1}$ \\ 'ISA Associates, Inc., AleXandRia, VA; \\ 2Mount Sinal Medical Center, New York, NY
}

\section{Introduction}

As part of the Young Adults in the Workplace (YIW) initiative, funded by the Substance Abuse and Mental Health Services Administration, ISA Associates is building on more than a decade of research to explore and test innovative, theoretically sound substance abuse prevention methods designed specifically for working adults (Cook et al., 2003). The prevention approaches are based on a social-learning model of adult substance use developed by Royer Cook and colleagues (Cook et al., 1996a, 1996b; Cook \& Youngblood, 1990), which includes a number of key elements. First, the model focuses on social-learning theory, which emphasizes behavioral modeling and the importance of selfefficacy (Bandura, 1977, 1986). Second, the model addresses substance abuse prevention within a health promotion framework. Instead of emphasizing the dangers and negative aspects of substance use-although such harmful aspects are not ignored-the model emphasizes the positive effects of decreasing substance use on overall health and wellness. Third, the model postulates that health behaviors are a function of the level of awareness, motivation, and skills associated with a particular health behavior and that to improve health an intervention must raise all three components to a sufficient level. Fourth, the model posits that the avoidance of substance abuse will occur (at least in part) as healthful behaviors provide rewards and as the social environment provides support for such behaviors.

ISA adapted the social-learning model for a young adult population and implemented the Healthy WorkLife for Young Adults (HWY) program 
with health care and support services staff in a large metropolitan area medical center. This chapter describes the content, implementation, and target population of the HWY program. Early process findings related to implementation challenges are also discussed.

\section{Program Description}

\section{Theoretical Framework}

In 1990, Cook and Youngblood developed a preliminary conceptual model to guide the development of workplace substance abuse prevention interventions that drew on existing health behavior theories and constructs, including the work of Bandura $(1977,1986)$; Rosenstock and colleagues' (1988) health belief model; and Cook's (1985) biopsychological model of healthful alternatives to drug abuse. The initial model viewed substance use as one type of unhealthful behavior and postulated that, at any point in time, individuals possess a particular level of awareness, motivation, and knowledge about the risks and benefits of alcohol and other drug use as well as other health practices. The three components (awareness, motivation, and knowledge) combine in multiplicative fashion: if any component is missing (or below threshold), the individual will not engage in the healthful behavior. For example, one must be sufficiently aware of the risks of substance abuse and the benefits of avoiding substance abuse in order to be motivated, and without the needed knowledge or skills (e.g., monitoring alcohol consumption, refusal skills) one is less likely to avoid substance abuse. The model suggests that by raising awareness, motivation, and knowledge/skills with respect to healthful behaviors, the individual is less likely to engage in substance abuse. This view is based on a general tendency for healthful behavior and substance abuse to be negatively correlated, if only moderately so. Stated somewhat differently, the more committed an individual is to a healthful lifestyle, the less likely he or she is to engage in health-damaging substance abuse.

Cook and Youngblood's model contains two decision points: one at which health behavior is begun or decided against, and one at which the behavior is continued or dropped. Support from the social environment-at work and at home-is a significant element in both stages. An organization can show its support for avoidance of substance abuse in a variety of ways, including personal statements by the chief executive officer, a display by managers of moderation in their drinking habits, and the provision of nonalcoholic beverage alternatives at company social functions. 
A worksite substance abuse prevention program based on this model looks quite different from most other such programs, despite the inclusion of central elements, such as self-efficacy and social support. First, the program emphasizes the benefits of healthful behaviors, rather than the dangers of substance abuse, although harmful effects are also covered. Second, the program materials promote the idea that healthful activities are fun and rewarding and present the program in ways that engage the audience's interest.

Based on the results of field tests of the interventions developed under the preliminary model, as well as findings from other investigators, Cook et al. (2003) expanded the conceptual model to more explicitly recognize the role of the work environment and the impact of job stress and the workplace culture on health and substance use patterns. Figure 2.1 presents the most recent version of this model.

\section{The HWY Intervention}

In both its conceptual foundations and its materials, the program implemented as part of the YIW initiative draws on two primary sources: the Healthy Workplace programs, ISA's series of workplace interventions recognized by the National Registry of Effective Programs as a model workplace substance abuse prevention program; and the Healthy WorkLife program, an interactive DVD-based health promotion and substance abuse prevention program developed by ISA under a contract from the National Institute on Drug Abuse and designed specifically to promote healthful practices and reduce substance abuse in workers younger than age 25 . As with all ISA workplace programs over the past 15 years, ISA cast HWY in a health promotion framework. However, because good health per se is not the primary motivator for young adults, HWY presents healthful practices as the keys to success in the workplace, provides the tools needed to compete effectively as an adult, and alters the path to money and status. The message is that to be successful at work, young workers need to be at the top of their game, productive, and healthy (mentally and physically), avoiding substance abuse, staying fit, and controlling emotions. In addition, they will feel better and live longer. One of the primary goals of the program is to help young adults make the connection between personal choices, such as substance use, and work. 


\section{Figure 2.1 Healthy WorkLife for Young Adults conceptual model for workplace substance abuse prevention}

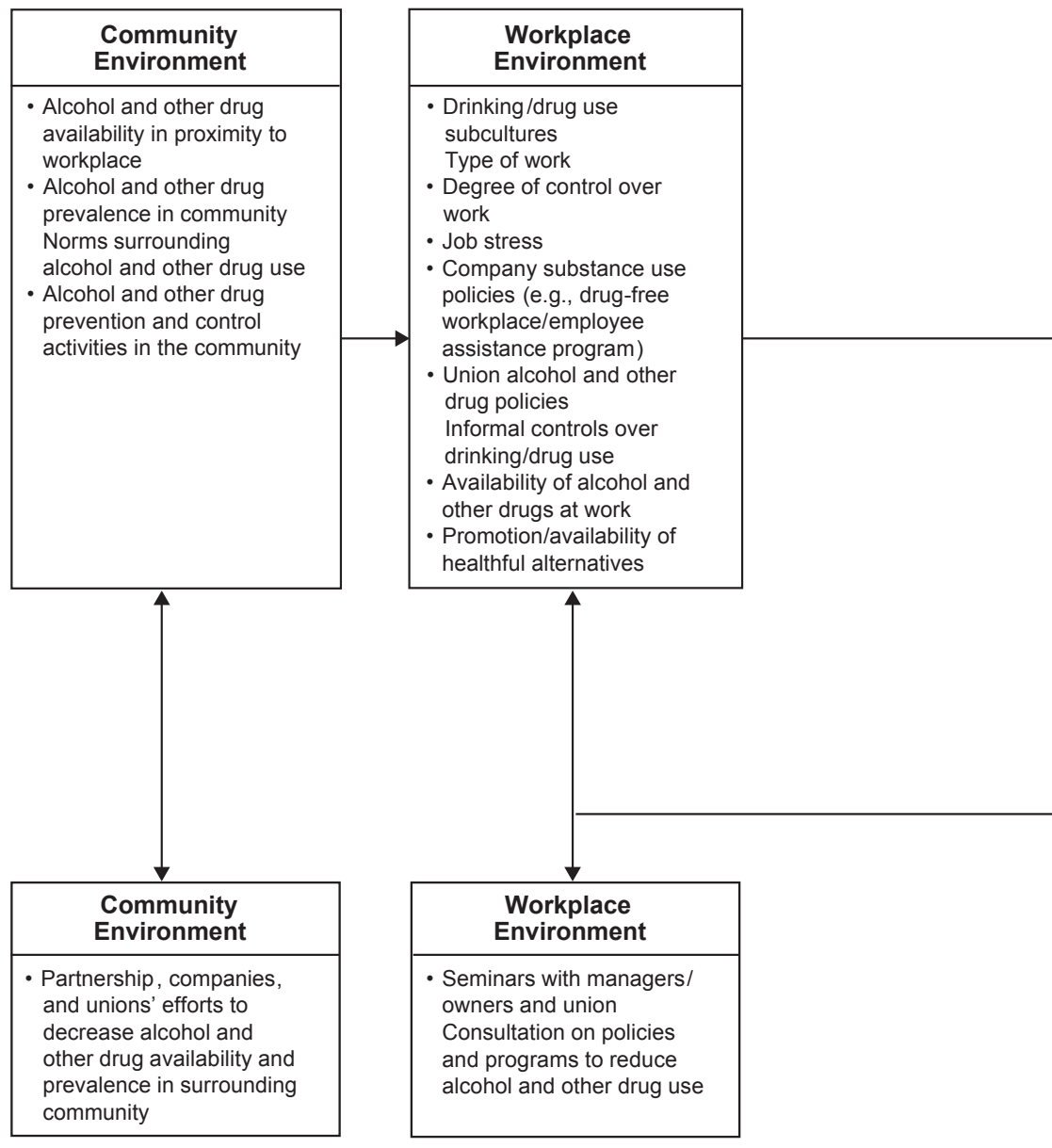

\section{Specific Program Components}

ISA originally designed the HWY program to be implemented in three classroom-based, 45 -minute workshops and supplemented by providing program participants with access to ISA-developed Web-based programs (see below). The three workshops, which are instructor led and centered on the interactive HWY DVD program, include the following topics:

- Session I: Introduction and Stress/Anger Management Part I 


\begin{tabular}{|c|c|c|}
\hline \multicolumn{3}{|c|}{ Individual Employee } \\
\hline $\begin{array}{l}\text { - AWARENESS of risks of } \\
\text { alcohol and other drug use } \\
\text { and benefits of healthful } \\
\text { behavior } \\
\text { - MOTIVATION to avoid } \\
\text { risks of alcohol and other } \\
\text { drug use and gain benefits } \\
\text { of healthful behavior } \\
\text { - KNOWLEGE of how to } \\
\text { avoid risks of alcohol and } \\
\text { other drug use and gain } \\
\text { benefits of healthful } \\
\text { behavior }\end{array}$ & $\begin{array}{l}\text { - ATTITUDES, BELIEFS, } \\
\text { AND INTENTIONS } \\
\text { regarding } \\
\text { - alcohol use, } \\
\text { - other drug use, and } \\
\text { - health behaviors (for } \\
\text { self and family, during } \\
\text { and after work) }\end{array}$ & $\begin{array}{l}\text { - ALCOHOL AND OTHER } \\
\text { DRUG USE BY } \\
\text { EMPLOYEES } \\
\text { - Alcohol use: } \\
\text { - Frequency } \\
\text { - Quantity } \\
\text { - Circumstances } \\
\text { - Illicit drug use: } \\
\text { - Type } \\
\text { - Frequency } \\
\text { - Circumstances } \\
\text { - Prescription drug } \\
\text { misuse: } \\
\text { - Type } \\
\text { - Frequency } \\
\text { - Circumstances }\end{array}$ \\
\hline \multicolumn{3}{|l|}{$\hat{T}$} \\
\hline \multicolumn{2}{|l|}{$\begin{array}{l}\text { Demographic } \\
\text { Characteristics }\end{array}$} & \\
\hline \multicolumn{3}{|l|}{1} \\
\hline \multicolumn{3}{|l|}{ Prevention Strategies } \\
\hline \multicolumn{3}{|c|}{ Individual Employee } \\
\hline \multicolumn{3}{|c|}{$\begin{array}{l}\text { - Discussion groups, video and print materials, Web-based program-to raise awareness, } \\
\text { motivation, and knowledge/skills related to alcohol and other drug use and health }\end{array}$} \\
\hline
\end{tabular}

- Session II: Stress/Anger Management Part II: Coping Strategies and Avoiding Negative Coping (this module includes alcohol and other drug abuse prevention information)

- Session III: Staying Healthy (Nutrition) and the Connection Between Work and Health

As part of the workshops, the program provides participants with three pamphlets on stress and anger management, substance use, and nutrition that are designed to complement the HWY DVD material. 
To supplement the workshops and print materials, ISA provides participants with access to two of its Web-based programs: Stress and Mood Management and Smart Rx. The first Web-based program, Stress and Mood Management, helps users reduce stress and prevent mood and anxiety problems. The program includes engaging audio, video, and graphical elements. The four program modules are Stress Management, Managing Depression, Managing Anxiety, and Treatments that Work. The second Webbased program, SmartRx, focuses on women and provides information about how to safely take prescription medications for conditions such as insomnia, depression, anxiety, and chronic pain management. The SmartRx modules include Personal Assessment, Medication Facts, Smart Rx Use, and Managing Your Health (which includes information on non-drug options). This program has particular applicability for worksites with a female workforce. Both programs include tracking mechanisms that allow project staff to know which participants accessed the program, which modules they accessed, and how long they were in the program.

\section{Changes in Initial Program Implementation}

In December 2007, project staff implemented the initial program sessions at a large medical center that served as our research partner. The response to the first round of classes revealed that work demands and employee schedules made it difficult for medical center employees to attend classes. Therefore, to provide the maximum flexibility for employees to participate in the training program, ISA staff created a fully narrated, online version of the program that included the video segments from the DVD. Like the classroom-based program, the Web-based version has three segments. To access the online version of the program, participants log into the website using a unique ID and password. At the end of each segment, the participant submits his or her study ID electronically to the project staff, so project staff know when the participant completes each module. Participants in the YIW initiative had the option of completing the HWY program by attending three lunch-and-learn classroombased workshops or completing the three HWY modules online. The majority of participants chose the online option.

\section{The HWY Program Logic Model}

Figure 2.2 presents the logic model that relates the HWY program to expected outcomes both for individuals and for workplaces. We expect that individuals participating in HWY will exhibit (1) increased connection between healthful 
practices and work; (2) increased awareness of the risks of alcohol and other drug use; (3) positive changes in stress management practices (decreased substance use to reduce stress and increased positive stress relief practices); (4) greater reductions in stress symptoms; (5) decreased problem drinking, illicit drug use, and prescription drug misuse; (6) increased organizational commitment and job satisfaction; and (7) lower rates of job turnover.

We believe that individuals participating in the HWY program will change behaviors mainly as a function of exposure to the content in each program module (e.g., substance use, stress), which is intended to raise their awareness, motivate them, and impart skills. The model also posits that improvements in specific antecedent mediating variables must occur before meaningful changes in health behavior can be affected. It is hypothesized that awareness will be raised by providing information on the benefits and risks of specific health behaviors; motivation to engage in healthful behaviors will be raised by increasing participants' self-efficacy (e.g., through observational learning, changing behavior in small steps); and participants' skills to improve and maintain health practices will be increased through didactic guidance and observational learning. For example, the Stress Management modules of the program contain (1) information on the health risks of excessive stress and the health benefits of managing stress (thereby raising awareness), (2) video segments of people describing ways that they successfully managed their stress (thereby raising self-efficacy and motivation), and (3) video segments and related text that show how to engage in effective stress management techniques (thereby imparting skills to improve health practices). We expect these combined elements to result in improvements in participants' stress management abilities and reductions in their levels of stress.

We also believe that two prominent program characteristics act as precursors to employees participating in the program and being exposed to all major sections of the program, especially material addressing the more highly stigmatized topics of substance use. First, the material on alcohol and other drugs is embedded within the Stress Management modules, thereby reducing the avoidance effects of the stigma of substance use. Second, because the program is directed at young adults, who typically are less concerned than older workers about health risks per se, the program content emphasizes the connection between healthful living practices and success at work, in contrast to the usual emphasis on healthful living and longevity/avoidance of illness. 


\section{Figure 2.2 Healthy WorkLife for Young Adults (HWY) logic model}

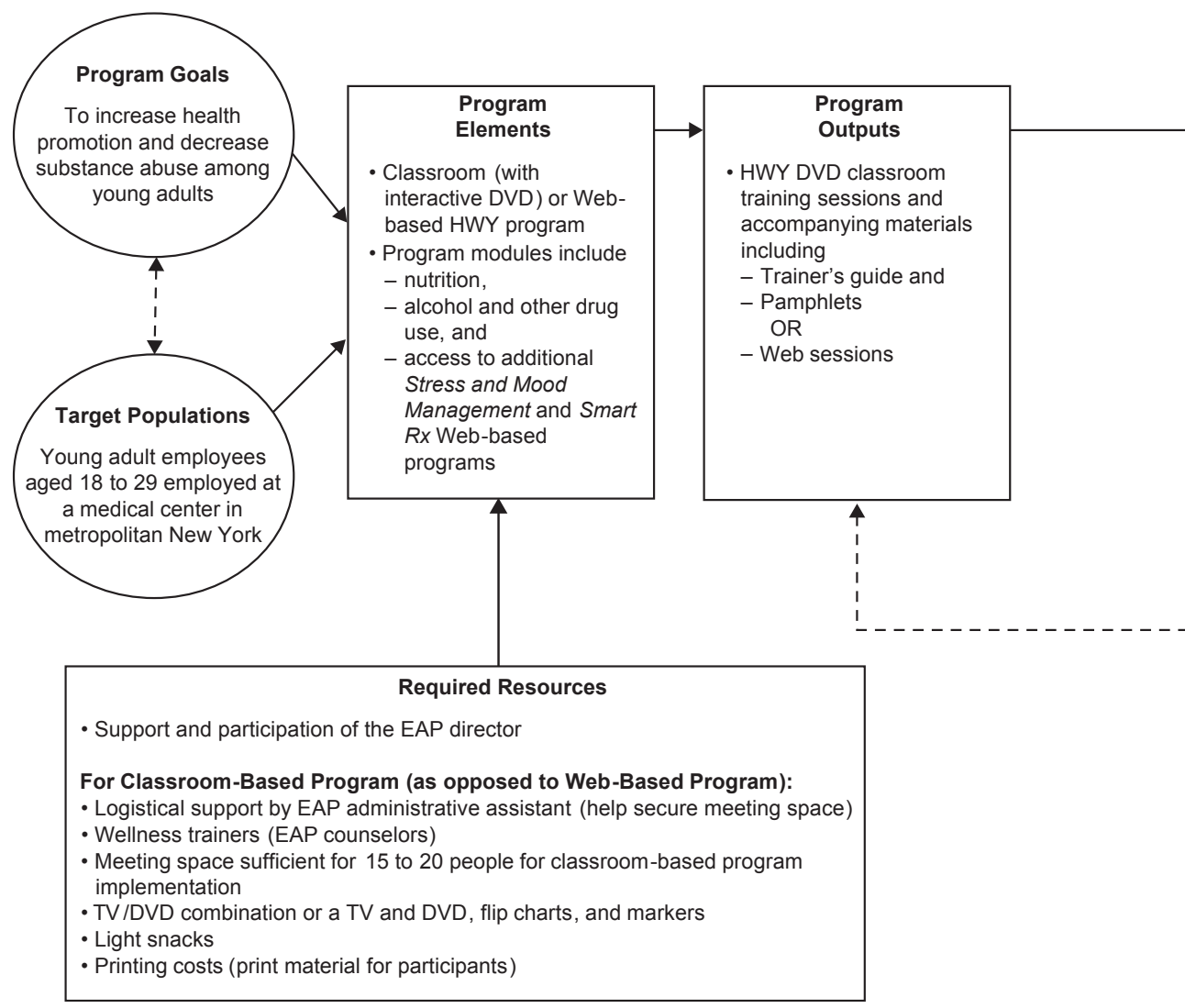

\section{Target Population}

ISA's research partner for the HWY intervention is a large medical center in the New York metropolitan area. The medical center has more than 10,000 employees and nearly 800 employees aged 18 to 24 . Because college- and graduate school-educated young adults (typically a significant portion of the employees working in a medical center) do not enter the workforce (or marry and have children) until closer to their middle to late twenties, ISA and the medical center staff considered the issues related to emerging adulthood (Arnett, 2004) to extend beyond age 24 for this group and included 25- to 29-year-olds in the project. Thus, the target population for the HWY program is young adults aged 18 to 29 working in ISA's partnering 


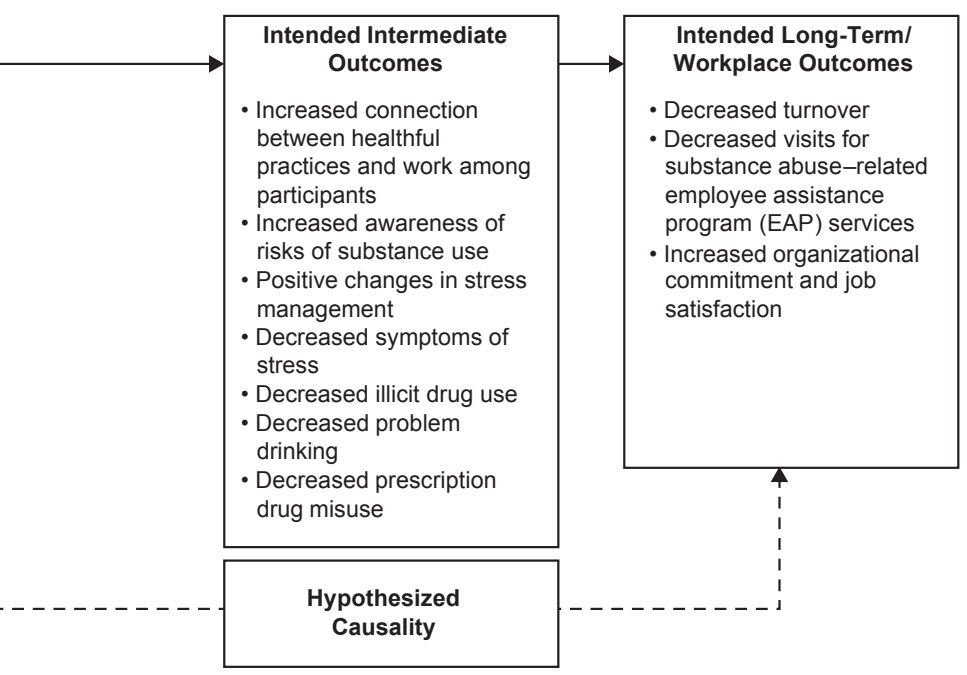

workplace. Educational enrollment is not a consideration in defining the target population.

The medical center has approximately 2,300 young adult employees aged 18 to 29 . The majority of these young adult employees (70 percent) are female. Thirty-two percent are white, 27 percent are Hispanic, 22 percent are African American, and 16 percent are Asian. The majority have been at the medical center for 1 year or less, and their years of service range from less than 1 year to 9 years. The overwhelming majority of these young adults are not married, and a slight majority of them are non-union employees.

To support the YIW cross-site evaluation (see Chapter 8 for more information about the cross-site evaluation and the core survey measures), ISA 
conducted a survey of HWY program participants and a comparison sample of employees. Between May 2007 and April 2008, 133 young adult employees completed the survey. This survey provides important information on the population actually served by the HWY program. Survey results indicate that female and white employees were overrepresented among the project participants: 89 percent of survey respondents were female, and 58 percent were white. Survey respondents were at the upper end of the target age range, with a mean age of 26 years. The demographic profile of the participants is likely due to the fact that nurses are overrepresented in our sample (because of the recruitment efforts of a particularly supportive nurse educator who reached out to specific nursing staff).

\section{HWY Program Participants}

Sixty-six employees in the target age range were recruited to participate in the HWY intervention. Of those, 49 (74 percent) completed one or more of the program topics/classes and 43 (65 percent) completed all three topics/ classes. Eight (19 percent) participants completed the intervention using the classroom-based implementation. The remaining participants accessed the HWY via the Web-based intervention alone or in combination with one or two classroom-based sessions.

\section{Early Process Findings: Challenges to Implementation}

Implementing a program in a large metropolitan medical center poses a number of challenges. One major challenge the project team faced was recruitment. During the recruitment process, we learned that to effectively develop and implement a health promotion and substance abuse program such as HWY, one must understand the complexities of workplace settings, particularly multifaceted workplaces such as health care settings. In multifaceted workforces with many bureaucratic layers, a number of factors can influence effective implementation, including the need to obtain approvals from multiple levels of management and, in some cases, unions; competing demands on employees' time or restricted access to employees during work hours; and the challenge of identifying employee health practices as a workplace priority. Each of these factors influenced our program's implementation.

Unlike some worksites in which we have conducted workplace-based research, the medical center would not allow the project team to send a targeted blast e-mail to all young adult medical center employees who had 
e-mail. Therefore, we needed to use a variety of recruitment strategies. For example, project team members placed recruitment flyers in selected locations throughout the medical center and delivered additional flyers to departments with large numbers of young adult employees. In addition, the project team staffed recruitment tables outside the main medical center cafeteria and during a health fair. Also, project staff and the medical center project liaison met with department heads and other managers to discuss recruitment strategies and to obtain permission to recruit employees in specific departments. The project team invited young adult employees in selected departments to a lunchtime meeting to learn more about the project. Although the department directors and managers were largely supportive of the project, these recruitment efforts met with limited success because few employees attended the lunchtime meetings.

Recruitment changed dramatically, however, because of the efforts of one nurse who championed the project among young nurses. Recruitment more than tripled when this nurse reached out to young nurses, particularly those working the night shift. What is clear is that active management support of the program was necessary at all stages of program implementation. Had the nurse who championed the program been able to reach out to those who initially signed up to encourage participation, we would likely have seen increased participation. However, that type of targeted support was not possible for this project, as the identity of study participants had to be appropriately protected. To increase program participation, the research team implemented a number of different strategies including individual e-mails and telephone calls to participants. These strategies increased completion somewhat, but it was clear that additional strategies and incentives were needed. To that end, the research team, with appropriate approvals, provided participants with a $\$ 25$ incentive as compensation for their time for completing the program.

Another major challenge was scheduling the health and wellness classes. The project team presumed that classes would have to be conducted at various times of the day and night to accommodate the 24-hour schedule of a medical center; however, the hectic schedule of a large metropolitan medical center made it nearly impossible for many young adults to take a 60-minute break during their working shift. This was true not only of individuals who work 12-hour floor shifts, such as nurses, but also of individuals who work more standard, 8-hour, 9:00 a.m. to 5:00 p.m. shifts. To address this barrier to participation, the research staff created an online version of the program classes. Once the online version was available, the majority of the program 
participants utilized the online version exclusively, or in combination with some of the workshop sessions. Fidelity of the Web-based intervention was strengthened by the fact that participants could not just page through the screens by hitting the next button or skip around in the program. The Web-based program was designed so that participants had to move through the course in a linear fashion, completing all the content on one screen before moving on to the next screen. Session observations and online checks indicated that all sessions were delivered or were fully accessible, as expected. However, because of the worksite scheduling constraints, program participation varied. Nearly two-thirds of participants completed all session topics.

\section{Conclusions}

Given the billions of dollars in preventable health care costs and industry financial loss attributable to substance abuse and other negative health practices, developing and testing effective health promotion and substance abuse prevention programs for the workplace is essential. Focusing these efforts on young adults is imperative because young people continue to be disproportionally represented among individuals who engage in high-risk health behaviors.

To effectively develop and implement such programs, program developers must understand the complexities of workplace settings in which these programs are being implemented. In addition, program developers need to be innovative in developing varied mechanisms to enhance employee access to program materials. In an ideal setting, health promotion and substance abuse prevention training would be woven into standard new employee training. By integrating health and wellness messages into standard new employee training, the workplace sends the message that health practices are integrally related to work performance and follows up by providing employees with information and training that can help them make more healthful choices. In the absence of such an approach, implementing health promotion and substance abuse prevention programs will continue to be a challenge as employees find themselves with increasing competing demands for their time.

To address this challenge, worksite health and wellness programs will need to continue to use a combination of innovative strategies and incentives to penetrate the workforce and bring prevention messages to individuals who may need them the most. Given the diverse and dynamic nature of workplaces, 
programs need to allow flexibility while maintaining content fidelity. We believe that one of the greatest strengths of the HWY program is its flexibility. By the fact that it can be implemented in a variety of different ways (i.e., classroom-based, instructor-led training sessions; on-line; individual DVD implementation with User Guide), we were able to overcome a significant worksite constraint facilitating participant engagement and program delivery.

\section{References}

Arnett, J. J. (2004). Emerging adulthood: The winding road from late teens through the twenties. New York: Oxford University Press, Inc.

Bandura, A. (1977). Social learning theory. New York: General Learning Press.

Bandura, A. (1986). Social foundations of thought and action: A social cognitive theory. Englewood Cliffs, NJ: Prentice Hall.

Cook, R. (1985). The alternatives approach revisited: A biopsychological model and guidelines for application. International Journal of the Addictions, 20(9), 1399-1419.

Cook, R. F., Back, A. S., \& Trudeau, J. (1996a). Substance abuse prevention in the workplace: Recent findings and an expanded conceptual model. The Journal of Primary Prevention, 16(3), 319-339.

Cook, R. F., Back, A. S., \& Trudeau, J. (1996b). Preventing alcohol use problems among blue-collar workers: A field test of the Working People program. Substance Use \& Misuse, 31(3), 255-275.

Cook, R. F., Back, A. S., Trudeau, J., \& McPherson, T. L. (2003). Integrating substance abuse prevention into health promotion programs in the workplace: A social cognitive intervention targeting the mainstream user. In J. B. Bennett \& W. E. K. Lehman (Eds.), Preventing workplace substance abuse: Beyond drug-testing to wellness (pp. 97-133). Washington, DC: American Psychological Association.

Cook, R. F., \& Youngblood, A. (1990). Preventing substance abuse as an integral part of worksite health promotion. Occupational Medicine: State of the Art Reviews, 5(4), 725-738.

Rosenstock, I. M., Strecher, V. J., \& Becker, M. H. (1988). Social learning theory and the health belief model. Health Education Quarterly, 15(2), 175-183. 



\title{
Substance Abuse Prevention for the Young Workforce in the Railroad Industry: An Adaptation of the PREVENT Program
}

\author{
Rebecca Spicer, Ted Miller, and Eduard Zaloshnja \\ Pacific Institute for Research and Evaluation, Calverton, MD
}

\section{Introduction}

Historically, workplace characteristics and an occupational drinking culture enabled alcohol use to become an important component of worker lifestyle in the railroad industry. Drinking at work and when on call was so pervasive that in the 1860s and 1870s rail labor organizations served as temperance groups and required sobriety for membership. However, it was easy to hide alcohol and other drug use because many workers were largely unsupervised for much of their time on duty, traveled over long distances, and had frequent overnight or abnormal shifts. These work characteristics have not changed much over the years.

In 1977, to determine the extent and impact of worker substance use, the Federal Railroad Administration conducted a large survey of the railroad industry, the Railroad Employee Assistance Project (Manello \& Seaman, 1979). The survey findings indicated that railroad employees were twice as likely as other employed persons to drink to intoxication. Among survey participants, 13 percent reported drinking on the job at least once in the past year. In fact, on-the-job drinking was four times higher than estimated by railroad supervisors and labor representatives. In addition, coworkers were reluctant to report on-the-job drinking incidents. For instance, although 35 percent of workers reported witnessing on-the-job drinking or intoxication, less than 1 percent of these events were reported.

Awareness of the consequences of substance use and abuse led to policy changes incorporating severe penalties and an industry-wide ban on alcohol and other drug use on duty or before coming to duty. Since before the Civil War, railroads have had operating rules in place that prohibit on-the-job substance use. The Federal Railroad Administration's current version of this 
rule, Rule G, prohibits on-the-job substance use or working while under the influence of alcohol or other drugs, including prescription drugs. Violation of Rule $\mathrm{G}$ results in severe penalties, including termination. Some of the nation's earliest employee assistance programs (EAPs) were started in the railroad industry to treat employees with substance use problems and to provide aid to employees who violated this ban.

Railroad employees have also taken a greater role in the prevention and treatment of substance use problems among their coworkers. Peer intervention programs, for example, focus on peers (coworkers), changing attitudes toward on-the-job substance use, and training coworkers to recognize and intervene with workers with substance use problems (Bacharach et al., 1996; Bamberger \& Sonnenstuhl, 1995; Eichler et al., 1988). In 1987, a passenger railroad company and some of its unions agreed to adopt an ongoing version of PeerCare, a substance abuse prevention and early intervention program described in more detail later in this chapter.

Today, as the aging railroad workforce retires, a new cohort of young workers is entering the workplace and bringing with them new and different substance use problems. Although the vast majority of workplace substance abuse probably goes undetected, the railroad company's administrative records can place a lower bound on problem rates. Between 1996 and 2000, for example, the railroad company's administrative records identified 5.6 percent of workers under age 25 with an indicator of substance abuse; 2.4 percent had one or more alcohol- or other drug-related visit to the EAP; and 3.3 percent had taken an excused alcohol- or other drug-related absence from work via PeerCare. Among workers tested for alcohol or other drugs at least once between 1996 and 2000, 18- to 24-year-olds had the highest percentage of positive tests ( 4.9 percent). In addition, absenteeism, disrespect, fighting, and other problem behaviors frequently co-occur with alcohol and other drug problems. The railroad company's disciplinary records show that during this same time period, 3.6 percent of young workers were charged with absenteeism problems and an additional 1.9 percent were charged with other problem behaviors. These numbers highlight the need for effective substance abuse prevention and early intervention programs targeting young workers.

With a large percentage of the railroad company's existing workforce retiring between 2005 and 2010, it is imperative to focus attention on relevant issues for the large, incoming young workforce. To address the needs of the young workforce at the railroad company, the Pacific Institute for Research 
and Evaluation (PIRE), in collaboration with the railroad company's PeerCare, has adapted PREVENT (Personal Responsibility and Values: Education and Training), a program originally designed for US Navy recruits. As part of the Substance Abuse and Mental Health Services Administration's (SAMHSA's) Young Adults in the Workplace (YIW) initiative, the current project revised the US Navy's PREVENT curriculum to meet the needs and culture of the railroad company's young workforce. This chapter describes the content and implementation of PREVENT in a railroad company. It also describes the target population and provides early process findings.

\section{Program Description}

PREVENT is a facilitated 2-day training program for young workers that addresses alcohol and other drug abuse and other important challenges that young adults may face when transitioning into full-time work. The interactive group discussion format is designed to boost workers' understanding of personal responsibilities in their lives, in particular regarding alcohol and other drug use, smoking, financial management, stress management, and suicide prevention. PREVENT's design recognizes that knowledge alone rarely produces change or modifies behavior. Therefore, the program uses discussions among peers to create personal recognition that changes are needed and then provides time to plan those changes.

The intervention is an enhancement of and is managed from within PeerCare. PREVENT complements PeerCare by addressing the needs of a highrisk group: young adults entering the workforce. PeerCare is a union-operated, company-funded peer support program that covers 90 percent of the railroad company's 23,000 culturally diverse employees. Components of PeerCare are described in the PeerCare section below.

\section{History and Structure of PREVENT}

In 1974, the US Navy contracted with the University of West Florida to provide the Navy's first alcohol prevention program, the Navy Alcohol Safety Action Program. In 1980, the Navy created the Navy Drug Safety Action Program to combat increased drug use. These two programs were combined in 1982 to create PREVENT.

PREVENT's personal responsibility approach to behavior change has been applied successfully across a variety of risk-related behavioral concerns. As participants learn to apply skills in one risk-related behavior, they can 
translate their successes to other areas. This approach allows PREVENT to address a spectrum of related needs. In addition to the alcohol and other drug use modules, PREVENT includes modules addressing other health and lifestyle behaviors, including (1) nutrition and fitness; (2) risky sexual behavior, including unplanned pregnancies, sexual assaults, sexual harassment, and sexually transmitted diseases; (3) tobacco use; (4) violence, including workplace and domestic violence; and (5) financial management.

In addition, PREVENT instills positive behaviors that can enhance employee performance. For example, communication skills (listening, speaking for self or I statements, observation to interpretation, styles of communication) are taught and practiced as a routine part of the course. Stress management is also covered and practiced. A core component of the course involves examining how personal beliefs, values, expectations, and thoughts influence behavior. The overall goal is to reduce impulsive actions and choices and to act in a way that is more responsible to oneself and others. As participants are able to examine their beliefs, values, and expectations, especially as they relate to relationships with others, they may be able to reduce their impulsive behaviors and act from a more thoughtful place.

As noted previously, the railroad PREVENT adaptation is housed and managed from within PeerCare. Over its 20 -year existence, PeerCare's efforts have centered on changing the railroad company's workplace climate and culture of substance use. However, the railroad company's newest and youngest workers are less involved in PeerCare than are older workers, and it is not clear whether the younger workforce has gotten the PeerCare message. PeerCare is used to reinforce and follow through on the PREVENT messages by including a post-PREVENT mentoring program between the PREVENT participants and PeerCare team members. The mentoring program takes advantage of the existing network of peers to reinforce the PREVENT program.

\section{PeerCare}

The core of the railroad company's substance abuse prevention and early intervention efforts is PeerCare, which was created in 1987 and rapidly spread as it was added to union contracts. The program's mission is to reduce substance abuse in the workplace, in part by changing occupational norms that condone this behavior. This union-management partnership uses the occupational peer group to achieve a cultural shift from enabling working under the influence of alcohol or other drugs to maintaining a substance-free workplace. 
In exchange for employee efforts, management moved from a punitive approach to supportive and restorative aid for substance abusers. Thus, the program is designed to educate, intervene, and refer workers to appropriate support services to attain healthier, substance-free lifestyles without employer disciplinary action. It is part of a larger corporate behavioral health care program that includes (1) 2,400 active volunteers who aim to keep the workplace substance-free and steer employees with alcohol or other drug problems to help; (2) the PeerCare mark-off, which allows drunk or drugged employees to absent themselves from the workplace confidentially without penalty; and (3) a tailored version of SAMHSA's GetFit website called "On the Right Track." Other substance abuse prevention and treatment components at the railroad company include random (for 20 percent of safety-sensitive employees), pre-employment, post-accident, and for-cause alcohol and other drug testing; an in-house EAP; health insurance with unlimited but casemanaged behavioral health/substance abuse treatment coverage; and written substance abuse policies.

In essence, PeerCare is peers supporting peers, with volunteer teams of union workers at the heart of the program. Team members are diverse with regard to gender, race/ethnicity, language skills, and job title. Almost all complete a 1- to 2-day training course to learn how to recognize and intervene with a coworker who has an alcohol or other drug problem. More than 6,500 union and management employees have received PeerCare training. In early 2000, the 152 active teams included 2,400 employee volunteers. However, PeerCare and the EAP currently have no materials targeting younger workers and little expertise in the specialized substance abuse issues of this population. These gaps have become issues in this decade because a wave of retirements and the hiring of younger workers have increased the need for this expertise. PeerCare and the EAP are committed to increasing their capacity to reach younger workers.

\section{Program Delivery}

PREVENT workshops include 20 or fewer participants plus one trained outside facilitator. Ten to 15 participants is ideal because it allows sufficient variation in viewpoints to foster and sustain discussion while being small enough to allow all participants to contribute.

Through facilitator-led group discussion, participants examine their personal goals and values, assess whether their behaviors are in line with their goals and values, and consider whether they want to bring their behaviors 
more in line with their goals and values. The PREVENT facilitator is trained in a 3-day workshop that covers the theory of PREVENT in addition to techniques for motivational interviewing and for engaging participants in the discussion. After the initial training, facilitators receive 10 hours of on-the-job training with another facilitator.

At the railroad company, participants are contacted at their worksites and invited to join the PREVENT class, although supervisor permission is also required. To get a representative sample of the workforce, supervisors are asked to consider only operational burden (rather than behavioral or performance factors) when giving permission for a worker to attend.

\section{Theoretical Model}

PREVENT embraces the transtheoretical model (Prochaska \& Velicer, 1997), which integrates several theories of behavior change around a stages of change approach (Table 3.1), via its threat-minimization framework, which also draws on Weinstein and Sandman's (1992) precaution adoption model. This model is a framework for understanding how individuals adjust to perceived hazards.

\section{Table 3.1 PREVENT's threat minimization framework}

\begin{tabular}{|c|c|c|}
\hline Level & Current Stage & Action to Move to Next Level \\
\hline 0 & Unaware of risk or threat & Obtain information \\
\hline 1 & Exposed to the facts & $\begin{array}{l}\text { Shift to concern toward the risks of a behavior, but } \\
\text { not necessarily for self }\end{array}$ \\
\hline 2 & $\begin{array}{l}\text { Seeing threat generally, but } \\
\text { not necessarily to self }\end{array}$ & Shift to concern for one's behavior-associated risks \\
\hline 3 & Seeing threat to self & $\begin{array}{l}\text { Identify barriers to change; plan to overcome them; } \\
\text { decision for action }\end{array}$ \\
\hline 4 & Deciding to reduce threat & Engage in changing the identified behavior \\
\hline 5 & Taking action & Sustain new behavior over a period of time \\
\hline 6 & Maintaining behavior & \\
\hline
\end{tabular}

PREVENT = Personal Responsibility and Values: Education and Training.

The course content and facilitator training emphasize classroom activities that draw on the precontemplation, contemplation, preparation, and maintenance stages of the transtheoretical model. Evaluation data from the Navy PREVENT program suggest that PREVENT is a successful interactive behavioral change intervention, as has been demonstrated for counselingbased interactive transtheoretical model approaches, compared with non- 
interactive interventions such as self-help guides (Curry, 1993; Glynn et al., 1992; Schwartz, 1987).

PREVENT encourages health-enhancing, risk-reducing changes for participants that are based on personal values and experiences. An individual's alcohol drinking patterns, interpersonal skills, or conflict management approach is rooted in other intrinsic values and experiences. Therefore, the change or learning process is quite different from learning a skill such as solving a math equation or learning to be an engine mechanic; typically, acquisition of these kinds of skills is not tied to strong personal values or experiences. Relearning a set of skills that leads to a reduction in the amount of alcohol consumed each week, for example, may require addressing values, attitudes, and past experience. The ultimate control for behavior change lies with the participant. This premise underlies the stages of change model and has important ramifications for facilitator comportment and skills.

PREVENT is a stages of change-based intervention. Merely parsing a behavior problem and its proposed resolution into a series of change stages does not in and of itself ordain an intervention as a stages of change approach. In fact, an essential structure is necessary for an intervention to take on the characteristics of a stages of change approach. The transtheoretical model concept of processes of change has proven applicable to a broad variety of problem areas (Prochaska, 1984; Prochaska \& DiClemente, 1983). Table 3.2 presents Prochaska and Velicer's (1997) typology of the processes of change in relation to the stages of change.

Table 3.2 Stages of change in which change processes are most emphasized

\begin{tabular}{lll}
\hline Stages of Change & Processes \\
\hline 2. & Precontemplation & $\begin{array}{l}\text { Consciousness raising, dramatic relief, environmental } \\
\text { reevaluation }\end{array}$ \\
\hline 3. & Contemplation & Self-reevaluation \\
\hline 4. & Preparation & Self-liberation \\
\hline 5. & Action & $\begin{array}{l}\text { Contingency management, helping relationship, counter- } \\
\text { conditioning, stimulus control }\end{array}$ \\
\hline 6. & Maintenance & \\
\hline
\end{tabular}

Source: Adapted from Prochaska and Velicer, 1997. 


\section{Program Goals}

The PREVENT program has six measurable goals:

\section{Advance young workers through a stages of change model to} reduce risky behaviors. The PREVENT program is designed to work with participants regardless of the stage they are in when they enter the program. Participation in a facilitated workshop and use of a transtheoretical model framework are designed to motivate participants to progress up the stages of change through group discussion, contemplation of values (both verbally and nonverbally), and planning of steps to make changes that will take them closer to their goals and in line with their values.

2. Reduce alcohol and other drug use. The two biggest modules in the six-module railroad PREVENT adaptation relate to alcohol and other drug use. PREVENT is not an educational program on alcohol and other drug use. Instead, the workshop enables participants to contemplate their own alcohol and other drug use behaviors, discuss the values they attach to their use or non-use, and assess whether their substance use is in line with their values and goals. Participants put together a plan to reduce or discontinue alcohol and other drug use if they feel it will allow them to stay true to their values and better meet their own short- and long-term goals. In PREVENT, it does not matter where the participant is within the stages of change. The goal of PREVENT is to motivate participants to make changes in their lives that reflect progress up one or more stages.

3. Enhance workers' ability to make sound decisions. Throughout the PREVENT workshop, group discussion revolves around values and value conflicts. Participants are motivated to make decisions and behavioral changes that are consistent with their values. Value conflicts (e.g., conflicts between personal, organizational, and family values) arise during the workshop. How participants cope with value conflicts and the role of value conflicts in personal decision making are discussed.

4. Improve communication skills. Awareness of value conflicts and how others make decisions helps to improve communication skills. In addition, PREVENT participants engage in an exercise on communication styles.

5. Reduce the risk of workplace injury. Achieving the above four goals will have an impact on workplace injury rates. Ample evidence exists that 
alcohol-, other drug-, and hangover-related impairment increases the risk of injury. This impairment adversely affects coordination and the ability to perceive and respond to hazards, which may result in injury to the user and other innocent victims (Moskowitz \& Robinson, 1988; Normand et al., 1994; Törnros \& Laurell, 1991; Yesavage \& Leirer, 1986). Previous analyses of the impact of PeerCare found that a reduction in workplace injury rates and costs correlates with the implementation of PeerCare (Miller et al., 2007; Spicer \& Miller, 2005).

6. Reduce workplace performance problems. Absenteeism, disrespect, fighting, and other problem behaviors frequently co-occur with alcohol and other drug problems. Through its effects on alcohol and other drug problems, PREVENT is expected to reduce workplace performance problems.

\section{Adapting the Navy's PREVENT Program to the Railroad Company's Young Adult Workforce and Workplace}

Adapting the PREVENT curriculum to the railroad company first involved reducing the class time from 3 to 2 days, in response to concern that the operational burden of a 3-day class would reduce management support of the program. The adaptation also involved eliminating Navy-specific references and terms and incorporating company policies, values, and culture.

To reduce the class time from 3 to 2 days, several modules were eliminated. These were selected by consulting PeerCare staff and a small focus group of young workers. In particular, PeerCare staff listed alcohol and other drugs as the priority modules, and young workers cited financial management as an issue of concern. Company staff felt that sexual harassment, sexual behaviors, and violence were too sensitive and might delay the implementation of the intervention. Relative to the other possible modules, physical fitness and nutrition were not perceived as issues that needed to be addressed. Thus, the Navy PREVENT curriculum was shortened from 3 days to 2 days by excluding the sections on sexual harassment, sexual behaviors, violence, and physical fitness and nutrition. Modules retained in the railroad adaptation of the curriculum are interpersonal responsibility and values, alcohol and other drugs (by far the largest section), tobacco use, personal finances, suicide prevention, and stress.

Thinking ahead toward replication of the PREVENT program in other companies, we created a skeleton workbook, absent all Navy and railroad 
references. Using the skeleton curriculum, any corporation can insert its company-specific values and policies. In addition, we modified the PREVENT course facilitators guide to correspond to the new railroad adaptation of the curriculum.

\section{Enhancing the PREVENT/PeerCare Amalgamation}

To enhance the PREVENT and PeerCare relationship and to reinforce the PREVENT program, we implemented a mentoring program that pairs one trained volunteer PeerCare team member with a PREVENT participant post-program. The PeerCare team member follows up with the participant after the training. The follow-up is personal and tailored to the situation and rapport between the mentor and participant. At a minimum, the follow-up involves making initial contact (in person, by telephone, or by e-mail), making introductions, asking the participant if he or she has made progress in meeting his or her action steps, and giving the participant the opportunity to ask for help or further contact. Action steps are plans that the PREVENT participant made during the class to meet a specific goal. For personal confidentiality reasons, the mentor does not know what action steps the participant has listed. Depending on the receptiveness of the participant, the mentor can have a more in-depth conversation about challenges the participant is facing, both in meeting his or her action steps and about life in general. The mentor can share his or her experiences with similar challenges and give advice in overcoming challenges in meeting action steps and in life in general. After the initial contact, this relationship can be anything the participant and mentor want it to be. The amount of contact between mentor and mentee is monitored for the purposes of the evaluation.

\section{Target Population}

The study company is a large national passenger railroad company that employs approximately 23,000 people in 47 states and the District of Columbia. The vast majority (about 80 percent) of the workforce is blue-collar and unionized. The company has about 200 worksites throughout the continental United States that are divided into six regions. The target population of the PREVENT program is workers at the railroad company aged 18 to 29. The educational enrollment status of workers is not a consideration in defining the target population. The company employs about 1,000 workers in this age group, which is about 4 percent of the company workforce. Forty-five 
percent are minorities (primarily African American but with large Hispanic and Southeast Asian representation). The majority (65 percent) of employees are male. Females are particularly underrepresented within trades that are traditionally male (e.g., track maintenance, engineers, conductors). These occupations also have the characteristics that put workers at high risk for substance abuse (e.g., unsupervised for long periods of time, travel over long distances, overnight and/or abnormal shifts) and carry the greatest risk of injury. A more even distribution of women and men is seen among the secretarial, reservation, and sales occupations.

Almost universal union membership for permanent employees made turnover among employees under age 25 a very modest 23 percent over a 5 -year horizon. However, the young adult workforce is expected to increase over the next decade. Many employees hired at the time the railroad company was founded in the 1970s are reaching the 30 years of service required for full Railroad Retirement Board pensions. Between 2005 and 2010, more than 30 percent of the railroad company's 23,000 employees will fully vest for retirement, although not all will reach the age of 60 when their pension payouts begin. Thus, hiring of young workers is accelerating despite overall workforce shrinkage.

Each of the grantees administered a survey to support the YIW crosssite evaluation (see Chapter 8 for more information about the cross-site evaluation and the core survey measures). All railroad company employees aged 18 to 29 were invited to respond to the survey. In the initial round of data collection, 244 out of approximately 1,000 employees responded. The sex and race distribution of the survey respondents were similar to those of the target population. Sixty-six percent of respondents were male and 54 percent were white. The average age of respondents is 26.3 years, indicating the skew in the age distribution of the respondents toward the upper age limit of the targeted population. Very few respondents ( 6 percent) were below the legal drinking age of 21 .

\section{Early Process Findings}

In adapting the Navy PREVENT program to the railroad company, it was important to examine the differences and similarities between the two organizations in the areas of workforce and organizational characteristics, workplace policies, and workplace culture that may impact the usefulness of the PREVENT adaptation. Table 3.3 compares these organizational characteristics (differences between the organizations are shaded). 


\section{Table 3.3 Characteristics of the US Navy versus the railroad company}

\begin{tabular}{|c|c|}
\hline US Navy & Railroad Company \\
\hline Young workforce, in general: & Young workforce, in general: \\
\hline Worldwide & Nationwide \\
\hline Trained by the Navy & $\begin{array}{l}\text { Often specialize in a trade before being } \\
\text { hired }\end{array}$ \\
\hline $\begin{array}{l}\text { Change worksites every few years; } \\
\text { some jobs are "on the road" }\end{array}$ & $\begin{array}{l}\text { Some jobs are based in one worksite, } \\
\text { whereas others are "on the road" }\end{array}$ \\
\hline Majority male & Majority male \\
\hline Includes safety-sensitive jobs & Includes safety-sensitive jobs \\
\hline Policies: & Policies: \\
\hline Access to behavioral health care & Access to behavioral health care \\
\hline $100 \%$ insured & $100 \%$ insured \\
\hline $\begin{array}{l}\text { Department of Defense-mandated } \\
\text { drug and alcohol testing, including } \\
\text { random and pre-employment testing }\end{array}$ & $\begin{array}{l}\text { Department of Transportation-mandated } \\
\text { drug and alcohol testing, including random } \\
\text { and pre-employment testing }\end{array}$ \\
\hline Written alcohol and drug use policies & Written alcohol and drug use policies \\
\hline Culture: & Culture: \\
\hline "Readiness": on the job 24/7 & Some long shifts, but not $24 / 7$ \\
\hline Navy_-"Shipmates helping shipmates" & Unionized-“We are our brother's keeper" \\
\hline $\begin{array}{l}\text { Follow direction of supervisor, line of } \\
\text { authority }\end{array}$ & Mistrust of management \\
\hline $\begin{array}{l}\text { Historically, a culture of drinking on and } \\
\text { off the job }\end{array}$ & $\begin{array}{l}\text { Historically, a culture of drinking on and off } \\
\text { the job }\end{array}$ \\
\hline $\begin{array}{l}\text { "The Right Spirit": Campaign to prevent } \\
\text { substance abuse on and off the job by } \\
\text { changing workplace culture }\end{array}$ & $\begin{array}{l}\text { PeerCare: Peer-to-peer program to prevent } \\
\text { substance abuse on and off the job by } \\
\text { changing workplace culture }\end{array}$ \\
\hline
\end{tabular}

Note: Differences between the two organizations are shaded.

Workplace values and policies were incorporated into the curriculum from a wide range of sources (e.g., PeerCare, drug testing, human resources, managed care program).Written policies exist, but we relied on testimony from PeerCare team members and staff to portray the workplace culture and values. Value conflicts (in particular between management and the unions) were inevitable. In general, the adaptation of the PREVENT program takes more of the union perspective because this is the population the program is designed to serve. However, embedded in the PREVENT curriculum is a discussion of value conflicts, which allows these issues to be explored further. 
After each PREVENT workshop, participants respond to four open-ended questions regarding their experience of the workshop. Overall, participants have expressed enthusiasm for the program. The majority said the most helpful part of the PREVENT workshop was the discussion of personal values. Nearly all said the workshop made them think about making changes in their lives. Representative participant comments include, "It was a reality check for me with my values and what I do and think," and "I found out more about myself and my living choices." Most participants came away from the workshop feeling that they wanted to make changes in their lives, in particular to reduce alcohol consumption and better manage personal finances.

\section{Conclusions}

In adapting the PREVENT curriculum, a wide range of workplace culture, values, and policies had to be consolidated. In general, the final product takes a union perspective because this is the population the program is designed to serve. The majority of participants in the PREVENT program said the most helpful part of the PREVENT class was the discussion of personal values, and most said that the class made them think about making changes in their lives.

The lessons learned from PREVENT may be useful to future programs. One important issue to consider is the number of days to dedicate to the PREVENT workshop. In this project (and at the Navy PREVENT), these are paid full days of work for the participants whose regular posts must be filled by alternates. The Navy developed a curriculum for a 3-day workshop, but we felt we would get better management buy-in if we reduced the program to 2 days. However, some supervisors were still unwilling to release workers in jobs for which it was difficult to find replacements.

Unexpected and unfortunate workplace events that are related to the program objectives can sometimes boost support for the program, such as a worker's suicide or an alcohol-related workplace injury. In the railroad PREVENT adaptation, for example, an alcohol-related train crash could affect substance abuse awareness and behaviors and possibly impact the importance that the company and the federal government place on the project. A case in point is the 1987 Chase, Maryland, crash, which involved an engineer on a Conrail train who was high on marijuana, missed a signal, and caused a crash into one of the company's passenger trains, killing 16 people. In response to this incident, the federal government increased pressure to address railroad alcohol and other drug use, which led to the birth of PeerCare. Even non- 
company railroad and non-alcohol-related crashes can affect the program by increasing attention and/or funding.

In any workplace project, management support is critical for both program implementation and sustainability, and commitment from one or more people in a decision-making position can help overcome challenges and barriers to project viability. At the railroad company, disruptions in management and company leadership delayed program implementation. However, PeerCare's commitment to this project kept it viable. Once the leadership situation stabilized, great progress was made.

\section{References}

Bacharach, S. B., Bamberger, P. A., \& Sonnenstuhl, W. J. (1996). MAPS: Laborbased peer assistance in the workplace. Industrial Relations, 35(2), 261-275.

Bamberger, P. A., \& Sonnenstuhl, W. J. (1995). Peer referral networks and utilization of a union-based EAP. Journal of Drug Issues, 25(2), 291-312.

Curry, S. J. (1993). Self-help interventions for smoking cessation. Journal of Consulting and Clinical Psychology, 61, 790-803.

Eichler, S., Goldberg, C., Kier, L., \& Allen, J. (1988). Operation RedBlock: Case study of a peer prevention substance abuse program for railroad industry personnel. Rockville, MD: Federal Railroad Administration and Institute for Human Resources.

Glynn, T. J., Anderson, D. M., \& Schwarz, L. (1992). Tobacco-use reduction among high-risk youth: Recommendations of a National Cancer Institute Expert Advisory Panel. Preventive Medicine, 20(2), 279-291.

Manello, T. A., \& Seaman, F. J. (1979). Prevalence, costs, and handling of drinking problems on seven railroads. Final report. Washington, DC: University Research Corp.

Miller, T. R., Zaloshnja, E., \& Spicer, R. S. (2007). Effectiveness and benefit-cost of peer-based workplace substance abuse prevention coupled with random testing. Accident Analysis and Prevention, 39(3), 565-573.

Moskowitz, H., \& Robinson, C. (1988). Effects of low doses of alcohol on driving-related skills: A review of the evidence (Report No. DOT HS 807 280). Washington, DC: National Highway Traffic Safety Administration.

Normand, J., Lempert, R. O., \& O’Brien, C. P. (Eds.). (1994). Under the influence? Drugs and the American work force. Washington, DC: National Academy Press. 
Prochaska, J. O. (1984). Systems of psychotherapy: A transtheoretical analysis (2nd ed.). Homewood, IL: Dorsey Press.

Prochaska, J. O., \& DiClemente, C. C. (1983). Stages and processes of selfchange of smoking: Toward an integrative model of change. Journal of Consulting and Clinical Psychology, 51(3), 390-395.

Prochaska, J. O., \& Velicer, W. F. (1997). The transtheoretical model of health behavior change. American Journal of Health Promotion, 12(1), 38-48.

Schwartz, J. (1987). Review and evaluation of smoking cessation methods: The United States and Canada, 1978-1985. Bethesda, MD: US Department of Health and Human Services.

Spicer, R. S., \& Miller, T. R. (2005). Impact of a workplace peer-focused substance abuse prevention and early intervention program. Alcoholism: Clinical and Experimental Research, 29(4), 609-611.

Törnros, J., \& Laurell, H. (1991). Acute and hang-over effects of alcohol on simulated driving performance. Blutalkohol, 28(1), 24-30.

Weinstein, N. D., \& Sandman, P. M. (1992). A model of the precaution adoption process: Evidence from home radon testing. Health Psychology, 11(3), 170-180.

Yesavage, J. A., \& Leirer, V. O. (1986). Hangover effects on aircraft pilots 14 hours after alcohol ingestion: A preliminary report. American Journal of Psychiatry, 143(12), 1546-1550. 



\title{
Team Resilience: Health Promotion for Young Restaurant Workers
}

\author{
Joel B. Bennett and Charles C. Aden \\ Organizational Wellness \& Learning Systems, Ft. Worth, TX
}

\section{Introduction}

National studies suggest that 18 - to 25 -year-old restaurant workers present the highest occupational risk for substance abuse and depression of any age or occupational group (Bennett et al., 2008; Ensuring Solutions, 2008; Frone, 2006a, 2006b; SAMHSA, 2007). According to the National Restaurant Association (2008), about 50 percent of adults have worked in a restaurant during their lives and 32 percent of adults had their first job in a restaurant. Thus, restaurants serve as a setting in which new, at-risk workers can learn health behaviors with significant positive downstream effects for society. This chapter reviews the development of an innovative curriculum to reduce young worker risks while addressing operational concerns in restaurant management. We viewed the restaurant as a venue through which workers learn important life attitudes and skills, including the commitment and follow-through necessary for tedious restaurant work and that managers require for sustained business. Indeed, restaurants have perhaps the highest employee turnover of any industry.

The following sections provide an overview of the Substance Abuse and Mental Health Services Administration's (SAMHSA's) Young Adults in the Workplace (YIW) grant project, the restaurant industry and participating organization, and demographics of participants. We describe the new curriculum, which went through a series of adaptations (see Bennett et al., 2010), and present the logic model that informed program development. We describe the target population and process findings related to program implementation. Our efforts in program development cast a very broad net; we aimed to create a program that would promote as many strength factors as possible. This chapter focuses on these factors. Future work will examine how program elements can be packaged for scalability and dissemination in the field. 
The current chapter also reviews processes wherein an evidence-based program that has proven effective in one field or with a certain population is adapted for use in another field. The program for young restaurant workers we highlight here (Team Resilience) was informed by an existing curriculum (Team Awareness) that was originally developed for adult employees. Others have described many challenges associated with translating research into practice or adapting programs for use outside of initial clinical trials (Fixsen et al., 2005; Fixsen et al., 2007). We hope that our experiences in meeting these challenges will be helpful to others who want to improve the reach and utility of workplace prevention programs.

\section{Program Description}

For the YIW initiative, Organizational Wellness \& Learning Systems partnered with a national restaurant chain to adapt and deliver a highly interactive, classroom-based training program (Team Awareness) (Bennett \& Lehman, 2000) that has been scientifically reviewed and entered into the National Registry of Evidence-Based Programs and Practices (2002, 2007). The adapted program, Team Resilience, appeals to young adults' sense of resilience and draws on the opportunity that restaurant work provides this age group for learning important life skills, such as communication and work-life balance (Arnett, 2004; Bennett et al., 2006).

We selected the restaurant industry because of inherent occupational and behavioral health risks for young workers. Restaurant workers (food preparation and service) have a greater incidence of substance abuse than workers in any other occupation (e.g., Kjaerheim et al., 1995; SAMHSA, 1997, 2007; Zhang \& Snizek, 2003). For the National Survey on Drug Use and Health, more than 17 percent of food service workers reported illicit drug use, with no change from 1994 to 2007. Another national study found such workers to be among the five highest-risk occupational categories (Frone, 2006a, 2006b). Compared with 17 other occupations, food service workers were about 9 times more likely to work under the influence of illicit drugs or alcohol. Compared with 21 different occupations, food service workers had the secondhighest rate of major depressive episode in the past year (at 10.3 percent), with greater risk for 18 - to 25 -year-olds (at 11.5 percent) (SAMHSA, 2007). Also, although serious psychological distress is higher among young adults aged 18 to 25 (roughly 18 percent) than among those aged 26 to 49 (12.2 percent) and 50 or older (7.0 percent), young adults are least likely to receive mental health services (Office of Applied Studies, 2008). 
It is possible that the disproportionately high substance abuse among restaurant workers is simply because they are younger (and substance abuse is more common among younger groups). It would seem that age, and not the industry type, may be the responsible factor. However, past research, as well as our own field investigations, suggests that there may also be a culture that supports drinking, late-night revelry, and stress relief following a demanding work shift. We make this statement with great caution so as not to perpetuate stereotypes and to emphasize that there is significant variation in culture from restaurant to restaurant. At the same time, the Team Awareness curriculum was designed to address risks in occupational subcultures, and our approach was geared to address such risk. It also promotes help-seeking for depression and distress that appeared to be high in young restaurant workers.

We identify four reasons why addressing behavioral health risks may also be relevant to the future development of restaurant industry and careers. First, restaurants are perhaps the largest employer of young adults (Bureau of Labor Statistics, 2007), and an intervention should be of interest to an industry that has itself acknowledged significant alcohol and other drug (AOD) problems (Batrus Holweg International, 2003; Berta, 2003). Second, as noted, restaurants have among the highest levels of turnover of any industry (Chapman, 2004), which is relevant because substance abuse is related to job instability (SAMHSA, 1997; Zhang \& Snizek, 2003). Not surprisingly, in our restaurant sample, lower job commitment was associated with marijuana use and alcohol hangovers. Third, heavy drinking is associated with work injuries among young adults (Veazie \& Smith, 2000). This is especially relevant for the current sample, because young worker injuries (e.g., slipping on spills, cuts, burns) are highest in restaurants (Castillo, 1999). Fourth, AOD use predicted absenteeism and theft in a large sample of entry-level restaurant workers (Bolin \& Heatherly, 2001). Also, as explained below, the proximal outcome of the Team Resilience logic model is a positive work environment. For young workers, a positive work environment is related to greater well-being (Grebner et al., 2004) and organizational commitment (Frone, 1998).

To summarize, a program that could address substance abuse and related behavioral health factors is not only important for the well-being and health of the employees themselves; it could also improve many outcomes for the workplace (e.g., liability due to on-the job injuries, productivity, turnover). Thus, at all stages of program development we sought to keep a dual focus on the workers and the industry that would be critical to the future dissemination and sustainability of the program. 
The remainder of this section describes the adaptation of the Team Resilience program using fidelity principles of the Team Awareness training and inputs from stakeholders, the final training structure, and the logic model. We believe that the methodology described here can be applied to other restaurants employing a large number of young adults.

\section{Team Awareness: The Original Program}

The Team Awareness program (Bennett et al., 2000) was the starting point for adaptation. The core logic of Team Awareness follows research showing that work group cohesion is a protective factor against adult AOD abuse, whereas drinking climate (e.g., peers support and join in alcohol use) is a risk factor (e.g., Bacharach et al., 2002; Bennett \& Lehman, 1998). In its original format, Team Awareness is an 8-hour training program for adult workers (Bennett et al., 2000) and includes six modules that facilitate positive social interaction, promote a healthy work environment, and destigmatize help-seeking for $\mathrm{AOD}$ and mental health concerns. For example, the program addresses the possibility that employees tolerate counterproductive coworkers (e.g., those who consumed alcohol on the job) (Bennett \& Robinson, 2000) because the work climate supports their behavior, as in shared AOD use (Bennett et al., 2000). Module content covers (1) relevance to employees and the employees' group through seven core prevention principles, which are reiterated in all other modules (Table 4.1); (2) policy and resources (e.g., the employee assistance program [EAP]); (3) tolerance versus responsiveness toward troubled workers; (4) stress, coping, and substance use; (5) communication; and (6) peer referral, support, and encouragement. The program uses minilecture, interactive scenarios; a "Risks \& Strengths" game; role-play activities; and communication exercises.

Randomized studies have shown that Team Awareness reduces problem drinking and drinking climate and improves help-seeking behaviors, employee assistance utilization, and supervisor responsiveness to troubled workers (Bennett \& Lehman, 2001; Bennett et al., 2004; Lehman et al., 2003; Patterson et al., 2005). In 2002 and 2007, reviewers with the National Registry of Evidence-Based Programs and Practices (Brounstein et al., 2006; Hennessy et al., 2006) rigorously evaluated the program and included it in the registry as an evidence-based program. Previous work with Team Awareness suggested it may be useful to young workers, but it required some, if not significant, modification from its use with adults. 


\section{Table 4.1 Seven "ounce of prevention" principles from the Team Awareness curriculum}

1. Identify and reduce risks that cause or aggravate the problem.

2. Identify and increase strengths that address the problem.

3. Know and appreciate policy as your guide and safeguard.

4. Understand your own tolerance for the situation and adjust if necessary.

5. Work together as a team to communicate and solve the problem.

6. Develop or enhance stress problem-solving skills (alternative solutions).

7. Communicate the problem and support others (don't isolate and withdraw).

\section{Program Adaptation and Innovation}

The developers used three core inputs to create the new Team Resilience program: (1) the original evidence-based practice (EBP), Team Awareness (Bennett et al., 2000); (2) stakeholders (i.e., young adults); and (3) linking concepts. Linking concepts refers to ideas (e.g., stress, communication) used to reference back to the original program and allow for innovation in the new program. The signature assumption of any EBP is that it has core content and principles that account for effectiveness. The new program should retain some core aspects and maintain fidelity to the original content and principles of the program (Dusenbury et al., 2003). At the same time, the likelihood of the EBP's being accepted (buy-in) is improved through capacity-building by modifying programs to best fit the culture, ethos, and belief systems of the target group (Stevenson \& Mitchell, 2003). Finally, there may be a set of linking concepts that could be used to help translate between the EBP and the target population. These three inputs helped us adapt the actual training material into a new format. We synthesized the core inputs through six types of meetings, which we call touch points.

\section{Six Touch Points}

The research team met with others (e.g., subject matter experts [SMEs], advisory group) to showcase, discuss, or test the three core inputs. We refer to these meetings as touch points rather than steps because the meetings are not necessarily sequential. For example, an SME may be consulted before or after a focus group, whose ideas may be tested with an advisory group, or advisors may make suggestions that need to be discussed with an SME. 
Touch Point 1 (Key Informants). We first met with key informant restaurant managers and shadowed representative young workers in their work setting.

Touch Point 2 (Subject Matter Experts). SMEs provided input on program design. Before meeting with four SMEs, we prepared insights from shadowing (touch point 1) to stimulate input from SMEs into the design of training exercises and topics for discussion.

Touch Point 3 (Focus Groups). Through extensive interviews, six different focus groups reviewed elements from the original Team Awareness training and tested ideas proposed by the SMEs. These groups provided feedback on elements to be retained, revised, or discarded. We included groups with diverse populations-restaurant trainers, managers, students, servers, back-of-house workers, Spanish speakers-to further ensure that the material is culturally sensitive.

Touch Point 4 (Employee Advisory Committee). We formed an employee advisory committee (EAC) composed of young employees of the restaurants who met four times (monthly) to review the training. The work of the EAC concluded the transition from program development to implementation. We presented a prototype program to EAC members, who gave feedback, generated new curricula, and validated early content and design decisions. We used the EAC to (1) identify sources of influences on worker decisions to use AOD, (2) uncover beliefs about AOD abuse, (3) gauge the level of education regarding restaurant policy and the value placed on work training, and (4) determine knowledge of addiction and AOD treatment.

Touch Point 5 (Management Steering Committee). We also recruited participants for a management steering committee, which is distinct from the EAC in that it is composed of professionals, managers, senior leaders, and other key influencers in the work setting. Steering committee members met monthly and were provided updates as the translation process proceeded.

Touch Point 6 (Pilot Curriculum). Incorporating input from previous touch points, we created an initial model and showcased elements with focus groups. We considered the training a work in progress and later reviewed it in an intensive 2-day adaptation retreat that included SMEs. We reviewed the new program against fidelity guidelines of the EBP and SME input. The key output of this retreat was a model ready to be developed into a training manual. 


\section{Resilience: Final Training Principles}

We titled the program Team Resilience because information collected from the six touch points, as well as previous studies, suggested that young adults were more receptive to learning about resilience (Masten et al., 2006; Osgood et al., 2005) than about wellness (healthy lifestyle) or awareness-raising activities, per se. Moreover, many studies have shown that resilience (or hardiness) is a significant protective factor for AOD risk (Maddi et al., 1996; Moon et al., 1999; Wong et al., 2006). Accordingly, we reviewed the literature on resilience (Bonanno, 2004; Clausen, 1991, 1993; Friborg et al., 2003; Maddi, 2005; Masten et al., 2006; Rutter, 1989; Werner, 1989) and adapted the original Team Awareness curriculum to address the resilience interests of this at-risk population.

To preserve fidelity, the curriculum aligned concepts of resilience with principles (and some activities) from the original Team Awareness curriculum. Specifically, we examined the literature on resilience and extracted five distinct psychological constructs that appeared-when assembled togetherto constitute the major dimensions of resilience. To aid easy recall of these constructs, we labeled them "Five Cs:" confidence (sense of control), commitment (sense of calling), community (caring), compassion (having character), and centering (coping). We compared these five constructs with the seven core prevention principles of Team Awareness and the Team Awareness training modules. As a result of this comparison activity, we retained the core principles of Team Awareness in the new curriculum. However, significant modifications were required, and we created new content to appeal to the young restaurant worker. Table 4.2 describes the resiliency characteristic for each of the Five Cs, the source for its psychological construct, and the related Team Awareness principles (from Table 4.1) and Team Awareness modules. The last column indicates where the seven Team Awareness principles fit in the five Team Resilience constructs. 
Table 4.2 The Five Cs of resiliency: Their derivation and correspondence to Team Awareness (TA)

\begin{tabular}{|c|c|c|c|}
\hline Resiliency Constructs & $\begin{array}{l}\text { Psychological } \\
\text { Construct }\end{array}$ & $\begin{array}{l}\text { TA Principles } \\
\text { [Number] }\end{array}$ & $\begin{array}{l}\text { TA Module } \\
\text { (and How It Was } \\
\text { Modified for TR) }\end{array}$ \\
\hline $\begin{array}{l}\text { Confidence (Control) } \\
\text { Positive self- } \\
\text { focus, hardiness, } \\
\text { knowing your limits, } \\
\text { optimism, hope }\end{array}$ & $\begin{array}{l}\text { Self- and collective- } \\
\text { efficacya } \\
\text { Internal locus of } \\
\text { control }^{b}\end{array}$ & $\begin{array}{l}\text { [3] Know and } \\
\text { appreciate policy } \\
\text { as your guide and } \\
\text { safeguard }\end{array}$ & $\begin{array}{l}\text { TA Module } 2 \text { (Risks } \\
\text { and Strengths } \\
\text { Game)-modified in } \\
\text { a new game and in } \\
\text { TR Module } 6\end{array}$ \\
\hline $\begin{array}{l}\text { Commitment } \\
\text { (Calling) } \\
\text { Goals and dreams, } \\
\text { goal setting, } \\
\text { clarifying direction } \\
\text { and career identity, } \\
\text { hardiness }\end{array}$ & $\begin{array}{l}\text { Planful competence }{ }^{b} \\
\text { Personal structure } \\
\text { Achievement } \\
\text { motivationa }^{a}\end{array}$ & $\begin{array}{l}\text { [1 and 2] Identify and } \\
\text { increase strengths, } \\
\text { reduce risks; } \\
\text { [6] develop or } \\
\text { enhance stress } \\
\text { problem-solving } \\
\text { skills }\end{array}$ & $\begin{array}{l}\text { TA Module } 3 \\
\text { (Stress)—discusses } \\
\text { hardiness and the } \\
\text { C of commitment; } \\
\text { modified in TR } \\
\text { Module } 7\end{array}$ \\
\hline $\begin{array}{l}\text { Community (Caring) } \\
\text { Giving/receiving } \\
\text { help, peer referral } \\
\text { skills (NUDGE), know } \\
\text { how to listen, get } \\
\text { help, welcome new } \\
\text { hires }\end{array}$ & $\begin{array}{l}\text { Social supporta,b,c } \\
\text { and connectedness }{ }^{a}\end{array}$ & $\begin{array}{l}\text { [7] Communicate } \\
\text { the problem and } \\
\text { support others (don't } \\
\text { withdraw) } \\
\text { [5] Work together } \\
\text { as a team to } \\
\text { communicate and } \\
\text { solve problems }\end{array}$ & $\begin{array}{l}\text { TA Modules } 5 \text { and } 6 \\
\text { (Communication and } \\
\text { Encouragement)- } \\
\text { core elements } \\
\text { retained in TR } \\
\text { Module } 4\end{array}$ \\
\hline $\begin{array}{l}\text { Compassion } \\
\text { (Character) } \\
\text { Integrity, character } \\
\text { strengths, and } \\
\text { virtues, heart- } \\
\text { centered leadership, } \\
\text { responsiveness }\end{array}$ & $\begin{array}{l}\text { Social competence } \\
\text { and adeptnessc } \\
\text { Dependabilityc }\end{array}$ & $\begin{array}{l}\text { [4] Understand your } \\
\text { own tolerance for } \\
\text { the situation and } \\
\text { adjust if necessary; } \\
\text { [7] support others }\end{array}$ & $\begin{array}{l}\text { TA Module } 3 \\
\text { (Tolerance and } \\
\text { Responsiveness) } \\
\text { and TA Module } 6 \\
\text { (NUDGE)_core } \\
\text { elements retained in } \\
\text { TR Module } 5\end{array}$ \\
\hline $\begin{array}{l}\text { Centering (Coping) } \\
\text { Wellness, stress } \\
\text { management, } \\
\text { spiritual health, } \\
\text { work-life balance }\end{array}$ & $\begin{array}{l}\text { Positive coping } \\
\text { Problem solving }\end{array}$ & $\begin{array}{l}\text { [6] Develop or } \\
\text { enhance stress } \\
\text { problem-solving } \\
\text { skills }\end{array}$ & $\begin{array}{l}\text { TA Module } 4 \text { (Stress } \\
\text { and Coping)—core } \\
\text { elements retained in } \\
\text { TR Module } 3\end{array}$ \\
\hline
\end{tabular}

TA = Team Awareness; TR = Team Resilience; NUDGE = Notice, Understand, Decide, use Guidelines, and Encourage.

a Masten et al., 2006

b Clausen, 1993

c Friborg et al., 2003

d Maddi, 2005 


\section{Final Training Structure and Content}

The Team Resilience training is designed to be conducted over 3 days, with one 2-hour session per day and 30 to 45 minutes of the Journey to Resilience game, which is described below. Sessions include employees from all job types. Training uses mini-lectures, discussions, interactive group work, role-playing, and communication skills practice. For each session, participants choose to be on one of three teams for various exercises. The training has some participantdriven elements, the central one being peer nomination of two ambassadors in Session 3. These ambassadors are further trained in a 90-minute session on how to carry the message of the program forward.

We worked with the restaurants to establish several logistical procedures prior to program delivery. First, to enhance recruitment, we asked managers to recommend one or two staff (who were well networked and popular) to encourage attendance and sign-up via a poster in the back of the restaurant. Second, we provided incentives for participation. Participants who attended training received $\$ 15$ or $\$ 20$ (depending on the area) and also could receive more cash prizes through participation on the winning team in the game aspect of the training. Third, in this particular setting, trainings were mostly scheduled from 9:00 a.m. to 11:00 a.m. on weekday mornings before the restaurant opened for lunch. In some cases, training was conducted on a Saturday morning and in the evening. The following is a synopsis of the main training elements.

\section{Session 1: The Map_Emerging Adulthood and Resilience (Two Modules)}

Module 1: Relevance. Participants complete and discuss a brief survey of emerging adulthood.

Module 2: Resilience and the Five Cs. Participants are introduced to the concept of resilience through group discussion and program materials.

\section{Session 2: The Terrain/Your Compass (Five Modules)}

Session 2 has five modules, one for each of the Five Cs. Participants decide as a group which $\mathrm{C}$ they want to improve, and teams set a goal and discuss how long it may take to reach it. Teams share goals with the entire group and are reinforced (through incentives like candy and applause) for clarifying their intentions. The modules include self-assessments, group exercises, and discussion. 


\section{Session 3: The Destination (Two Modules)}

Session 3 has two modules taken directly from the Team Awareness program. Toward the beginning of Session 3, all participants are asked to nominate two individuals to be Team Resilience ambassadors. Nominations were collected by training staff and tabulated to select the two nominees with the most votes.

Module 8: Communication. Participants review guidelines and participate in exercises developed to facilitate effective communication.

Module 9: Peer Referral Training (Encourage Help). The Team Awareness NUDGE (Notice, Understand, Decide, use Guidelines, and Encourage) model instructs on peer referral using role-playing.

The Journey to Resilience (Restaurant Game) - Team Competition We created a new game that integrated policy and AOD information and met three specific goals: (1) reinforce the restaurant as a learning environment for resilience, (2) teach the Five Cs, and (3) motivate participants to reduce turnover via commitment to team attendance at each game. At the end of each session, 30 minutes is reserved for play. Teams move markers around a 4 - $\mathrm{ft}$ by 5 -ft game board designed to resemble the floor plan of a restaurant. Each space represents a guest table or area of the restaurant (e.g., kitchen, dry storage), which offers a chance to gain points in one of the Five Cs. In each turn, teams are presented with fun activities or questions that earn team points when answered correctly. We developed the questions based on policy guides on wait staff's responsibilities for alcohol service (a legal requirement for the job), concepts used by the host restaurant, and content from preceding modules. The goal of the game is to earn a balance of points across all Five Cs. In each session, members on the team with the most points receive a cash prize. Points are added cumulatively, and the team with the most points at the end of Session 3 wins added incentives. A bar in the floor plan shows the risks of varying levels of alcohol use.

\section{Ambassador Training}

After completing the training, we contact the two ambassadors to attend a separate 90-minute session. One or two training staff meet with the ambassadors to review their roles and ask them to describe why they feel the other would make a good ambassador. The training includes a review of the team goals developed in Session 2, further practice of the NUDGE model, ways to use the Team Resilience Welcome brochure, and encouragement to promote the use of different tools given in the training, including the EAP. 


\section{Booster Training}

We introduce a single 60- to 90-minute booster session 6 months after the initial intervention. The session reviews the Five Cs of resilience; the best coworker exercise; the Welcome brochure; and the EAP, GetFit, and How to Get Help resources. Small teams compete in a true-false quiz game modeled after the restaurant game (Journey to Resilience).

\section{Incentives}

In program restaurants, participants received $\$ 20$ for each session attended. After arriving at a session, participants were divided into teams based on the number attending. For example, if there were nine participants, participants were divided into three teams. At the end of each session, game points were tallied from the Journey to Resilience game, and each team member from the team with the most resilience points for that session received an additional $\$ 20$. Team members could earn extra commitment points for their team between Sessions 1 and 2 by visiting one of the three health websites (GetFit. samhsa.gov, StopSmokingCenter.org, or an employee assistance website) and bringing proof of having completed any exercise or survey. Participants completed a session rating sheet at the end of each session.

\section{Logic Model}

Figure 4.1 shows the logic model of the Team Resilience intervention program. For purposes of this section, we present the logic model as it may be useful to others who wish to replicate the entire Team Resilience model in all its aspects: to build the curriculum, understand the intended impact of the program, and evaluate such impact. The logic model has 13 distinct components, which are described in this section: (1) primary inputs, (2) program goals, (3) target population, (4) antecedent variables, (5) rival elements, (6) program elements, (7) available resources, (8) program outputs, (9) key proximal mediators, (10) intermediate outcomes, (11) long-term outcomes, (12) decreased turnover, and (13) hypothesized causality.

Primary inputs overlap with the inputs described above, in the Program Adaptation and Innovation section, and include theory (emerging adulthood and resilience), context (i.e., policy), stakeholders (e.g., steering committee, EAC), observations from the field, and consultants (SMEs). These inputs significantly informed the innovations and goals of the program and helped us be sensitive to factors that could affect program delivery and outcomes. 


\section{Figure 4.1 Logic model: Team Resilience program}

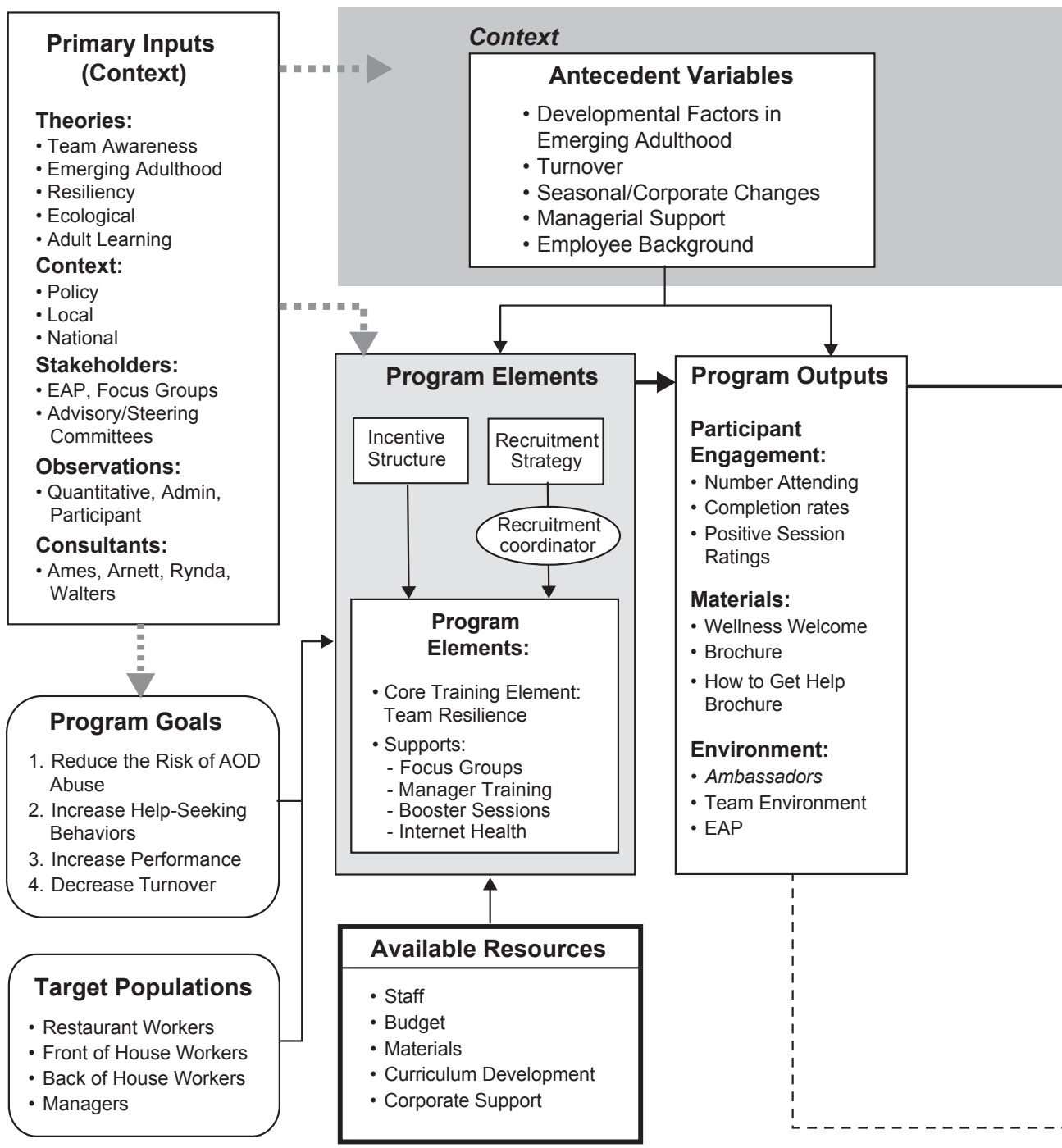




\section{Intervening/Rival Elements}

- Policy Changes

- Other EAP

- Employee Transfer/Contamination

- Rival Intervention

- Programs

Key Proximal Mediators

- Team Resilience

- Emerging Adulthood

- Manager Responsiveness
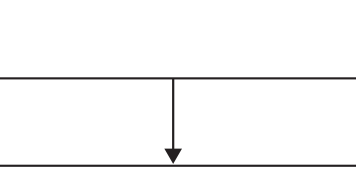

\section{Intermediate Outcomes}

- Smoking Climate

- Drinking Climate

- Stress (Personal, Job)

- AOD Attitudes

- AOD/Tobacco Use

- Restaurant Climate

- (Pride, Stigma)

\section{Long-term Outcomes}

- Help-Seeking

- AOD Outcomes

- Psychological Outcomes

- Job Performance

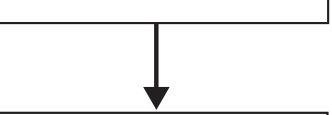

Decreased Turnover

(Business-Level Metrics)

\section{Hypothesized Causality}

\section{Implicit Causal Model:}

Ambassadors $=$

Individual

(Outreach)

L Group

Processes

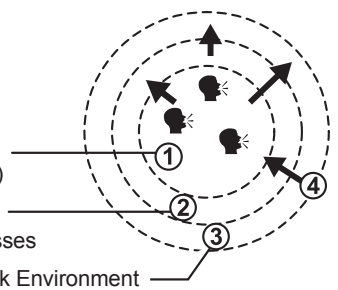

LWork Environment 
The targeted outcomes (program goals) of Team Resilience are to reduce AOD risk, increase help-seeking, increase job performance, and decrease turnover. Specifically, participants are told that the primary purpose of the Team Resilience training is [to] increase personal resilience by enhancing team communication and team commitment skills; skills that can be learned during the transition to adulthood and by working in a restaurant.

The target population is restaurant employees, specifically employees aged 16 to 25, and management personnel (general and assistant managers) who interact with and can serve as leaders/role models for the young adults included in the target population.

Context refers to surrounding (antecedent and rival) variables that can influence program outputs during the course of program implementation and yet operate independently of the intervention. Context presents a threat or an alternative explanation for outcomes.

Antecedent variables include the developmental or maturational changes that occur during the course of the implementation in the emerging adult sample. They also include trends in turnover, seasonal variations in restaurant staffing patterns, corporate administrative changes, managerial support, and various individual-level background factors (e.g., socioeconomic status).

Rival elements include intervening or known rival events outside of the program that might affect the hypothesized short-term and longterm outcomes of the program (e.g., changes in substance abuse policies, introduction of other related programs). These rival events include employee access to EAPs, rival intervention programs (e.g., at college during their nonwork hours), or other corporate programs that emphasize some element of substance abuse education (e.g., responsible alcohol service policy).

A number of program elements support the Team Resilience training. For example, enrollment strategies are critical to make the program happen, and we identify the necessity of an incentive structure as well as a recruitment strategy involving a recruitment coordinator. In addition, Team Resilience requires specific supports: focus groups (like those described in Touch Point 3 above), manager training, booster sessions, ambassador training, and access to health websites.

The logic model identifies five available resources: staff, budget, materials, curriculum development, and corporate support. These resources serve as the foundation for the system access and activities necessary to implement the program. 
Available resources and system access and activities guide the type of intervention deliverables or outputs. There are three types of program outputs: participant engagement, materials, and environment. For participant engagement, we expect that a good number of young workers attend the training, complete all sessions, and provide positive post-session ratings. For materials, in addition to the curriculum itself, the participants receive brochures, pamphlets (e.g., How to Get Help), and resources customized to the local workplace policy, benefits, and culture. For environment, through the interaction of participants with materials, the training yields ambassadors and others who help carry (socially market) the team message and EAP visibility forward into the workplace environment.

Key proximal mediators are expected to change as a function of the training. The three main mediating variables are team resilience, emerging adulthood, and managerial responsiveness. Team resilience is assessed by asking about the level of mutual support at work, welcoming newcomers, and the ability of coworkers to deal with stress and hardship. Emerging adulthood is assessed with personal perceptions of instability, sense of identity, and feeling in between being an adolescent and adult. Managerial responsiveness is assessed with employee perceptions of managers' sensitivity to worker needs.

Intermediate outcomes include (1) smoking climate and drinking climate as work climate risks that are directly targeted by the training-training activities are designed to elicit discussion about these social factors in the local restaurant; (2) core personal attitudes toward AOD use as well as actual AOD behaviors-Team Resilience should, over time, influence workers' attitudes and behaviors, especially individuals at risk for AOD problems; and (3) changes in the restaurant climate, including increased pride in the restaurant, less stigma associated with working in the restaurant, and positive communication among coworkers. To avoid confusion, we note that while participants are told that the purpose of the training is to increase personal resilience, this is communicated to the group or team as a whole. Moreover, the purpose deliberately mentions that such resilience is obtained through the team. Accordingly, restaurant climate is a key mediator. 
We specified five types of long-term outcomes: help-seeking attitudes and behaviors, alcohol and drug behaviors (both at and away from work), psychological outcomes such as depression and distress, and job performance. The key corporate outcome for this model is decreased turnover. Some might argue that staying in a stressful, low-paying, substance abuse-inducing job is less desirable than finding a better job in another industry, especially for those who are at high AOD risk. However, we believe that many restaurant workers who once had AOD problems were able to address their problems because of the positive qualities modeled by coworkers and managers-qualities targeted by Team Resilience, specifically commitment (goal-setting skills, clarifying direction and career identity, and hardiness).

The implicit causal model of Team Resilience guides the transfer of training by linking program elements (Team Resilience training and available resources) to outcomes. By "transfer of training," we mean that content (ideas, resources) reviewed in the classroom is transferred (1) into the work environment, (2) into the personal lives' of the participants, and subsequently (3) to others who did not attend training or new hires who come into the restaurant at some later date. The entire logic model rests on this core assumption: Activities $\rightarrow$ Implicit Causal Model $\rightarrow$ Outcomes. We developed the implicit causal model for Team Resilience, which specifies three levels of influence within the work environment: (1) individual outreach or peer-topeer social marketing, (2) work group interaction and processes, and (3) the overall work environment (e.g., leadership, norms, culture). This causal model highlights the centrality of the work group and peer-to-peer follow-up from training as keys to the success of the program.

The implicit causal model follows from the original theory of Team Awareness (Bennett et al., 2000). This model is based on work culture/work environment theories of alcohol use (Ames \& Janes, 1990; Trice, 1990). For there to be sustained and long-term outcomes in reduced AOD risks, the Team Resilience curriculum has to be used within the work environment by trained employees in ways that continually promote the prevention message of the training. Figure 4.2 shows the schema of the implicit causal model. Again, this model is implicit; we hope to identify potential programmatic methods for planting seeds that will endure amid the many barriers that exist in the restaurant setting (e.g., turnover, lack of management support, busy schedules, many part-time workers). That is, we developed the causal model more as a guide for sustained program implementation than as an explicit model to be tested. 
Figure 4.2 Implicit causal model: peer-to-peer social marketing of Team Resilience

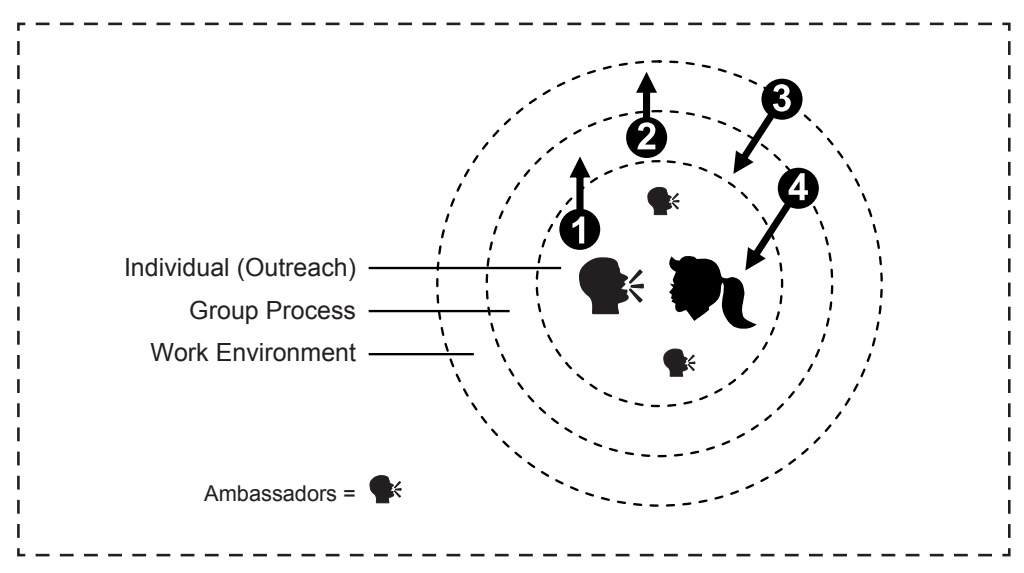

Note: 1. Ambassadors and Team Resilience participants model team resilience. 2. Training concepts become part of work group processes. 3. Over time, Team Resilience is part of the worksite culture. 4. Newcomers pick up training concepts and continue individual outreach.

The model posits three concentric circles of influence from one-on-one interaction or outreach to group processes (small group social norms) to work environment or restaurant work climate and social culture. We emphasize that these spheres of influence are theoretical and ideal because significant barriers exist within the restaurant culture that may prohibit continued messaging of Team Resilience. For example, as described above, one program output is the ambassador, who has received Team Resilience training and is willing to continue the message into the post-training work environment (e.g., through the use of brochures). Because of high turnover and general flux of work staff in this age cohort, the concept of resilience must filter into the work environment over time. At the same time, high turnover is a barrier to social marketing as ambassadors may themselves turn over; thus, ambassadors' roles might not be fulfilled unless managers actively seek out replacement ambassadors.

We envision the following sequence (as depicted in Figure 4.2):

1. Ambassadors and training participants use concepts or materials from the training to reach out to coworkers and new hires (e.g., uses the word resilience or refers to any of the Five Cs). 
2. Over time, references to training concepts or materials-such as utilization of the peer-referral skills (NUDGE) or any program outputs (e.g., how to get help, EAP, brochures, health websites)-become part of the work group interaction and processes.

3. Eventually, we hope that one-to-one peer referral, assistance, and social support will become the social norms of the culture. A single 6-month booster session facilitates renewal of concepts and ideas to support ambassadors and reinforce Team Resilience in the environment.

4. As newcomers enter the social system or as employees come and go through turnover, these environmental messages are picked up from the work group. In turn, these new workers continue individual outreach.

\section{Target Population}

The target population for our project was 18 - to 25 -year-old employees of a national restaurant chain, in the area of full-service casual dining. Our corporate partner had approximately 550 restaurants in the United States, the majority of which were company-operated. Restaurants were located in 47 states. Our study focused on company-operated restaurants within four geographic regions where the restaurant had a stated need for services: three municipalities/Metroplex areas in Texas, and the Chicago metropolitan area. Educational enrollment is not a consideration in defining the target population.

To support the YIW cross-site evaluation, we conducted a baseline survey of young workers in our partnering restaurants (see Chapter 8 for more information about the cross-site evaluation and the core survey measures). Baseline survey data were originally collected from 526 participants recruited from 28 participating restaurants. Recruitment procedures specifically targeted 18- to 25-year-old workers. Of all initial participants, 51 percent (269) are female, 80 percent are white, 18 percent are Hispanic or Latino, 12 percent are black or African American, 3 percent are American Indian, 2 percent are Asian, and $<1$ percent are Native Hawaiian or Pacific Islander. The average age of those reporting $(\mathrm{N}=516)$ is 22.4 years (standard deviation [SD] $=4.14$ ), with 4.5 percent between ages 16 and 17, 45 percent between ages 18 and 21, 32 percent between ages 22 and 25, and about 19 percent aged 26 or older.

Across 14 restaurants, 113 Team Resilience program participants attended Session 1; 117 attended Session 2; and 115 attended Session 3. In terms of 
degree of attendance, 85 participants ( 45 percent) attended only one session, 49 (26 percent) attended two sessions, and 54 (29 percent) attended all three sessions.

\section{Early Process Findings}

We collected two types of process findings that will be useful for interpreting subsequent quantitative findings on training effectiveness and outcomes:

(1) key insights that emerged during the adaptation process, especially from interviews and focus groups with young adults; and (2) session ratings collected from individuals who attended the Team Resilience training sessions. These process data help to place training effects in context.

Based on information obtained from various stakeholders (see the six touch points discussed in the Program Adaptation and Innovation section), we developed recommendations for program success. Specifically, we felt that a program for young restaurant workers would be more effective if participants (1) had multiple opportunities for attendance, (2) received appealing incentives tied to their participation, (3) experienced highly interactive and fun activities, (4) had the opportunity for discussion and dialogue with emphasis on listening, (5) experienced the training as meaningful and relevant to the journey of their lives, (6) experienced the training as meaningful and relevant to being a best coworker among their work peers, (7) experienced the concept of resilience within the pragmatic context of their personal experiences, (8) experienced the concept of resilience through concrete and interactive activities, (9) had the opportunity for self-disclosure, and (10) had coworkers (ambassadors) who could potentially model the Five Cs and extend the Team Resilience message into the work environment (post-training activities).

\section{Response to Training (Engagement)}

In this section, we review only employee responses (engagement) to the training program. Training engagement is a central part of the logic model and is a focus of this chapter. We focus on workers who participated in the training program from the 14 program restaurants that were randomly assigned to receive the training.

We included young restaurant workers who attended at least one of the three sessions of the Team Resilience training $(n=188)$ in this sample. Available demographic and other survey data on this trained sample show it to be similar to the overall sample of employees who were surveyed (and were assigned to the control group or did not attend training). 
After each session, participants completed a 21-item survey asking for their response to the training, as well as their perceptions of training utility and its impact on them (Table 4.3). Responses were on a five-point Likert scale (where $1=$ strongly disagree and $5=$ strongly agree). The table shows the percentage agreeing with each statement for each of the three sessions and also reports the results of paired t-test comparisons between Session 1 and Session 3.

The results generally show that the majority of participants reacted positively to the training. Although participants reacted to the sessions differently, the trend across sessions was increasingly positive. For example, at Session 1, only 54 percent agreed with the statement that "today's program made me more aware of alcohol and drug risks," but this increased to 69 percent in Session 2 and 70 percent in Session 3; the percentage reporting "agree" or "strongly agree" increased significantly from Session 1 to Session 3. Similar increases were found for intentions to use the EAP phone coach

\section{Table 4.3 Percentage of participants agreeing (agree or strongly agree) with statements across three training sessions and simple $t$-test comparing Session 1 with Session 3 (paired)}

\begin{tabular}{|c|c|c|c|c|}
\hline & $\overline{\frac{c}{ㄷ ㅡ ㄹ ~}}$ & 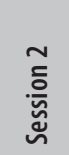 & 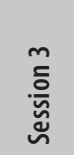 & 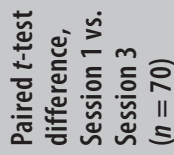 \\
\hline $\begin{array}{l}\text { 1. I enjoyed participating in today's } \\
\text { activities }\end{array}$ & $92 \%$ & $94 \%$ & $94 \%$ & $<1$ (NS) \\
\hline $\begin{array}{l}\text { 2. My coworkers would find today's } \\
\text { program "fun" }\end{array}$ & $87 \%$ & $92 \%$ & $92 \%$ & $2.67^{*}$ \\
\hline $\begin{array}{l}\text { 3. Today's program motivated me to } \\
\text { improve in one or more areas of health/ } \\
\text { wellness }\end{array}$ & $73 \%$ & $88 \%$ & $86 \%$ & $4.15^{* * *}$ \\
\hline $\begin{array}{l}\text { 4. The trainer \& staff were well prepared \& } \\
\text { organized }\end{array}$ & $96 \%$ & $94 \%$ & $96 \%$ & $<1$ (NS) \\
\hline $\begin{array}{l}\text { 5. The program made me aware of } \\
\text { strengths (resilience) I have as a young/ } \\
\text { emerging adult }\end{array}$ & $85 \%$ & $80 \%$ & $82 \%$ & $<1(\mathrm{NS})$ \\
\hline $\begin{array}{l}\text { 6. The "Journey to Resilience" board game } \\
\text { was informative and helpful }\end{array}$ & $86 \%$ & $85 \%$ & $84 \%$ & 1.54 \\
\hline $\begin{array}{l}\text { 7. Today's program made me aware of risks } \\
\text { I face as a young or emerging adult }\end{array}$ & $78 \%$ & $80 \%$ & $80 \%$ & $2.07^{*}$ \\
\hline $\begin{array}{l}\text { 8. Other young or emerging adults could } \\
\text { benefit from today's session }\end{array}$ & $92 \%$ & $91 \%$ & $89 \%$ & $<1$ (NS) \\
\hline
\end{tabular}




\section{Table 4.3 Percentage of participants agreeing (agree or strongly agree) with statements across three training sessions and simple $t$-test comparing Session 1 with Session 3 (paired) [continued]}

\begin{tabular}{|c|c|c|c|c|}
\hline & $\overline{\bar{c}}$ & 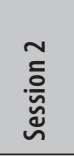 & $\stackrel{m}{\frac{m}{\tilde{c}}}$ & 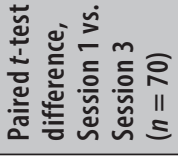 \\
\hline $\begin{array}{l}\text { 9. Today's program made me more aware } \\
\text { of alcohol and drug risks }\end{array}$ & $54 \%$ & $69 \%$ & $70 \%$ & $4.18^{* * *}$ \\
\hline $\begin{array}{l}\text { 10. Today's session could help young or } \\
\text { emerging adults with restaurant work }\end{array}$ & $82 \%$ & $84 \%$ & $81 \%$ & 1.42 \\
\hline $\begin{array}{l}\text { 11. The program could improve employee } \\
\text { willingness to seek help for personal } \\
\text { problems (loneliness, relationship } \\
\text { problems) }\end{array}$ & $81 \%$ & $86 \%$ & $84 \%$ & $<1$ (NS) \\
\hline $\begin{array}{l}\text { 12. I plan to talk to other coworkers about } \\
\text { the material we reviewed today. }\end{array}$ & $76 \%$ & $72 \%$ & $80 \%$ & $2.66^{*}$ \\
\hline $\begin{array}{l}\text { 13. I see myself reading and using the Team } \\
\text { Resilience brochure }\end{array}$ & $57 \%$ & $67 \%$ & $67 \%$ & $3.21^{* *}$ \\
\hline $\begin{array}{l}\text { 14. I can see myself calling or using the EAP } \\
\text { phone coach line }\end{array}$ & $45 \%$ & $50 \%$ & $60 \%$ & $5.65^{* * *}$ \\
\hline $\begin{array}{l}\text { 15. I see myself visiting \& using the EAP Web } \\
\text { tools }\end{array}$ & $49 \%$ & $65 \%$ & $63 \%$ & $3.90^{* *}$ \\
\hline $\begin{array}{l}\text { 16. I see myself using the Get Fit Web } \\
\text { tools (http://getfit.samhsa.gov or Stop } \\
\text { Smoking Center). }\end{array}$ & $49 \%$ & $65 \%$ & $67 \%$ & $3.69^{* * *}$ \\
\hline $\begin{array}{l}\text { 17. Today's session can help me be more } \\
\text { caring and compassionate with others. }\end{array}$ & $78 \%$ & $76 \%$ & $88 \%$ & $3.75^{* * *}$ \\
\hline $\begin{array}{l}\text { 18. Today's session can help me manage } \\
\text { stress and be more centered. }\end{array}$ & $77 \%$ & $82 \%$ & $87 \%$ & $3.44^{* * *}$ \\
\hline $\begin{array}{l}\text { 19. Today's session can help me be more } \\
\text { confident and follow my dreams. }\end{array}$ & $76 \%$ & $81 \%$ & $87 \%$ & $3.70^{* * *}$ \\
\hline $\begin{array}{l}\text { 20. I feel more committed to follow through } \\
\text { on my goals as a result of today's session. }\end{array}$ & $74 \%$ & $84 \%$ & $83 \%$ & $3.18^{* *}$ \\
\hline $\begin{array}{l}\text { 21. Today's session improved community } \\
\text { and teamwork in our restaurant. }\end{array}$ & $81 \%$ & $80 \%$ & $88 \%$ & $5.18^{* * *}$ \\
\hline
\end{tabular}

${ }^{*} \mathrm{p}<.05 ;{ }^{* *} \mathrm{p}<.01,{ }^{* * *} \mathrm{p}<.001 ; t$-test comparison is of the entire five-point item. 
line (45 percent to 60 percent), the EAP Web tool (49 percent to 63 percent), and the GetFit Web tool (49 percent to 67 percent). The highest ratings were responses to items asking about the $5 \mathrm{Cs}$, with about 77 percent of participants agreeing with these items at Session 1 and more than 85 percent agreeing by Session 3. Importantly, the percentage of participants who agreed with the statement that "today's program motivated me to improve in one or more areas of health/wellness" increased significantly from Session 1 (73 percent) to Session 3 (86 percent). Also, these ratings were compared across those with and without depression and AOD risk. Compared with their counterparts, those employees with such risks were not only as likely to attend training but also rated the program as strongly.

\section{Conclusions}

We drew some initial conclusions about effectiveness from the prevention efforts described here. First, it is possible to design a prevention program for young restaurant workers that they will find appealing and that, according to self-reports, had an impact on their awareness of AOD risks, the EAP, and resilience (see Table 4.3). At Session 1, for example, 45 percent of participants agreed with the statement "I can see myself calling or using the EAP phone coach line"; by Session 3, this had increased to 60 percent. Second, this finding is made more salient by the fact that while the alcohol, drug, and mental health risks in this population are typically higher than in other occupations, those with such risks were as likely to attend (and be engaged in) the training as those without such risks.

Another conclusion pertains to efforts we took to adapt an existing evidence-based practice and to create a logic model that was detailed enough to guide programmatic efforts. Indeed, the positive results just reviewed may not have been possible without (1) gathering insights from stakeholders and the target population, and (2) applying those insights in building a program that would be relevant and meaningful for the younger worker. We believe that all elements reviewed in this chapter are likely necessary to include in building an effective program. That is, to build an effective program, it is necessary to (1) understand unique aspects of the target industry, occupation, and host organization; (2) develop an adaptation process (e.g., six touch points) that gathers significant input from experts, stakeholders, and the target group; (3) use this input to align the new curriculum with some previous and evidencebased curriculum; (4) develop a logic model to support process analysis, 
replication, and program evaluation; and (5) collect and appropriately analyze data in a randomized trial with follow-up.

As with all research studies, this study has some caveats and cautions concerning the proposed prevention model. First, because of its current full format and length, the Team Resilience program will be very difficult to replicate in real-world settings without significant backing and support from the restaurant industry and both senior and local management. As researchers, we had the luxury of casting a broad net to build a robust curriculum that included 6 hours of training, ambassadors, social marketing, EAP marketing, incentives, and booster sessions. Because of the time and effort required, a program that attempts to replicate all elements will not receive the same level of support as a program that includes only some elements. Further discussions with managers and industry experts will not only help to focus the curriculum but may also help create buy-in among those who have the power to make the decision to use or institutionalize the curriculum.

Second, because of the inherent problem of young adult turnover in the industry, managers will have a difficult time justifying any investment of time for prevention for employees who are "here today and gone tomorrow." However, with replication and other positive findings, Team Resilience may be sustained within the restaurant industry as a program that can help retain workers. The National Restaurant Association currently has "Jobs and Careers" as one of its imperatives, with the goal of improving job satisfaction and tenure.

In concluding, we note that the Team Resilience model has many components and is a fairly complex socio-ecological approach. We believe that this is one of its core strengths. Our primary intent in this preliminary review of Team Resilience was not to evaluate all of its components but rather to begin to identify potential leverage points (protective factors) within the work environment that could limit substance use, misuse, and dependence. Our hope is that, as the data are fully mined, we will be able to provide some practical insights to an industry that has been neglected by prevention science for far too long. 


\section{References}

Ames, G., \& Janes, C. (1990). Drinking, social networks, and the workplace: Results of an environmentally focused study. In P. M. Roman (Ed.), Alcohol problem intervention in the workplace: Employee assistance programs and strategic alternatives (pp. 95-111). Westport, CT: Quorum Books.

Arnett, J. J. (2004). Emerging adulthood: The winding road from the late teens through the twenties. New York: Oxford University Press.

Bacharach, S., Bamberger, P., \& Sonnenstuhl, W. J. (2002). Driven to drink: Managerial control, work-related risk factors and employee drinking behavior. The Academy of Management Journal, 45(4), 637-658.

Batrus Hollweg International (2003). Productivity crimes: Realities, risks \& profit potential. Dallas, TX: Batrus Hollweg International.

Bennett, J. B., Aden, C., \& Rigdon, W. (2008, February). Youth in transition: Young adults in the workplace. Discussant for panel presentation at the Community Anti-Drug Coalitions of America (CADCA) Conference, Washington, DC.

Bennett, J. B., Aden, C., Broome, K., Mitchell, K., \& Rigdon, W. (2010). Team resilience for young restaurant workers: Research-to-practice adaptation and assessment. Journal of Occupational Health Psychology, 15(3): 223-236.

Bennett, J. B., \& Lehman, W. E. K. (1998). Workplace drinking climate, stress, and problem indicators: Assessing the influence of teamwork (group cohesion). Journal of Studies on Alcohol, 59(5), 608-618.

Bennett, J. B., \& Lehman, W. E. K. (2000). Workplace substance abuse prevention and help-seeking: Comparing a team-oriented and informational training. Journal of Occupational Health Psychology, 6(3), 243-254.

Bennett, J. B., \& Lehman, W. K. (2001). Workplace substance abuse prevention and help seeking: Comparing team-oriented and informational training. Journal of Occupational Health Psychology, 6(3), 243-623.

Bennett, J. B., Lehman, W. E., \& Reynolds, G. S. (2000). Team awareness for workplace substance abuse prevention: The empirical and conceptual development of a training program. Prevention Science, 1(3), 157-172.

Bennett, J. B., Patterson, C. R., Reynolds, G. S., Wiitala, W. L., \& Lehman, W. E. K. (2004). Team Awareness, problem drinking, and drinking climate: Workplace social health promotion in a policy context. American Journal of Health Promotion, 19(2), 103-113. 
Bennett, J. B., Patterson, C. R., Wiitala, W. L., \& Woo, A. (2006). Social risks for at-risk drinking in young workers: Application of work-life border theory. Journal of Drug Issues, 36(3), 485-514.

Bennett, R. J., \& Robinson, S. L. (2000). Development of a measure of workplace deviance. Journal of Applied Psychology, 85(3), 349.

Berta, D. (2003, August 4). Employee behavior study alarms operators. Nation's Restaurant News, 37(31).

Bolin, A., \& Heatherly, L. (2001). Predictors of employee deviance: The relationship between bad attitudes and bad behavior. Journal of Business and Psychology, 15(3), 405-418.

Bonanno, G. A. (2004). Loss, trauma, and human resilience: Have we underestimated the human capacity to thrive after extremely aversive events? American Psychologist, 59(1), 20-28.

Brounstein, P. J., Gardner, S. E., \& Backer, T. (2006). Research to practice: Efforts to bring effective prevention to every community. The Journal of Primary Prevention, 27(1), 91-109.

Bureau of Labor Statistics (2007). Employment situation summary. Retrieved November 8, 2007 from http://www.bls.gov/news.release/empsit.nr0.htm

Castillo, D. N. (1999). Occupational safety and health in young people. In J. Barling \& E. K. Kelloway (Eds.), Young workers: Varieties of experience (pp. 159-200). Washington, DC: American Psychological Association.

Chapman, L. S. (2004). Expert opinions on "best practices" in worksite health promotion (WHP). American Journal of Health Promotion, 18(6), 1-6.

Clausen, J. S. (1991). Adolescent competence and the life course: Or why one social psychologist needed a concept of personality. Social Psychology Quarterly, 54(1), 4-14.

Clausen, J. (1993). American lives: Looking back at the children of the great depression. New York: Free Press.

Dusenbury, L., Brannigan, R., Falco, M., \& Hansen, W. B. (2003). A review of research on fidelity of implementation: Implications for drug abuse prevention in school settings. Health Education Research, 18(2), 237-256.

Ensuring Solutions. (2008). Workplace screening \& brief intervention: What employers can and should so about excessive alcohol use. Retrieved March 29, 2008, from http://www.ensuringsolutions.org/usr_doc/Workplace_SBI_ Report_Final.pdf 
Fixsen, D. L., Naoom, S. F., Blase, K. A., Friedman, R. M., \& Wallace, F. (2005). Implementation research: A synthesis of the literature. Tampa, FL: University of South Florida, Louis de la Parte Florida Mental Health Institute, The National Implementation Research Network.

Fixsen, D. L., Naoom, S. F., Blase, K. A., \& Wallace, F. (2007). Implementation: The missing link between research and practice. The APSAC Advisor, 19(1\&2), 4-11.

Friborg, O., Hjemdal, O., Rosenvinge, J. H., \& Martinussen, M. (2003). A new rating scale for adult resilience: What are the central protective resources behind healthy adjustment? International Journal of Methods in Psychiatric Research, 12(2), 65-76.

Frone, M. R. (1998). Predictors of work injuries among employed adolescents. Journal of Applied Psychology, 83(4), 565-576.

Frone, M. R. (2006a). Prevalence and distribution of alcohol use and impairment in the workplace: A US national survey. Journal of Studies on Alcohol, 67(1), 147-156.

Frone, M. R. (2006b). Prevalence and distribution of illicit drug use in the workforce and in the workplace: Findings and implications from a US national survey. Journal of Applied Psychology, 91(4), 856-869.

Grebner, S., Elfering, A., Semmer, N. K., Kaiser-Probst, C., \& Schlapbach, M.-L. (2004). Stressful situations at work and in private life among young workers: An event sampling approach. Social Indicators Research, 67(1-2), 11-49.

Hennessy, K. D., Finkbiner, R., \& Hill, G. (2006). The National Registry of Evidence-Based Programs and Practices: A decision-support tool to advance the use of evidence-based services. International Journal of Mental Health, 35(2), 21-34.

Kjaerheim, K., Mykletun, R., Aasland, O. G., Haldorsen, T., \& Andersen, A. (1995). Heavy drinking in the restaurant business: The role of social modeling and structural factors of the work-place. Addiction, 90(11), 1487-1495.

Lehman, W. E. K., Reynolds, G. S., \& Bennett, J. B. (2003). Team and informational trainings for workplace substance abuse prevention. In J. B. Bennett, \& W. E. K. Lehman, (Eds.), Preventing workplace substance abuse: Beyond drug testing to wellness (pp. 165-201). Washington, DC: American Psychological Association. 
Maddi, S. R. (2005). On hardiness and other pathways to resilience. American Psychologist, 60(3), 261-262.

Maddi, S. R., Wadhwa, P., \& Haier, R. J. (1996). Relationship of hardiness to alcohol and drug use in adolescents. American Journal of Drug and Alcohol Abuse, 22(2), 247-257.

Masten, A. S., Obradovic, J., \& Burt, K. B. (2006). Resilience in emerging adulthood: Developmental perspectives on continuity and transformation. In J. Arnett \& L. Tanner (Eds.), Emerging adults in America: Coming of age in the 21st century (pp. 172-190). Washington, DC: American Psychological Association.

Moon, D. G., Hecht, M. L., \& Jackson, K. M., \& Spellers, R. E. (1999). Ethnic and gender differences and similarities in adolescent drug use and refusals of drug offers. Substance Use \& Misuse, 34(8), 1059-1083.

National Registry of Evidence-Based Programs (2002). SAMHSA model programs: Effective substance abuse and mental health programs for every community. Available from http://www.modelprograms.samhsa.gov

National Registry of Evidence-Based Programs and Practices. (2007). SAMHSA's national registry of evidence-based programs and practices. Available from http://nrepp.samhsa.gov/index.asp

National Restaurant Association. (2008). 2008 restaurant industry forecast: What will restaurant customers want in 2008? Washington, DC: National Restaurant Association.

Office of Applied Studies. (2008). Results from the 2007 National Survey on Drug Use and Health: National findings (DHHS Publication No. SMA 084343, NSDUH Series H-34). Rockville, MD: Substance Abuse and Mental Health Services Administration. Also available online: http://oas.samhsa.gov

Osgood, D. W., Foster, E. M., \& Flanagan, C. (2005). On your own without a net: The transition to adulthood for vulnerable populations (xiv, $401 \mathrm{pp}$ ). Chicago, IL: University of Chicago Press.

Patterson, C., Bennett, J., \& Wiitala, W. (2005). Healthy and unhealthy stress unwinding: Promoting health in small businesses. Journal of Business and Psychology, 20(2), 221-247.

Rutter, M. (1989). Pathways from childhood to adult life. Journal of Child Psychology and Psychiatry, 30(1), 23-54. 
Stevenson, J. F., \& Mitchell, R. E. (2003). Community-level collaboration for substance abuse prevention. The Journal of Primary Prevention, 23(3), 371-404.

Substance Abuse and Mental Health Services Administration (SAMHSA). (1997). Guidelines and benchmarks for prevention programming: Implementation guide. DHHS Publication No. (SMA) 95-3033. Rockville, MD: SAMHSA.

Substance Abuse and Mental Health Services Administration (SAMHSA), Office of Applied Studies (2007, October 11). The NSDUH report: Depression among adults employed full-time, by occupational category. Rockville, MD: SAMHSA. Retrieved July 15, 2009, from http://www.oas. samhsa.gov/2k7/depression/occupation.pdf

Trice, H. M. (1990). Implications for intervention and prevention in three streams of EAP-related research. In P. M. Roman (Ed.), Alcohol problem intervention in the workplace: Employee assistance programs and strategic alternatives. (pp. 339-359). Westport, CT: Quorum Books.

Veazie, M. A., \& Smith, G. S. (2000). Heavy drinking, alcohol dependence, and injuries at work among young workers in the United States labor force. Alcoholism: Clinical and Experimental Research, 24(12), 1811-1819.

Werner, E. E. (1989). Vulnerability and resiliency: A longitudinal perspective. In M. Brambring, F. Lösel, H. Skowronek, \& W. de Gruyter (Eds.), Children at risk: Assessment, longitudinal research, and intervention (pp. 158-172). Oxford, England.

Wong, M. M., Nigg, J. T., Zucker, R. A., Puttler, L. I., Fitzgerald, H. E., Jester, J. M., Glass, J. M., \& Adams, K. A. (2006). Behavioral control and resiliency in the onset of alcohol and illicit drug use: A prospective study from preschool to adolescence. Child Development, 77, 1016-1033.

Zhang, Z., \& Snizek, W. E. (2003). Occupation, job characteristics, and the use of alcohol and other drugs. Social Behavior and Personality, 31(4), 395-412. 


\title{
Substance Abuse Prevention in the Electrical Industry: The NECA-IBEW Team Awareness and Team Vigilance Programs
}

\author{
Eric Einspruch, ${ }^{1}$ Chris O’Neill, ${ }^{2}$ Kelly Jarvis, ${ }^{1}$ \\ Kelly Vander Ley, ${ }^{1}$ and Paméla Raya-Carlton ${ }^{1}$ \\ 1RMC Research Corporation, Portland, OR; \\ 2Oregon Nurses Foundation, Tualatin, OR
}

\section{Introduction}

The National Electrical Contractors Association (NECA)-International Brotherhood of Electrical Workers (IBEW) Drug-Free Workplace Program was founded in 1990 as a pioneering effort to standardize policies across all contractor worksites, to improve the health and safety of electrical workers, and to enhance the productivity of the electrical industry. Because electricians are employed in a high-risk occupation, accidents can easily be fatal. The high rate of substance use in the construction industry is an additional risk factor and young electricians, who are predominantly male, are at additional risk for substance use (and hence, potential injury or death) due to their age. Thus a critical need exists to develop workplace substance abuse prevention programs designed to influence young adults in the construction trade, especially those employed at worksites with high safety risks. Industry stakeholders believe that the program benefits contractors, customers, and workers and their families.

An important aspect of the strategy between labor and management to address substance use in the workplace is a progressive attitude toward treatment: instead of firing employees who test positive for drug use, NECA and IBEW leadership believe in helping individuals regain control of their lives and their careers. This strategy is intended to promote healthy, drugfree workers; a stable workforce; and mutual respect between employers and employees.

In 2004, NECA and IBEW established a national set of minimum drugfree workplace standards that must be included in all union local collective bargaining agreements. However, many stakeholders among the various union 
locals believe that the Drug-Free Workplace Program is missing a key pieceprevention-which NECA-IBEW Team Awareness and NECA-IBEW Team Vigilance are designed to fill.

As part of the Substance Abuse and Mental Health Services Administration's (SAMHSA's) Young Adults in the Workplace (YIW) initiative, RMC Research Corporation-in collaboration with the Oregon Nurses Foundation, NECA, IBEW, and Organizational Wellness \& Learning Systems-has adapted the SAMHSA model program Team Awareness for use with electrician apprentices, foremen, and other supervisors and is now studying its implementation. RMC Research Corporation was one of three YIW grantees to adapt Team Awareness for its workplace partner. The foundation for the study was established at the time the initial YIW grant proposal was developed, when the RMC Research Corporation study team met with NECA-IBEW industry stakeholders to identify their interests. Representatives from NECA, IBEW, and Electrical Training Centers (ETCs) indicated their interest in increasing apprentice work ethic, decreasing apprentice substance use, increasing foremen vigilance for safety risks (including enforcing the drug-free workplace policy), and comparing drug testing results with other information about current substance use (e.g., from a self-reported measure of use). This chapter describes the content and implementation of the NECA-IBEW YIW program, describes the target population, and presents early process findings.

\section{Program Description}

This section describes the theory, goals, salient messages, adaptation, and marketing of the NECA-IBEW YIW program. The adapted program has two training components: NECA-IBEW Team Awareness, a substance abuse prevention program for electrician apprentices, and NECA-IBEW Team Vigilance, a program to help electrician foremen and other supervisors address employee performance and confront problems (including substance abuse).

Both programs were adapted from the original Team Awareness program (Bennett et al., 2000). Although the target population for this grant is apprentices aged 18 to 24 (emerging adults known for their high rate of substance use), NECA-IBEW Team Awareness is delivered to intact classrooms and therefore is received by all apprentices regardless of age. NECA-IBEW Team Awareness recognizes that electricians work in an occupation that involves safety risks and where the consequences of injury can be catastrophic. It also recognizes the nomadic nature of electrician work (i.e., electricians form and re-form new work teams on a regular basis as work assignments change). Therefore, NECA-IBEW Team Awareness is conceptualized as an occupational 
intervention. NECA-IBEW Team Awareness incorporates the IBEW Code of Excellence, the electrical industry's statement on values of the trade. Given the number of NECA chapters and IBEW union locals and members, the number of electricians in the field, and the anticipated workforce development trends, the results of this study have significant potential to be disseminated widely and to have an impact on a national scale.

\section{Theory/Logic Model}

\section{Team Awareness Program}

Team Awareness targets psychosocial factors in the workplace, including the work environment, group processes, perceptions, tolerance of coworkers who use alcohol or other drugs, and attitudes toward policy. These psychosocial factors influence employee substance use, the negative effect of substance use on coworkers, and employees' response to workplace policy. Theoretically, the Team Awareness model rests on the premise that prevention programs require supportive elements in the work environment to be effective and that training programs should provide relevant skills and enhance multiple social factors supporting the transfer of these skills. To achieve this goal, workplace prevention programs need to address both individual employees and intragroup relations among work groups. Coworkers may enable workers with substance problems by covering for them or doing extra work to make up for absent workers (Roman et al., 1992). Alternatively, coworkers may encourage the worker to get help (George \& Tucker, 1996).

The theoretical and empirical derivation of Team Awareness is described in Bennett et al. (2000). Central to the Team Awareness model is that work environments involve risk factors and protective factors. Risk factors include safety-related occupations (e.g., Ames \& Grube, 1999; Lehman et al., 1995; Lund et al., 1991) and drinking climate (Bennett \& Lehman, 1999; Greenburg \& Gruneberg, 1995), whereas protective factors include social integration (Trice \& Sonnenstuhl, 1990) and organizational wellness (e.g., Quick, 1999; Rosen, 1991).

The research model for the original Team Awareness is that worker substance use interacts with workplace policy, and the effectiveness of policy to regulate substance use is influenced by workplace environment, group processes, and perceptions and attitudes. Relevant aspects of the workplace environment include safety-related occupations, drinking climate, social integration, and organizational wellness. Relevant aspects of group processes include neutralization of deviance (i.e., the process by which group members 
justify, rationalize, support, or tolerate coworker deviant behaviors) (Robinson \& Kraatz, 1998) and teamwork. Relevant influences on perceptions and attitudes include exposure to coworker use, tolerance, and level of support of the policy. Attitudes and behaviors that support neutralization include disconnection from policy, poor communication, inadequate coping, tolerance and resignation, and withdrawal and antagonism. Team Awareness was designed as a team-oriented training to prevent workplace substance abuse, with the hypothesized causality that substance use prevention may be achieved by addressing attitudes and behaviors that support neutralization. Outcome studies of Team Awareness suggest a direct impact on variables of relevance

\section{Figure 5.1 NECA-IBEW Team Awareness logic model}

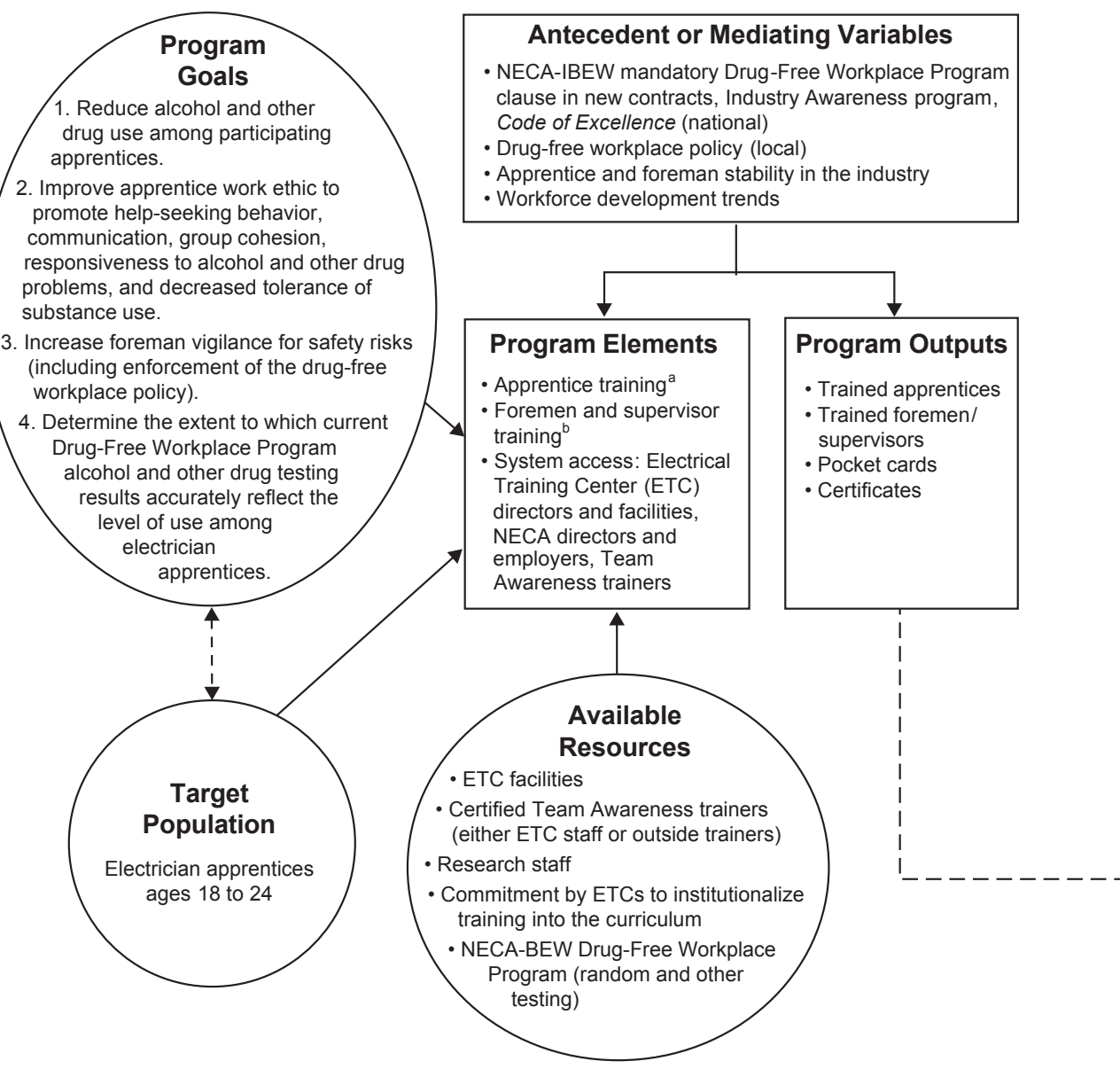


for alcohol or other drug prevention, such as drinking climate, help-seeking behavior, and substance use (Bennett, 2004; Bennett \& Lehman, 2001, 2002;

Bennett et al., 2004; Lehman et al., 2003).

\section{NECA-IBEW Team Awareness Program}

The NECA-IBEW Team Awareness logic model (Figure 5.1) is firmly rooted in the original Team Awareness logic model. The logic model illustrates the connections among the program goals, elements, outputs, and outcomes. It also shows the relationship between these aspects and the target population, available resources, antecedent or mediating variables, intervening or rival events, and hypothesized causality.

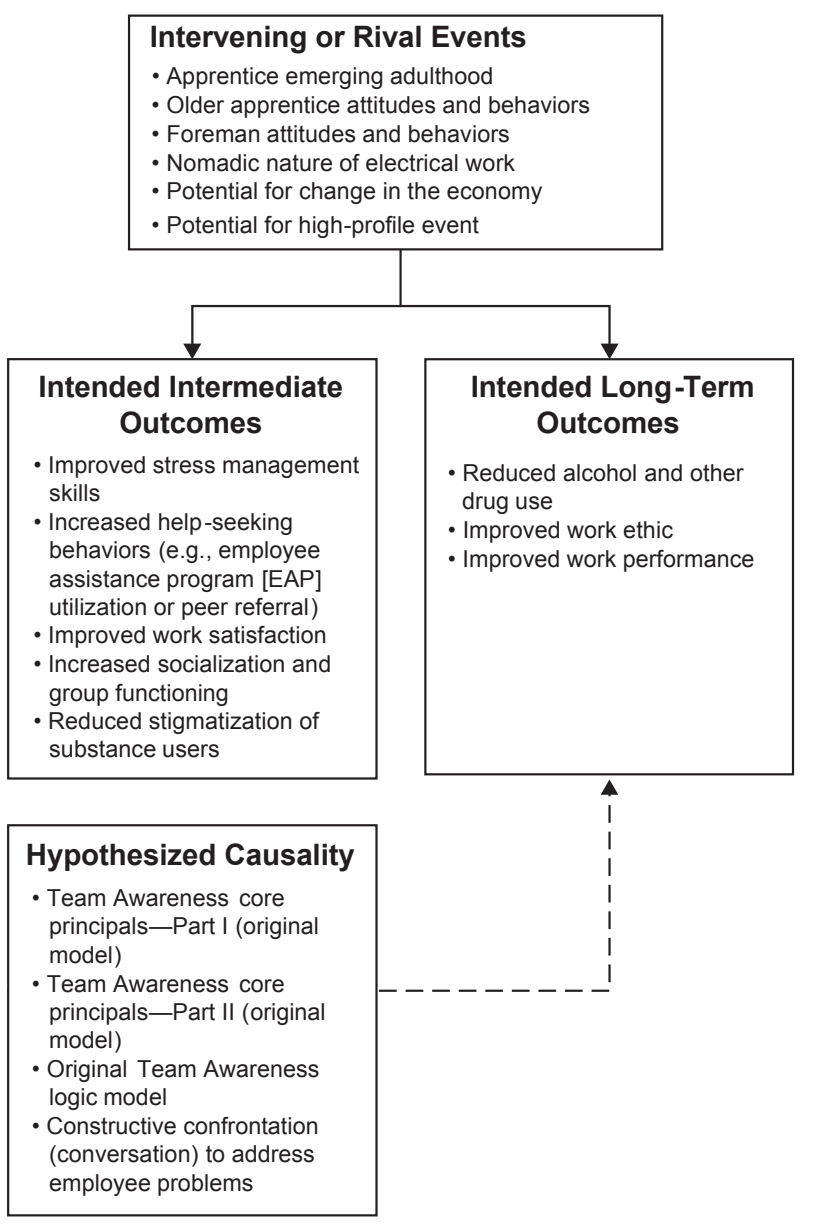

$\mathrm{NECA}=$ National Electrical Contractors Association; IBEW = International Brotherhood of Electrical Workers;

ETC = Electrical Training Centers.

a Apprentice sessions include (1) Relevance to You and Your Work Group: Orientation to NECA-IBEW Team Awareness,

(2) Policy and Tolerance,

(3) Risky Business team game,

(4) Learning from Success and Failure, (5) Improving Workplace Communication, and (6) Encouragement: The NUDGE Model.

b Foremen/supervisor sessions include (1) Relevance to You as Foreman: Orientation to NECA-IBEW Team Awareness; (2) Key Concepts: Management and Leadership, IBEW Code of Excellence, Negligence, Reasonable Suspicion, and Fitness for Duty; and (3) the Six-Step Model of Constructive Confrontation. 


\section{NECA-IBEW Team Vigilance Program}

The NECA-IBEW Team Vigilance logic model (Figure 5.2) represents major adaptations from the original Team Awareness training for supervisors. Supervisor training is an essential part of drug-free workplace programs, and supervisors are an important link between employees and the employee assistance program (EAP) (Scanlon, 1991). Training is designed to affect supervisors' knowledge about the effects of substance abuse and the laws, rules, and guidelines for handling employee substance abuse; their self-efficacy with regard to handling employee performance and conduct problems at work; their tolerance for deviance in the workplace; and their motivation to address substance abuse among employees. A central component of supervisor training is constructive confrontation (Polcin, 2003), using a six-step approach that centers on workplace performance (which can be documented) rather than

\section{Figure 5.2 Logic model: Team Vigilance training for NECA-IBEW foremen and other supervisors}

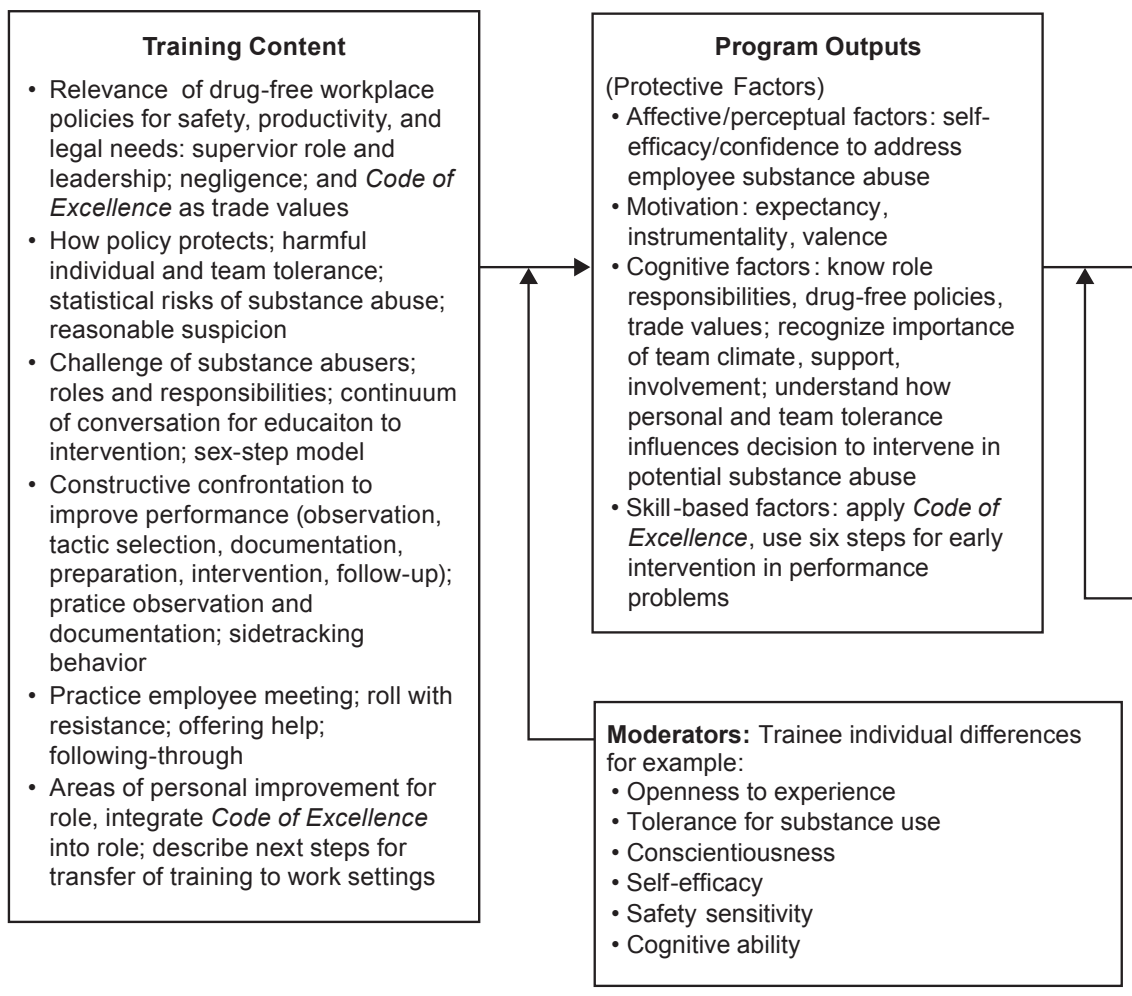


the substance problem (which can be denied by the employee). Several studies of the constructive-confrontation strategy generally conclude that it leads to increased employee acceptance of treatment and an improvement in overall job performance (Hilker et al., 1972; Normand et al., 1994; Trice \& Beyer, 1984). Evidence also suggests that formal training improves the effectiveness of supervisory interventions (Googins et al., 1990).

Constructive confrontation is an intervention strategy with the hypothesized causality that employee performance will improve if the employee is provided with both positive messages of support and coercive messages of warning if employee performance or conduct does not improve (Trice \& Beyer, 1984). Initially, messages are delivered informally. However, failure by the employee to improve work performance leads to formal, progressive discipline. Built on the research foundation of social control

\section{On-the-Job Outcomes for} Supervisors

- Reduced harmful tolerance

- Increased referral to employee assistance program (EAP)

- Increased referral for reasonable suspicion testing - Increased vigilance for safety risks

Hypothesized Target Outcomes for Employees

- Reduced incidence and prevalence of employee substance use

- Reduced workplace deviance

- Increased safety task performance and contextual performance

- Improved safety culture

Moderators: Contextual factors, for example:

- Electrical industry drug -free workplace policy and comprehensive program

- Team tolerance for substance use

- Structural job characteristics and job design

- Training transfer climate

- Supervisor-subordinate relationship 
theory, the work group or team is the locus where team members and the team supervisor can exert influence that may motivate an employee to admit his or her alcohol problem and possibly accept the offer of help and/or improve work performance or conduct problems.

When informal intervention is ineffective or change is not sustained, it is followed by progressive discipline as defined by company policy. Escalation of sanctions to achieve and sustain employee change assumes that the work group can make the personal costs of noncompliance with expectations high enough that the employee is motivated to make necessary changes. This trade-off between retaining status on the team (or any employment status) and escalating sanctions is clarified through the structure of the discussion between team members and the employee in both the formal and informal interventions. The key feature is that discussion combines expressions of support with warnings of consequences if the employee does not make the necessary change.

Although the majority of the NECA-IBEW Team Vigilance materials remain faithful to the principles of Team Awareness, the purpose of the training departs noticeably from the original supervisor module. The original model focuses on the relationship between the supervisor and employee, whereas the adapted model focuses on performance and salient references to policy. Because the adapted program reflects a high priority identified by the electrical industry stakeholders, yet does not fit sufficiently within the Team Awareness framework, the training was renamed Team Vigilance to distinguish it from the original Team Awareness supervisor training. During the development of NECA-IBEW Team Vigilance, the NECA attorney who reviewed the material requested changes in the definition of negligence and other small points in the training. As a result of questions during the development of the Team Vigilance training manual, the NECA-IBEW DrugFree Workplace Committee initiated a review of the data collection form used by supervisory personnel to establish the basis for implementing reasonable suspicion drug testing. The revised reasonable suspicion drug testing form reflects the study team recommendations to replace some indicator behaviors with more objective labels.

Industry Practice Areas Related to Team Awareness

In addition to the Drug-Free Workplace Program mentioned above, three practice areas in the electrical industry directly relate to the NECA-IBEW Team Awareness training program. First, because of the catastrophic impact 
of accidents, the electrical industry conducts extensive training to promote workplace safety. In each of their 5 years of training, apprentices learn basic and advanced practices to maintain a safe working environment. In response to strict Occupational Safety and Health Administration regulations, the electrical industry has institutionalized safety as both an asset and a cost of doing business. Some of the larger electrical contractors hire safety directors, and some of the ETCs also house safety directors, who are major supporters of substance abuse prevention training, such as NECA-IBEW Team Awareness, especially training that promotes increased foreman and supervisor confidence to implement reasonable suspicion drug testing when needed.

Second, the electrical industry is highly competitive, and the unionized sector is constantly maneuvering for competitive advantage over the nonunion sector. The primary competitive message of NECA-IBEW is that unionized labor provides higher-quality work and thus provides a better return on investment. Hence, NECA and IBEW jointly developed Industry Awareness, a national program intended to educate leaders in the unionized sector about what union members need to do to deliver on the quality message. The program is delivered in a multimedia format and can be adjusted for 4 to 8 hours of content and discussion. The program includes segments on (1) NECA and IBEW structure, services, and objectives; (2) the NECAIBEW partnership; (3) teamwork and common goals for the industry; (4) understanding the costs of doing business; (5) attitudes in the workplace; (6) customer service; and (7) leading different generations of workers. The last three program segments are an excellent fit with the adapted Team Awareness program for the electrical industry, emphasizing awareness as a key asset for management and labor.

Third, IBEW has launched its own craftsmanship or values-of-the-trade campaign to increase member competitiveness. It is summarized in the IBEW Code of Excellence, which promotes 16 value statements. Each union local is encouraged by the international union to adopt the Code and promote it to members through formal education. Five of the seven union locals involved in the research project have adopted the Code, but all of the ETC directors endorse the inclusion of the Code in the apprentice training content. The first four statements of the Code are to (1) come on time, fit for duty, and ready for work; (2) obey recognized customer and employer work rules; (3) demonstrate zero tolerance for alcohol and substance abuse; and (4) exercise proper safety, health, and sanitation practices. The remaining 12 statements address similar comportment, skill, and ethical issues. NECA chapters endorse the IBEW Code of Excellence. 
The IBEW Code of Excellence focuses various industry efforts (e.g., apprenticeship training, safety programs, labor-management partnership) on the key attitudes, skills, and knowledge needed for electricians and electrical contractors to be competitive. The Code reflects the highest and best meaning of what it means to be a master craftsperson. NECA-IBEW Team Awareness fully integrates the IBEW Code of Excellence from the first to the last module in an effort to harness the power of the idea of master craftsmanship in service to a safer, drug-free workplace.

Program Goals

NECA-IBEW Team Awareness can be viewed as an enhanced drug-free workplace program, a team-building or communication program, and a work culture intervention. The training focuses on the following social factors in the work group or team:

- reducing coworker enabling of problem employees or neutralization of deviant workers (e.g., ignoring, tolerating, and minimizing problems),

- reducing drinking climates or social norms that promote the heavy use of alcohol as the primary method of social bonding (training does not advocate the elimination of drinking as much as moderation in such climates), and

- increasing the sense of work group cohesion or team spirit as a protective factor, focusing on team productivity and safety.

NECA-IBEW Team Vigilance training is intended to improve supervisor observation, tactics, and communication skills to reduce safety risks and improve team performance.

\section{Salient Messages}

The NECA-IBEW Team Awareness and Team Vigilance trainings consistently repeat clear primary messages. The following key messages are common to both trainings:

- Substance use is both a private and public concern.

- Safety policies exist to protect workers rather than to judge personal morality.

- The IBEW Code of Excellence is an expression of electrical trade values.

- Offering help is a union value. 
- There is no risk-free alternative to communicating in a safety situation.

- Employee assistance is a confidential resource for workers who need help.

The following key messages apply specifically to the NECA-IBEW Team Awareness training for apprentices:

- Consider if it is better to get caught or to get help.

- Resistance is a normal human response so learn to roll with it when communicating.

- The NUDGE (Notice-Understand-Decide-use Guidelines-Encourage) model increases the likelihood of success when communicating a message that the recipient may resist.

The following key messages apply specifically to the NECA-IBEW Team Vigilance training for foremen and other supervisors:

- Foremen and supervisors are most effective when focused on employee performance.

- Success is more about how the supervisor responds than how the worker responds.

- Follow the six-step model of constructive confrontation to resolve performance problems.

- There are both costs and benefits to tolerating or responding to performance problems.

- Supervisory style can be unproductive if one overreacts or underreacts rather than responds to problems.

- The greatest risk is not taking action.

- Resistance is normal, so expect sidetracking behavior when confronting performance problems.

- Use the 10-step model for meeting with an employee regarding performance problems to increase the likelihood of success.

- Always follow through by communicating with the employee about what has improved or next steps if improvement has not been sufficient.

The overall idea is that repeating these messages creates changes in perception within the occupation about what will and will not be tolerated by promoting the values of the electrical trade as the rationale for performance improvement and offering help. 


\section{Program Adaptation for Young Adults}

We adapted the original Team Awareness program for the electrical industry in three phases: mobilizing industry stakeholders, collecting participant information and revising program components, and pilot testing the revised training content.

\section{Phase I: Mobilizing Industry Stakeholders}

In Phase I, industry stakeholders were asked to describe their training processes and needs sufficiently for the study team to select an appropriate workplace intervention from the list approved by the National Registry of Evidence-based Programs and Practices (NREPP). The study team conducted focused discussions with leaders from labor, management, benefits administration, and apprentice training. The study team also conducted indepth interviews with one of the local safety directors and one of the ETC directors.

Based on this assessment, the study team determined that apprentices already received some drug education, but not from an NREPP program. In addition, although supervisor training for implementation of the drugfree workplace policy was available from the Drug-Free Workplace Program administrator, training was delivered when requested rather than being required. After careful consideration of five NREPP workplace prevention programs, we selected Team Awareness as the best fit for the highly structured 5 -year apprentice training program.

Phase II: Collecting Participant Information and Revising Program Components

In Phase II, we collected participant information and revised Team Awareness components, in consultation with Joel Bennett, $\mathrm{PhD}$ (one of the developers of Team Awareness who is now at Organizational Wellness \& Learning Systems) and with Donald Truxillo, PhD (of Portland State University), who has expertise in the evaluation of supervisor training. Dr. Bennett visited the study team to conduct apprentice focus groups, meet with ETC staff, and consult with the study team. Chris O'Neill (a certified Team Awareness trainer) conducted other focus groups. In addition, Dr. Bennett facilitated a 4-day retreat in June 2005 to help the study team synthesize the accumulated data and begin refining training content. Each of the original modules was reviewed to determine the need for revision while maintaining fidelity to the original core principles of Team Awareness, including the expanded risk and protective 
factor workplace prevention logic model, the focus on group processes (especially neutralization of deviance), and the development of communication skills to encourage peers to seek help for substance use problems.

Parallel to the review of Team Awareness for apprentice electricians, Dr. Truxillo provided consultation on a five-step model of constructive confrontation, which he has been evaluating for effectiveness. Supervisor confidence has been identified as a major factor in drug-free workplace program implementation, including referring employees to appropriate assistance. The goals of the supervisor training are that the supervisor (1) know his or her responsibility to deal with employee performance and conduct problems, but not to solve them; (2) understand the risks of not acting; (3) be able to address situations in an objective, timely, and safe manner; and (4) successfully follow a five-step intervention process. Based on promising preliminary results, Dr. Truxillo guided the merging of Team Awareness components with the constructive confrontation model. The merged training specifically addresses the need of the electrical industry to improve safety through increased vigilance for substance abuse but has the added benefit of improving foreman and supervisor skills to intervene effectively in every kind of performance problem.

\section{Phase III: Pilot Testing the Revised Training Content}

In Phase III, we pilot tested the revised training content (modules) for apprentices and foremen and further revised the content based on observation and feedback.

Apprentice pilot training sessions. Two apprentice pilot training sessions were conducted at one ETC in two schedule formats: (1) two 3-hour sessions that were 2 weeks apart for a total of 6 hours and (2) one 6-hour training session, including a lunch break. Both pilot training events provided abundant participant and observer feedback to refine the training content for apprentices.

During the training sessions, the study team tested a new combination of exercises and content and used the feedback from observers and apprentices to make additional modifications to the NECA-IBEW Team Awareness modules. For example, the first session included a new game called Risky Business, which was developed in consultation with an ETC instructor. The new game, which replaces the Risks and Strengths board game from the original Team Awareness, includes a simulation exercise that mimics the nomadic nature of 
the occupation while demonstrating the impact of health and safety risks on productivity and team cohesion.

Based on feedback from the pilot sessions, we modified the training content to meet the needs of apprentices aged 18 to 24. Feedback indicated that apprentices wanted (a) less didactic presentation and more activities, examples, and scenarios that are relevant to their experience; (b) assistance in communicating with management; and (c) more practice to demonstrate how the NUDGE model can be used in the work setting. In addition to reorganizing the training content to prioritize learning objectives in 6 hours rather than 8 hours (as in the original Team Awareness), the study team also incorporated the IBEW Code of Excellence as the touchstone for decision making, developed an original team game that simulates the nomadic nature of the electrical and construction trades (as described above), integrated activities to normalize learning from failure as well as success, and provided adequate time for apprentices to develop their own personalized scenarios for NUDGE practice based on guidelines used in competency testing (Truxillo et al., 2004).

The original Team Awareness training content for apprentices is compared with the adapted training in Table 5.1. The original and adapted versions of Team Awareness are similar in their experiential nature and their focus on relevance and ownership of policy, reducing stigma and tolerance, understanding communication norms and increasing communication skills, and encouraging others to get help when appropriate. The adapted version, however, has been tailored to the electrical industry.

Foremen and supervisor pilot training sessions. Two foremen and supervisor pilot training sessions were conducted in two schedule formats: (1) two 3-hour morning sessions held 1 week apart for a total of 6 hours or (2) one 6.5-hour training session, including a lunch break. The second pilot session included 30 minutes to test a local survey measure for the foreman training. Both pilot training events provided abundant participant and observer feedback to refine the training content for foremen and other supervisors.

Development of the foreman training was influenced by several salient differences from the apprentice training format. First, unlike apprentices, who comply with national training standards and curriculum, there is no common set of requirements for foreman certification that all ETCs use. Requirements that foremen be trained can be mandated through local collective bargaining agreements, but otherwise foreman training is voluntary. In addition, there 


\section{Table 5.1 Comparison of apprentice learning objectives in original and adapted Team Awareness programs}

\section{Original Team Awareness}

1. Relevance: Recognize the importance of addressing alcohol or other drug abuse and its relevance to teamwork and group performance, identify current levels of behavioral risk in the work setting related to alcohol and other drug use, set specific goals for enhancing team communication as a way of reducing risks

2. Team Ownership of Policy: Understand how substance use policy protects employees, identify ways that policy can enhance team or work group health as well as reduce risks, understand that effective policy requires shared responsibility

3. Reducing Stigma and Tolerance and Increasing Responsiveness: Identify both personal and group attitudes toward coworkers with alcohol, drug, or other behavior problems; recognize and potentially reduce risky levels of coworker tolerance; increase responsiveness to problems

4. Work Stress, Problem Solving, and Substance Use: Identify the effects of stress and signs of not coping well, identify personal coping style and whether stress is a risk factor for alcohol or other drug use, recognize healthy alternatives for dealing with stress
NECA-IBEW Team Awareness

1. Relevance: Recognize how alcohol and other drug abuse affects apprentices and teamwork, identify sources of personal stressors and effects, describe the role of team member, recognize IBEW Code of Excellence as electrical trade values

2. Team Ownership of Policy: Recognize how substance abuse policy protects workers, employers, and customers; estimate their team risks and strengths; explain how foreman and coworker tolerance harms others and teamwork; recognize the statistical risks of substance abuse for electrical and construction trades

3. Risky Business: Experience how risks can affect team performance, experience the difficulties and constraints when tools for resolving problems are limited to hire and fire, recognize that ignoring problems on the team is not a reliable way to achieve team objectives
4. Learning from Success and Failure: Recognize that there are risks when we communicate and risks when we do not, describe how we can learn from both success and failure, list at least six keys to successful communication in tricky situations, recognize what part of communication skills need improvement in order to have confidence in tricky situations

5. Speaking Up at Work: Identify norms and responsibilities in workplace communication, identify and reduce blocks to effective listening, practice guidelines for effective communication identify and reduce blocks to effective listening, understand the differences and roles of formal and informal communication in work setting

6. Peer Referral: The NUDGE Model: Understand the different steps in the NUDGE model, understand stages of change model and rolling with resistance, practice peer referral skills using role-play and NUDGE tools
6. Encouragement-The NUDGE Model: Recognize the link between stress, resistance, and ineffective communication; practice rolling with resistance; practice how to encourage others to get help 
is no national foreman training curriculum comparable to the apprentice program, so foreman training content varies from center to center. Second, because foremen are not involved in regular classroom training (except for National Electrical Code changes), access to them through ETCs is not certain. Although the ETC may provide the classroom space, often supervisory courses are promoted through the NECA chapter rather than the ETC. Third, the project advisory board members reported that the training need for foremen actually applied to other supervisors in the industry, including safety directors, human resource managers, general foremen, and others. Everyone with supervisory responsibility is in a role that promotes the consistent application of the policy or enables tolerance of substance abuse and other performance problems. Fourth, given their supervisory responsibility and authority, foremen and other supervisors are at a professional distance from apprentices and journeymen, even when all are members of the same union local.

These four factors combine in a way that renders the original Team Awareness supervisor training a poor fit for the industry-defined needs. Therefore, NECA-IBEW Team Vigilance integrates content about drug-free workplace policy and electrical trade values that is nearly identical to what apprentices receive, but it also emphasizes formal authority as well as informal influence. The original Team Awareness training content for foremen and supervisors and the adapted training are compared in Table 5.2.

The target population for Team Vigilance includes management supervisors, human resources directors, safety directors, and union foremen. The training is promoted through NECA chapter communication rather than the ETC. Training content focuses on the formal role of supervisory personnel while retaining activities that explore the personal stresses and leadership dimensions of the role; the drug-free workplace policy and the IBEW Code of Excellence (which are taught in tandem); and constructive confrontation (expressed as a 6-step supervisory intervention model and a 10-step employee meeting format), which is the primary skill set rather than NUDGE (a 5 -step peer intervention). In addition, personal planning time is allotted 


\section{Table 5.2 Comparison of foreman/supervisor learning objectives in original Team Awareness and adapted Team Vigilance programs}

\section{Original Team Awareness}

1. Relevance: Recognize the importance of addressing alcohol or other drug abuse and its relevance to teamwork and group performance; identify current levels of behavioral risk in the work setting related to alcohol and other drug use; set specific goals for enhancing team communication as a way of reducing risks

2. Team Ownership of Policy: Understand how substance use policy protects employees; identify ways that policy can enhance team or work group health and reduce risks; understand that effective policy requires shared responsibility

\section{NECA-IBEW Team Vigilance}

1. Relevance: Recognize the importance of addressing employee alcohol or drug abuse because it increases safety risks and reduces team cohesion especially in a stressful work environment; describe how the role of foreman/supervisor involves both managing people and leading team members; recognize that biggest risk for most foremen/supervisors is negligence because they under-react; recognize the IBEW Code of Excellence as specific expression of electrical trade values

2. Team Ownership of Policy: Recognize how substance abuse policy protects workers, employers, and customers; explain how foreman and coworker tolerance harms others and teamwork; recognize the safety risks of substance abuse for electrical and construction trades; define reasonable suspicion; understand that negligence is the greatest supervisory risk

3. Reducing Stigma and Tolerance and Increasing Responsiveness: Increase supervisor willingness to respond to employee behavioral problems and concerns (as opposed to tolerating them); enhance supervisor awareness of their own decisionmaking processes and emotional factors that underlie their decision to tolerate or respond; increase sense of support and community among supervisors and their sense of support from human resources

4. Work Stress, Problem Solving, and Substance Use: Identify the effects of stress and signs of not coping well; identify personal coping style and whether stress is a risk factor for alcohol or other drug use; recognize healthy alternatives for dealing with stress
3. Constructive Confrontation: Explain why it may be more difficult to achieve performance improvement with a team member who abuses alcohol or drugs; describe the difference between foreman/supervisor responsibility versus employee responsibility to improve performance or behavior; list six steps of the constructive confrontation model observation and objective documentation;
4. Observe, Document, Prepare: List the steps in the six-step model: (1) objective observation, (2) select intervention, (3) objective documentation, (4) preparation for employee meeting, (5) meeting with the employee, and (6) following up; practice objective name three sidetracking behaviors that could be a problem if not prepared; practice employee meeting with 10-step guidelines that protect all participants 


\section{Table 5.2 Comparison of foreman/supervisor learning objectives in original Team Awareness and adapted Team Vigilance programs (continued)}

Original Team Awareness

5. Workplace Communication Skills: Identify communication norms and responsibilities in the workplace and related skills for effective communication; identify and reduce blocks to effective listening; understand the differences and roles of formal and informal communication in work setting

\section{NECA-IBEW Team Vigilance}

5. Meet with Employee: Practice the 10-step employee meeting format; experience simulated employee resistance and how to redirect sidetrack behaviors back to the meeting purpose. The 10 steps are as follows: (1) mention employee contribution, (2) express concerns as ask for commitment to listen, (3) commit to listening to employee when finished, (4) state observations and concerns, (5) redirect interruptions and remind of commitment to listen, (6) ask to hear employee's side, (7) state expectations clearly and specifically with reference to job description or rules or IBEW Code of Excellence, (8) state potential consequences if no improvement, (9) express hope that consequences will be avoided and that the choice is the employees', and (10) set up a follow-up meeting and follow through

6. Peer Referral: The NUDGE Model: Understand the different steps in the NUDGE model; understand stages of change model and rolling with resistance; practice peer referral skills using role-play and NUDGE tools
6. Follow Up: Recognize the importance of following through with positive feedback when employee improves performance or conduct and delivering consequences in timely way when expectations are not met by employee

7. Personal Planning: Identify three current strengths and weaknesses when dealing with employee performance problems; explain how the IBEW Code of Excellence can be integrated into the performance counseling procedure; state their motivation and commitment to make improvements at the company and in themselves in terms of attitude, skills, and knowledge to address substance abuse and work ethic among electricians 
for strategizing the transfer of attitudes, skills, and knowledge to the work environment (including addressing personal and institutional barriers).

Comparing NECA-IBEW Team Awareness and Team Vigilance training. The NECA-IBEW Team Awareness training for apprentices and the NECAIBEW Team Vigilance training for supervisory staff complement one another. The dimensions of the two trainings are compared in Table 5.3.

\begin{tabular}{|c|c|c|}
\hline Training Dimension & NECA-IBEW Team Awareness & NECA-IBEW Team Vigilance \\
\hline Type of conversation & Peer encouragement & Constructive confrontation \\
\hline Model skill set & NUDGE model & Six-step model \\
\hline Setting for taking action & Informal & Formal \\
\hline Key skill to keep focus & Roll with resistance & Clear request and follow up \\
\hline Documentation required & No documentation & Formal documentation \\
\hline Role-play focus & Offering help (NUDGE) & 10 steps of successful meetings \\
\hline $\begin{array}{l}\text { Demonstrate team } \\
\text { responsibility }\end{array}$ & Getting caught/getting help & Responding vs. tolerating \\
\hline
\end{tabular}

\section{Marketing to Increase Program Participation}

Promoting participation of apprentices in NECA-IBEW Team Awareness training varied significantly from promoting foreman and other supervisor participation in Team Vigilance training.

\section{Promoting NECA-IBEW Team Awareness}

Apprentices participate in a 5-year training program and earn wages on the job while learning in the classroom and laboratory. The study team found that essential to promoting apprentice participation in the NECA-IBEW Team Awareness program was the successful recruitment of key local stakeholders, especially training directors, to incorporate the training into the ETC curriculum. Methods used to facilitate stakeholder recruitment and buy-in included telephone calls, personal visits, detailed orientation to the project goals and course content, production and distribution of one-page written descriptions, use of intermediaries, and presentations to the annual training directors conference.

One challenge during the course of the project was training director turnover: more than 50 percent of the training directors changed in the first 
4 years-in three cases because of retirement and in one case because of a union election. In these instances, however, the apprentices were already being trained, and some level of commitment to scheduling Team Awareness training preceded the new training directors. Nevertheless, study staff immediately assessed the new training directors' needs, interests, and concerns to ensure continued commitment to the project.

\section{Promoting NECA-IBEW Team Vigilance}

Promoting Team Vigilance to foremen and other supervisors was more difficult. Unlike the apprentice program, which requires mandatory instructional hours and uses a well-defined national curriculum, training for foremen and other supervisors is not required, except for license renewal. However, the Team Vigilance training course does not qualify for training hours that can be credited toward license renewal. Thus, identifying the motivators for participation in the Team Vigilance training became an effort in assessing local interests and levers of influence. Executive directors for the three participating NECA chapters emerged as the key stakeholders to promote participation in Team Vigilance.

\section{Target Population}

\section{Industry and Location}

The study is being conducted in seven IBEW union locals in urban and rural areas of the Pacific Northwest that are all enrolled in the same drug-free workplace program with the same provider network and the same health benefits plan (with minor exceptions). Thus, any change in policy, benefits, or procedures affects apprentices and foremen in all IBEW union locals equally. Early in the study, SAMHSA, the cross-site evaluation team, and RMC Research Corporation agreed to define the worksite as apprentice electricians and their foremen who are members in the IBEW union local.

Apprentice and journeyman electricians are employed by electrical contractors, and they change worksites often as one job ends and another begins. Apprentices may find work with numerous employers, although a handful of companies employ a vast majority of the apprentices. Foremen's roles can also change; for example, a person who is a journeyman on one job may be a foreman on the next, and vice versa. The nomadic nature of the occupation has been taken into account in the adapted training. Thus, the worksite is defined as the population under study, rather than a particular physical location. 
NECA-IBEW Team Awareness is delivered to apprentices in their ETCs, each of which has a director, faculty, and administrative staff. Representatives of NECA and IBEW oversee the ETC. Apprentices enroll in the ETC for their training; most participate in a 5-year training program that costs approximately $\$ 30,000$ per person and is funded by an education charge added to the hourly wage of all electricians paid by their employer. However, the full cost of educating an apprentice includes 5 years of wages, benefits, and on-the-job training, for a grand total of $\$ 250,000$ - a considerable investment in each apprentice. Therefore, it is important that apprentices remain drugfree and develop a positive work ethic. By providing NECA-IBEW Team Awareness training to apprentices in the context of their ETC, the training is institutionalized into the apprentice curriculum and helps to shape apprentice values from the outset of their program. Over the long term, the first year of apprenticeship training may be the best setting in which to provide training to effect change in the occupational culture because all who complete the apprenticeship will become journeymen and foremen in the future.

\section{Demographics}

There are more than 6,700 electricians in the participating IBEW union locals, including more than 2,300 certified foremen and more than 800 electrician apprentices. In any given year, the seven union locals have approximately 250 electrician apprentices aged 18 to 24 years. Approximately 96 percent of the apprentices are male, and approximately 92 percent are white (approximately 3 percent are Asian and 2 percent are Hispanic). ETC directors anticipate that the number of apprentices will increase in the coming years because of the increased demand for electricians and the retirement projections for current electricians. However, apprentice enrollment will fluctuate with the business cycle because apprentices are employed and depend on work being available.

An apprentice survey was administered in conjunction with the other YIW grantees and in cooperation with the NECA-IBEW stakeholders. The survey contains a set of core cross-site items, as well as items that are of particular interest to the NECA-IBEW directors (see Chapter 8 for more information about the cross-site evaluation and the core survey measures).

Study participants included electrician apprentices enrolled in seven NECA-IBEW ETCs in the Pacific Northwest. The current description includes data from surveys completed by a sample of 828 apprentices across the ETCs. The demographic profile is very similar to the target population; the majority of these apprentices are male (92 percent) and white (91 percent). On average, 
apprentices were 28.6 years old $(S D=6.9)$. About one-third ( 34 percent, $n=282$ ) of the apprentices were between 18 and 24 years of age.

\section{Early Process Findings}

\section{Program Aims}

The program aims are to (1) reduce alcohol and other drug use among participating apprentices; (2) improve apprentice work ethic to promote help-seeking behavior, communication, group cohesion, responsiveness to alcohol and other drug problems, and decreased tolerance of substance use; (3) increase foreman vigilance for safety risks (including enforcement of the drugfree workplace policy); and (4) determine the extent to which random drug testing results accurately reflect the perceived level of substance use among electricians.

Training for the first program wave began in Year 1, training for the second wave began in Year 2, and training for the third wave began in Year 3. Thus, training implementation was delayed for some IBEW union locals, yet all union locals ultimately received the training.

Overall, 40 trainings were conducted and 961 apprentices were trained. In addition, nine ETC instructors had been trained to deliver NECA-IBEW Team Awareness in these four ETCs. The instructors were trained in two train-thetrainer events, and they initially co-facilitated trainings alongside the study team before conducting trainings on their own. Instructors also received additional coaching and feedback on their training performance.

\section{Apprentice Responses}

Overall, the apprentices responded positively to the training. Table 5.4 shows average apprentice responses to items on an end-of-training evaluation form. As seen in the table, apprentices believed that the presenters were engaging and approachable, that participants had enough opportunities to be involved, that the presenters were organized and explained things clearly, and that the purpose of the workshop was clear. Apprentices also believed that the content was relevant to NECA-IBEW, that the skills taught were important for their career, that they learned new information from the training, and that the information was useful to them personally. 
Table 5.4 Apprentice post-training evaluation of the training

\begin{tabular}{ll}
\hline & Average \\
\hline I learned new information in this training. & 3.56 \\
\hline The content was relevant to NECA-IBEW. & 3.85 \\
\hline The information was useful to me, personally. & 3.49 \\
\hline The purpose of the workshop was clear. & 4.04 \\
\hline The presentation was well-paced. & 4.12 \\
\hline I had enough opportunities to be involved. & 4.53 \\
\hline The presenters were organized. & 4.46 \\
\hline The presenters explained things clearly. & 4.30 \\
\hline The presenters were engaging and approachable. & 4.55 \\
\hline The skills taught are important for my career. & 3.84 \\
\hline
\end{tabular}

Note: All items were on a 5-point scale from 1 (low agreement) to 5 (high agreement).

\section{Instructor Responses}

The ETC instructors who delivered the training rated it favorably. They commented that it took some time to get used to the training material, because they were much more accustomed to teaching technical material than interpersonal skills. Instructors also began to think about how they could make the usual technical material more interesting and engaging by incorporating a more interactive approach that is similar to Team Awareness. In addition, instructors thought that, over time, the currently novel Team Awareness message would become part of the occupational culture, similar to how safety orientation has become part of the occupational culture over the past 10 years. They believe that Team Awareness is important, and they are committed to its success.

\section{Advisory Board}

Along with integration into the apprentice curriculum, one of the key facilitators to implementation of Team Awareness was a strong and active advisory board representing the community of electricians, including the IBEW Minority Caucus, Women's Caucus, NECA/IBEW Electrical Training Center Safety Committee, NECA/IBEW Drug-Free Workplace Program Committee, and apprentice electricians in the target age group. The advisory board met quarterly throughout the project, providing guidance on training, study design, and implementation. In general, advisory board members were satisfied with the role and responsibility of the board, agreed that the board 
represents opinions of diverse stakeholders, and thought the board was an effective decision-making body.

Primary Barrier to Implementation

The primary barrier to implementation was difficulty generating foreman and supervisor interest in participating in the Team Vigilance training. Developing the Team Vigilance training took longer than anticipated, and therefore only two Team Vigilance trainings were conducted, with 10 persons being trained. These trainings were well-received by the participants, who hold high-profile positions in their companies. They indicated their intent to return to their companies and facilitate increased participation. In addition, participating NECA chapter managers remain committed to and enthusiastic about the training and are eager to find ways to recruit participants. It appears that participation will increase if there is greater incentive to do so-for example, if participation is encouraged (or required) by employers.

\section{Conclusions}

This chapter describes the adaptation of NECA-IBEW Team Awareness for electrician apprentices and the development of NECA-IBEW Team Vigilance for electrician foremen and other supervisors in the electrical industry. The trainings, which directly address the interests of industry stakeholders, have been implemented and are currently being tested for impact.

NECA-IBEW Team Awareness and NECA-IBEW Team Vigilance incorporated industry-identified values of the trade (in the form of the IBEW Code of Excellence) as the rationale for taking action, such as changing behaviors or offering help to someone in need. NECA-IBEW Team Awareness has been incorporated into the apprentice curriculum, and NECA-IBEW Team Vigilance is being offered to foremen and supervisors. Thus, an occupational, cultural intervention has begun.

These programs have also garnered the interest of national leadership and have significant potential for implementation on a national scale. Given the number of members of NECA chapters and IBEW union locals, the potential reach of the intervention is substantial. Indeed, participating leadership has already brought information about the study to the national level, for example, when one of the training directors and the program manager presented to the Education Committee of the National Joint Apprenticeship and Training Committee. 


\section{Sustainability}

The available and required resources for supporting the program beyond the study period include ETC facilities, certified NECA-IBEW Team Awareness trainers, the NECA-IBEW Drug-Free Workplace Program, and the commitment of the ETC directors to institutionalize the training. Primary among these is the interest and commitment of industry leaders-including NECA chapter managers, IBEW business managers, and ETC training directors-who have already experienced the benefits of the training and are willing to integrate it into the apprentice training. Despite the fact that turnover of the key leadership was about 50 percent during the course of the study, the program is sustained by the commitment of the incoming leadership.

Integrating the training into the apprentice curriculum will help to ensure that apprentices receive the messages at the beginning of their electrician career. Another key to sustainability is that ETC faculty are trained to deliver the program to apprentices. Thus, apprentices are hearing the key messages from the very people who are training them in the requisite skills for the trade. This helps apprentices understand that the communication skills they receive from NECA-IBEW Team Awareness are as important as the technical skills they acquire in the classroom or practice in the lab.

In addition, we have learned to be flexible in implementing the program (e.g., providing the training on different schedules to accommodate existing class schedules at each ETC), while adhering to key principles of fidelity. In the future, ETC instructors will need to continue to implement the program with fidelity and avoid making the program too personalized or adding or omitting material.

\section{Recommendations for Future Programs}

The following recommendations are based on the implementation of NECA-IBEW Team Awareness and NECA-IBEW Team Vigilance thus far:

- Address tobacco use in the next version of NECA-IBEW Team Awareness. Although we confirmed stakeholder perceptions that alcohol is the substance of choice, we also discovered a higher rate of tobacco use than anticipated. Tobacco can be included among the drugs referenced in the NECA-IBEW Team Awareness training. 
- Provide a checklist for trainers to use at the end of the training to determine whether all of the material was actually covered. The checklist would be similar to the one used for researcher rating of implementation fidelity, but perhaps not as detailed. Because the training is delivered by ETC faculty, they could return the following week to material that may have been omitted inadvertently.

- Re-play the Risky Business game at the end of the training so that apprentices can apply what they have learned. This modification would require either deleting some material or adding time. It could also be done as a booster session 1 year after the training, following review of key points of Team Awareness.

\section{- Further adapt the NECA-IBEW Team Awareness and Team Vigilance} material based on the experience gained delivering it for 3 years and from information obtained from apprentice and foreman surveys. For example, edit the material to create time to re-play the Risky Business game at the end of the training so that foremen and team members can practice the NUDGE skills to offer help to a team member who may benefit.

- Conduct additional research to better understand what works, for whom, and under what conditions, as well as how apprentice acceptance of the material may vary depending on where they are in their training (e.g., first year versus fifth year). In addition, it is important to know more about how to work with apprentice training classes that vary in personality (e.g., learning style, cohesion level) from year to year. It would also be useful to tie the impact of the program to employer experience rates (e.g., the rate of job accidents, which affects the cost of workers' compensation insurance premiums).

- Work to bring the program to scale. This could be done in collaboration with NECA, IBEW, and the National Joint Apprenticeship and Training Committee. Because this would involve implementation in other parts of the country, with different drug policy histories and different drug-free workplace programs, research would be required to learn about needed refinements and impacts in those areas.

- Adapt and implement the material for other tradespeople with whom electricians come into contact (e.g., ironworkers, sheetrock hangers, plumbers) to ensure a safer work site overall. 


\section{References}

Ames, G. M., \& Grube, J. W. (1999). Alcohol availability and workplace drinking: Mixed method analyses. Journal of Studies on Alcohol, 60(3), 383-393.

Bennett, J. B. (2004, spring). The small business wellness initiative: Reaching out with evidence-based substance abuse prevention programs. Wellness Management, 14-16.

Bennett, J. B., \& Lehman, W. E. (1999). Employee exposure to coworker substance use and negative consequences: The moderating effects of work group membership. Journal of Health and Social Behavior, 40(3), 307-322.

Bennett, J. B., \& Lehman, W. E. (2001). Workplace substance abuse prevention and help seeking: Comparing team-oriented and informational training. Journal of Occupational Health Psychology, 6(3), 243-254.

Bennett, J. B., \& Lehman, W. E. K. (2002). Supervisor tolerance-responsiveness to substance abuse and workplace prevention training: Use of a cognitive mapping tool. Health Education Research, 17(1), 27-42.

Bennett, J. B., Lehman, W. E., \& Reynolds, G. S. (2000). Team awareness for workplace substance abuse prevention: The empirical and conceptual development of a training program. Prevention Science, 1(3), 157-172.

Bennett, J. B., Patterson, C. R., Reynolds, G. S., Wiitala, W. L., \& Lehman, W. E. (2004). Team awareness, problem drinking, and drinking climate: Workplace social health promotion in a policy context. American Journal of Health Promotion, 19(2), 103-113.

George, A. A., \& Tucker, J. A. (1996). Help-seeking for alcohol-related problems: Social contexts surrounding entry into alcoholism treatment or Alcoholics Anonymous. Journal of Studies on Alcohol, 57(4), 449-457.

Googins, B., Schneider, R., \& Colan, N. (1990). Reexamining the role of supervisor training. In S. W. Gust, J. M. Walsh, L. B. Thomas, \& D. J. Crouch (Eds.), Drugs in the workplace: Research and evaluation data (pp. 209-224). NIDA Research Monograph No. 100. Rockville, MD: National Institute on Drug Abuse.

Greenburg, E. S., \& Gruneberg, L. (1995). Work alienation and problem alcohol behavior. Journal of Health and Social Behavior, 36(March), 83-102. 
Hilker, R. R., Asma, F. E., \& Eggert, R. L. (1972). A company-sponsored alcoholic rehabilitation program: Ten-year evaluation. Journal of Occupational Medicine, 14(10), 796-771.

Lehman, W. E. K., Farabee, D. J., Holcom, M. L., \& Simpson, D. D. (1995). Prediction of substance use in the workplace: Unique contributions of personal background and work environment variables. Journal of Drug Issues, 25(2), 253-274.

Lehman, W. E. K., Reynolds, G. S., \& Bennett, J. B. (2003). Team and informational trainings for workplace substance abuse prevention. In J. B. Bennett \& W. E. K. Lehman (Eds.), Preventing workplace substance abuse: Beyond drug testing to wellness. Washington DC: American Psychological Association.

Lund, A. K., Preusser, D. F., Blomberg, R. D., \& Williams, A. F. (1991). Drug use by tractor trailer drivers. In S. W. Gust \& J. M. Walsh (Eds.), Drugs in the workplace: Research and evaluation data (pp. 47-67). Rockville, MD: US Department of Health and Human Services.

Normand, J., Lempert, R. O., \& O’Brien, C. P. (Eds.). (1994). Under the influence? Drugs and the American work force. National Research Council/ Institute of Medicine. Washington, DC: National Academy Press.

Polcin, D. L. (2003). Rethinking confrontation in alcohol and drug treatment: Consideration of the clinical context. Substance Use and Misuse, 38(2), $165-184$

Quick, J. C. (1999). Occupational health psychology: The convergence of health and clinical psychology with public health and preventive medicine in an organizational context. Professional Psychology: Research and Practice, $30,123-128$.

Robinson, S. L., \& Kraatz, M. S. (1998). Constructing the reality of normative behavior: The use of neutralization strategies by organizational deviants. In R. W. Griffin \& A. O’Leary-Kelly (Eds.), Dysfunctional behavior in organizations: Violent and deviant behavior. Monographs in organizational behavior and industrial relations: Vol. 23 (pp. 203-220). Stamford, CT: JAI.

Roman, P. M., Blum, T. C., \& Martin, J. K. (1992). 'Enabling' of male problem drinkers in work groups. British Journal of Addiction, 87(2), 275-289. 
Rosen, R. H. (1991). The healthy company: Eight strategies to develop people, productivity, and profits. Los Angeles, CA: Jeremy P. Tarcher/Putnam.

Scanlon, W. F. (1991). Alcoholism and drug abuse in the workplace: Managing care and costs through employee assistance programs (2nd ed.). New York: Praeger.

Trice, H. M., \& Beyer, J. M. (1984). Work-related outcomes of the constructiveconfrontation strategy in a job-based alcoholism program. Journal of Studies on Alcohol, 45(5), 393-404.

Trice, H. M., \& Sonnenstuhl, W. J. (1990). On the construction of drinking norms in work organizations. Journal of Studies on Alcohol, 51(3), 201-220.

Truxillo, D. M., Donahue, L. M., \& Kuang, D. (2004). Work samples, performance tests, and competency testing. In J. C. Thomas \& M. Hersen (Eds.), Comprehensive handbook of psychological assessment: Industrial and organization assessment, Vol. 4 (pp. 345-367). Hoboken, NJ: John Wiley \& Sons, Inc. 



\title{
Adapted Team Awareness for Youth and Conservation Corps
}

\author{
Jean Denious, ${ }^{1}$ Chandra Ring, ${ }^{1}$ Nick Reese, ${ }^{1}$ Jennifer Hooks, ${ }^{1}$ \\ Caitlin Kozicki, ${ }^{2}$ Cori Stott, ${ }^{2}$ and Brie Reimann² \\ IOMNI InSTITUTE, DenVER, CO; \\ 2Peer Assistance Services, Denver, CO
}

\section{Introduction}

The Adapted Team Awareness program targets young adult workers employed by youth and conservation corps, termed corps members. Corps members conduct field work in a variety of areas relating to environmental conservation, including trail building, recycling, landscape maintenance, fire hazard reduction, flood prevention, and minor construction. During natural disasters, youth and conservation corps may also respond as needed for fire camp support, flood control, earthquake recovery, and oil spill cleanup. Upon entry into youth and conservation corps, many corps members lack essential job skills and training. Most youth and conservation corps organizations incorporate various life-skills classes and academic completion courses into corps members' employment and training, with some sites formally connected to charter schools that provide opportunities for corps members to complete a general equivalency diploma (GED) during their work tenure. The Adapted Team Awareness program is designed to prepare the targeted youth population for future successful employment while also helping to reduce substance use, create a culture of positive choices, and educate employees about the value of health-seeking behaviors. As part of the Substance Abuse and Mental Health Services Administration's (SAMHSA's) Young Adults in the Workplace (YIW) initiative, Peer Assistance Services (PAS) is implementing and OMNI Institute (OMNI) is evaluating the Adapted Team Awareness program in selected youth and conservation corps sites. This program was one of three YIW grantee programs to implement an intervention based on Team Awareness. Chapter 4 contains a more complete description of the original Team Awareness program. 
Some youth and conservation corps sites are residential, such that corps members live on-site and are provided with room and board. The participating organization in this study maintains both residential and nonresidential sites. We targeted residential sites for participation in the study because (1) the organization indicated a greater willingness to participate if its seven residential sites constituted the study sample, and (2) we believed that the greater level of interaction among staff and corps members who work and live together would enhance the feasibility and impact of implementation. Youth Corps staff includes education staff and crew leaders, and the crew leaders are often graduates of Youth Corps. This chapter describes the content and implementation of Adapted Team Awareness, describes the target population, and presents early process findings.

\section{Program Description}

The original Team Awareness program is a SAMHSA model workplace training program that addresses employee issues of substance use and abuse and the associated risks. Team Awareness has been shown to increase employee help-seeking for and supervisor responsiveness to troubled workers; create a healthier work climate; and reduce problem drinking. The training is designed to "promote social health and increased communication between workers; improve knowledge about and attitudes toward alcohol- and drugrelated protective factors in the workplace, such as company policy and Employee Assistance Programs (EAPs); and increase peer referral behaviors" (http://nrepp.samhsa.gov/ViewIntervention.aspx?id=69).

Team Awareness was initially developed for use with employees in traditional workplaces. However, in the initial phase of the YIW initiative, PAS and OMNI adapted the Team Awareness curriculum to better serve young adult employees in nontraditional workplaces, such as youth and conservation corps. The resulting program is referred to as Adapted Team Awareness. The following section describes the adaptation process.

\section{Program Adaptation for Young Adults}

During Phase I of the YIW grant, PAS and OMNI worked with Joel Bennett, $\mathrm{PhD}$, the creator of the original Team Awareness curriculum, and staff and employees at several youth and conservation corps sites to adapt the curriculum to be relevant, culturally sensitive, appropriate, and useful for this younger generation of workers in a nontraditional workplace. The adaptation 
process was thorough and was based on three major research components. First, to better gauge the overarching needs and considerations for the curriculum, we consulted current academic literature on characteristics of young adults, risk factors specific to substance abuse among young adults, the needs of young adults in the workplace, and other age-specific issues.

Second, we interviewed employees and staff at select youth and conservation corps sites to gather information about the needs, attitudes, behaviors, and learning styles of young adult employees. These employees also participated in a number of focus groups during the curriculum development process. The information gathered through these efforts drove the early stages of the adaptation process.

Third, we tested the adapted Team Awareness curriculum with employees and staff at select youth and conservation corps sites at several stages of the revision. After each pilot implementation, participants took part in focus groups to provide feedback and to identify areas of strength and weakness. We continually incorporated this feedback into the curriculum until a final version was developed.

In addition to making research-based content changes to the original curriculum, it was important to make changes to the delivery and presentation of the adapted curriculum. Research indicates that learning and communication styles of the current generation of young workers require the use of engaging, hands-on, and interactive learning experiences (Coomes, 2004; Ennett et al., 2003; Kinchin, 2003; Manual, 2002; Raines, 2003). Thus, we added multimedia presentation formats, group work and games, and physical activities to the curriculum. Select youth and conservation corps employees were asked to participate in a pilot session using these new presentational and activity elements. Their feedback suggested that such modifications could enhance and better sustain the impact of positive program messages.

The training consists of six modules that each build on lessons and skills developed in the previous module. Each module takes about 45 minutes to 1 hour to teach and includes individual work and group work. The curriculum empowers corps members to explore their values (personal and work) and to consider discrepancies between their choices/behaviors and stated values. The curriculum provides corps members with skills to explore the effects of alcohol and other drug use/abuse on themselves and their coworkers and to either seek help for themselves or reach out to a coworker to seek the appropriate assistance and resources. Asking for help or reaching out to a 
friend or coworker involves decision-making skills, which the curriculum teaches and allows corps members to practice during the training. In addition, the curriculum teaches corps members about the effects of stress and the skills needed to counteract these effects so they can gain control over their lives. The curriculum also addresses the importance of knowing the specific work policies where one is employed and why policies are created. Corps members are encouraged to read all current work policies in place (e.g., alcohol and other drug abuse prevention policy, grievance policy, operations manual, injury and illness prevention program) to ensure that they can comply with the organization's policies and procedures.

\section{Salient Messages}

During the Adapted Team Awareness trainings, corps members are encouraged to consider their beliefs, values, and goals as a way to help them identify and begin to address discrepancies between their core values and behaviors. Participants are also led through exercises during which they identify their roles in the workplace and in relation to others, including coworkers, family, and friends. Introspection, self-knowledge, and investment in a future self are all key components of the program.

Throughout the program, corps members are repeatedly encouraged to seek help for themselves or for others when it is needed. In each session, participants are given the language and skills needed to approach another person for help or to broach such an issue with a friend or coworker who may need assistance with substance use or other problems. Resources are provided to the participants in multiple settings and include access to information about their EAP, telephone hotline numbers, and contact information for local practitioners.

Having the curriculum presented by youth and conservation corps staff members conveys to corps members that their supervisors are aware of the real-life issues they are facing, that they are concerned, and that they want to be a part of the solution when the corps members are ready to address the issues. Respect and confidentiality are highlighted continuously, and corps members are encouraged to learn to share and to listen to each other's stories. In addition, corps members are given a toolbox of skills with which to address high stress levels, argumentative or disagreeable professional relationships, a lack of identified goals, and other issues. 


\section{Program Goals}

Adapted Team Awareness is intended to help high-risk young adults in nontraditional workplaces reduce substance use and abuse, increase helpseeking behaviors, and build skills and willingness to create a mutually supportive peer group within their workplace. These long-term goals are reached by (1) reducing the culture of acceptance and prevalence of substance use and abuse both within and outside of the workplace, (2) empowering corps members to increase their overall wellness and quality of life, (3) increasing corps members' desire to successfully seek, obtain, and retain fulfilling future employment, and (4) improving their ability to seek assistance with emotional, physical, and/or substance use and abuse problems, both for themselves and for others. Short-term goals include a stronger work ethic and sense of shared responsibility in the workplace, increased rapport and trust between corps members and supervisors, and healthier relationships among corps members. Figure 6.1 presents the logic model for Adapted Team Awareness.

\section{Target Population}

The vast majority of corps members are between 18 and 25 years of age, and they are often facing difficult life circumstances, including poverty, homelessness, lack of education, and abuse or domestic violence. Educational enrollment is not a consideration in defining the target population, although some corps members attend academic completion courses during their tenure in the corps. The majority of these young adult employees (67 percent) are male. Thirty-eight percent are white, 35 percent are Hispanic, and 18 percent are African American. These young adults represent a population at high risk for substance abuse and its accompanying issues.

The youth and conservation corps residential sites maintain a highly structured setting with fully scheduled workdays, set meal times, and required adherence to certain living standards, such as clean dorm rooms and work uniforms. Because the residential sites in the study are part of a single statewide organization, the general structure, mission, and programming are similar across the sites, with the primary difference being each site's specific geographic/regional location within the state. Corps staff at each site often work long hours, reflecting a dedication to the professional, social, and civic development of the corps members that goes beyond conventional employeremployee commitments. Furthermore, many corps staff have risen through the ranks of their program, beginning as corps members and working their way 


\section{Figure 6.1 Adapted Team Awareness logic model}

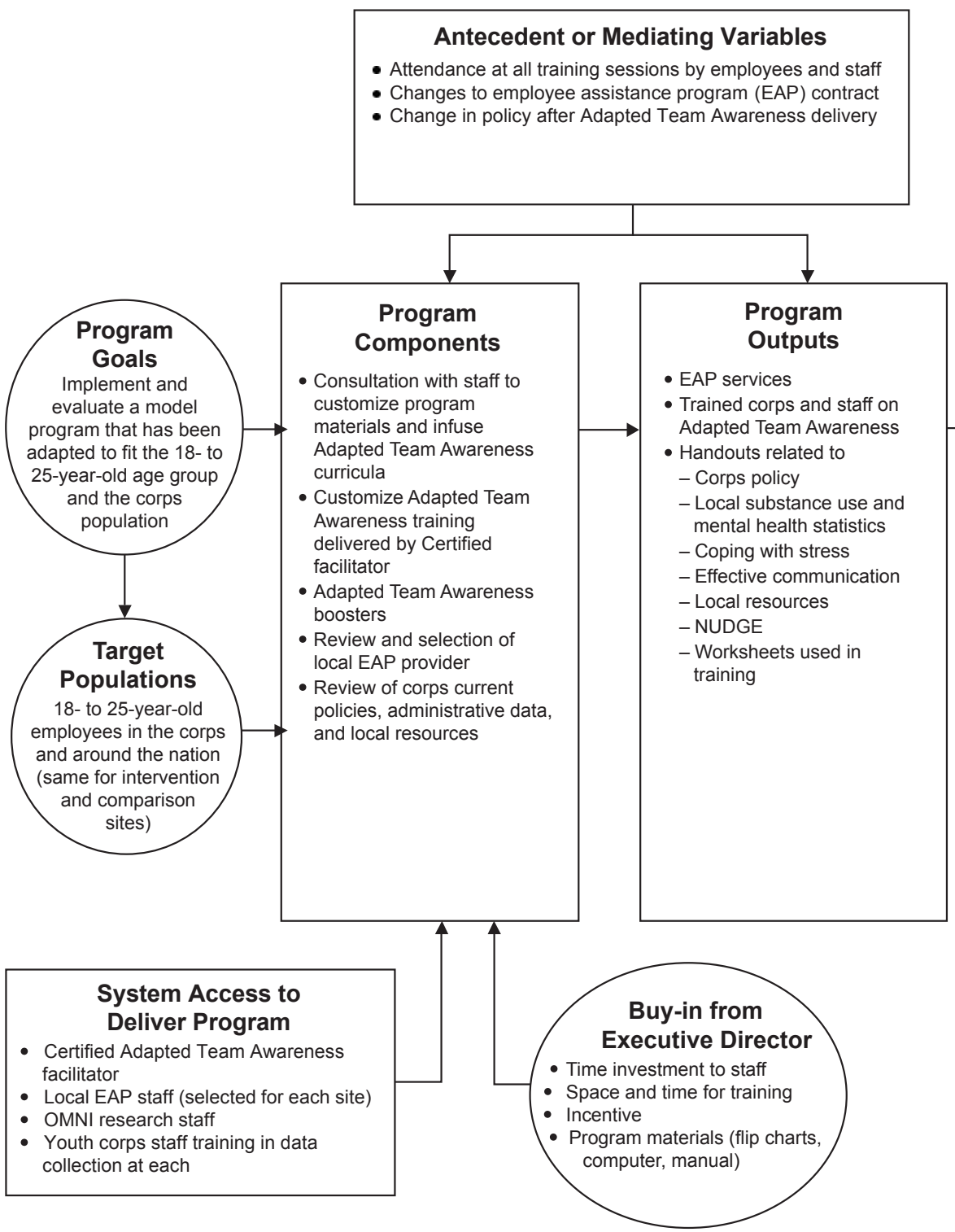

$\mathrm{AOD}=$ alcohol and other drug; $\mathrm{ATOD}=$ alcohol, tobacco, and other drug; EAP = employee assistance program; NUDGE = Notice-Understand-Decide-use Guidelines-Encourage. 


\section{Intervening Variables}

- Changes to corps staff and/or Executive Director

- Decrease of corps' (member, staff, Executive Director) buy-in or modeling of behavior

- Breaches of confidentiality by EAP provider, staff, or employees

- Reduced access to substances prohibiting opportunity for use during employees' experience

\begin{tabular}{|l|c|}
\hline \multicolumn{1}{|c|}{$\begin{array}{c}\text { Intended Intermediate } \\
\text { Outcomes }\end{array}$} & $\begin{array}{c}\text { Intended Long-Term } \\
\text { Outcomes }\end{array}$ \\
$\begin{array}{l}\text { ATOD-related outcomes } \\
\text { - Reductions in ATOD use/abuse, } \\
\text { job-related AOD use, problems } \\
\text { caused by AOD use; drinking } \\
\text { norms and enabling behaviors } \\
\text { among work peers }\end{array}$ & $\begin{array}{c}\text { Improved mental health } \\
\text { Improved job satisfaction } \\
\text { and job stability } \\
\text { - Increased perceptions of harm of } \\
\text { AOD use, motivation to change } \\
\text { prevalence of AOD abuse }\end{array}$ \\
$\begin{array}{l}\text { Workplace skills } \\
\text { - Increased communication, } \\
\text { problem-solving, and coping skills } \\
\text { - Decreased perceptions of stress } \\
\text { Team functioning } \\
\text { - Increased perception of group } \\
\text { cohesion, care, and problem- } \\
\text { solving abilities } \\
\text { Help-seeking } \\
\text { - Increased knowledge of EAP } \\
\text { services, help-seeking (utilization } \\
\text { of the EAP) } \\
\text { - Reduced perceived stigma of } \\
\text { help-seeking }\end{array}$ \\
(not measuring)
\end{tabular}


up into supervisory positions over a span of years. This history increases the relatability and credibility of these supervisory staff for corps members, many of whom-because of background and life experiences-distrust authority figures.

Adapted Team Awareness was implemented in seven geographically dispersed sites of a statewide youth and conservation corps organization: two semi-urban sites and five rural and semi-rural sites.

Each of the grantees administered a survey to support the YIW cross-site evaluation (see Chapter 8 for more information about the cross-site evaluation and the core survey measures). During the first quarter of 2008, 455 corps members across the seven sites were invited to participate in a survey. Among these participants, 419 (92.1 percent) consented to participate and were given the survey. Similar to the target population, the majority (68 percent) were male, 40 percent were white, and 24 percent were Hispanic.

\section{Early Process Findings}

\section{Flexibility}

The most important finding to emerge out of the early meetings and trainings is that flexibility is critical to the success of this program in diverse and regimented employment communities, such as youth and conservation corps. As a component of their jobs, corps member teams can be called out at any time to respond to national emergencies, which disrupts their schedules at the last minute and creates a need for innovative ways to present the curriculum.

Specifically, we capitalized on the modular structure of Adapted Team Awareness to allow for some flexibility in program delivery, such that sites could deliver modules one at a time or combined (no more than two at a time) and could complete the curriculum with corps members within a flexible time span. These variations were necessary to enable and ensure full implementation of the program in the midst of corps members' tight and sometimes unpredictable schedules. Additionally, some corps members are backcountry-based for a portion of their time with the corps. Thus, creative solutions were needed to enable trainers to hike out to the campsites to present the curriculum without the aid of overhead projectors, chalkboards, or even tables, for example. To address this need, we developed portable curriculum materials that could be carried in a backpack for miles into the backcountry and used while sitting around a campfire. 


\section{Staff Stability}

These challenges also highlight the need to train as many staff as possible at each participating site, as the adapted program model is a train-the-trainer approach, where employee staff are trained to train the corps members. Such an approach has important benefits, including capitalizing on the trust and established communication between corps staff and corps members to ensure the effectiveness of a curriculum that hinges on the willingness and ability of those involved to be open, honest, and thoughtful about their attitudes and behaviors. However, such a setup can also present a barrier to sustainability if staff turnover is an issue at a given corps site, leaving the site with too few trained staff members to implement the program with fidelity. Thus, staff stability is a key component of program success (and this characteristic subsequently informed the eligibility of current implementation sites).

Furthermore, to ensure that comprehensive training can be provided to as many staff members as possible, training should take place at each site (rather than having staff travel to one training location). This will help to ensure sustainability at each site. Having more trained staff can also increase support and buy-in for the program because even those staff who are not directly responsible for training corps members will understand the program and its intended goals.

\section{Perception/Use of Employee Assistance Programs}

The Adapted Team Awareness program was initially designed to encourage corps members to seek assistance with issues primarily through their EAP. In implementation, however, we found that EAPs were not always seen as an ideal initial source of help for these young adults. Corps members who are located in rural and semi-rural sites often have to travel several hours to participate in their EAP and thus have to confide in an administrator to access transportation and to get the needed time off of work. Many staff members and some corps members also expressed concern about having to call a number associated with their employers and speaking to a person whom they had never met. Many corps members prefer to seek help from adults on-site whom they know and trust.

To bridge this gap-without placing undue and inappropriate burden on corps staff to serve as counselors in addition to trainers-participating sites were provided additional resources to support such enhancements as a parttime, on-site counselor. On-site resources and the Adapted Team Awareness curriculum, which includes information on what EAPs are and how they 
can be used, are intended to work together to encourage and enable corps members to seek the help they need. Adapted Team Awareness demystifies the EAP and the process for using it, while on-site resources facilitate access to services and allow corps members the option of first reaching out to a known person on-site who can also help them utilize the EAP if appropriate.

\section{Variability in Staff Comfort Levels with Training}

Another early project finding was that staff have varying comfort levels with training corps members. Specifically, some staff communicated that-even with full understanding of Adapted Team Awareness concepts and activities as developed through their training - they anticipated being somewhat uncomfortable with acting as a teacher without additional training on general management and facilitation of group discussions. To address this concern, we developed and provided a prerequisite presentation on group dynamics and boundaries to all staff prior to their receiving the Adapted Team Awareness training to teach staff members the skills to make the teaching process more successful.

\section{Conclusions}

\section{Sustainability}

\section{Barriers}

Staff and Corps Member Turnover. One barrier to sustainability of the Adapted Team Awareness program at corps sites is turnover of staff and corps members, which affects training capacity and norm maintenance. With regard to the latter, Adapted Team Awareness is designed to inculcate healthy communication norms and to encourage abstention from substance use on the job and more positive attitudes toward help-seeking. With corps members continually entering and exiting the program (intended to be a 1-year tenure), it may be challenging to sustain the positive impacts of Adapted Team Awareness in the overall work environment as trained corps members leave and new untrained corps members arrive.

Limited Funding and Resources. Another potential barrier to sustainability of the Adapted Team Awareness program in its complete form is the funding and resources needed to maintain adequate counselor and EAP services for corps members who recognize-through Adapted Team Awareness-that they need help for a substance use issue. As a curriculum-based prevention program, 
Adapted Team Awareness is highly sustainable because trained personnel can continue to implement it as long as they like, and all of the accompanying materials are low-cost and reusable. However, if EAP or other intervention services are necessary to realize the full impact of Adapted Team Awareness, the youth and conservation corps will need to ensure that such services are available to corps members or that they are able to secure additional funding to provide them.

Limited Time Availability. A unique characteristic of youth and conservation corps as workplaces is the extent to which corps members' time is planned. The mission of most youth and conservation corps is to prepare the corps member for more successful future employment, including GED completion courses; workplace rules, such as showing up on time and keeping the dorm clean; and on-the-job skills training (e.g., operating power tools). However, fulfilling all of these requirements in the midst of corps work, which often constitutes hard physical labor, makes for tight schedules and highly fatigued corps members. Corps staff share these long, arduous schedules, given their supervisory roles across these job areas. Thus, incorporating an additional program requires a commitment to integrating the program into existing operations and buy-in from staff and the umbrella organization. This buy-in is necessary not only to energize staff sufficiently to take on more training responsibilities but also to ensure that corps members receive the message that the program is important and should be prioritized among their many work-time pursuits.

Facilitators

Highly Structured Work Environment. Some of the same factors that pose challenges to program sustainability can also facilitate program maintenance and effectiveness. Although the corps environment is intense and physically rigorous, the substantial amount of time fellow corps members and staff spend together-especially in residential corps sites-may serve to increase the speed at which the group- and individual-level changes targeted by Adapted Team Awareness occur. By having a work environment that naturally accelerates program impact, the outputs relative to inputs may be especially high. As noted earlier, the extent to which corps members' time is spoken for through work schedules, educational coursework, and even set meal times can be a barrier. However, this regimentation gives the corps and its staff more control over corps members' time than would be the case in other workplaces. Thus, program sustainability is less vulnerable to participant/employee characteristics. If staff are committed to the program, they have the means to incorporate it into corps members' formal work schedules. 
Affordability, Flexibility, and Portability of Curriculum. Other more conventional features of Adapted Team Awareness's sustainability are the staff buy-in and support for the importance of substance use prevention and the affordability, flexibility, and portability of the curriculum. This simplicity is essential to the sustainability of the program because youth and conservation corps programs exist on tight budgets that often do not allow expenditures for additional programming.

\section{Recommendations}

Integrate Prevention Curricula into Existing Workplace Programming

Although the Adapted Team Awareness program is too early in its implementation to draw conclusions about outcomes, early process findings suggest that the success and sustainability of prevention curricula in workplaces such as youth and conservation corps may hinge on the extent to which the training can be successfully integrated into existing workplace operations and programming. For example, many youth and conservation corps require entering employees to first undergo an orientation that lasts approximately 2 weeks and is designed to prepare corps members for a smooth introduction into their assigned sites' operations and work crews. Although certain components of Adapted Team Awareness are designed to draw on employees' experiences with their coworkers (and therefore are less applicable if an employee has not yet established those working relationships), the introductory modules are more overarching and could feasibly be incorporated into orientation schedules. Introducing the prevention curriculum in this early stage would send a clear message to new employees regarding the values and goals of youth and conservation corps, and it would reduce the potential for natural employee turnover to undermine or ameliorate positive program impacts on the work environment.

\section{Establish Criteria for Adapted Team Awareness Trainers at Workplaces}

Another area for consideration in future programs is the criteria that should be established for Adapted Team Awareness trainers at workplaces. The two most important factors to consider are the trainer's relationship with the participants and the trainer's capacity and skills to deliver the curriculum. These two factors, however, do not necessarily go hand in hand. Training the corps staff to deliver the curriculum maximizes the potential for corps members to be responsive to the trainer, to be willing to engage with the trainer, and to open up about difficult life issues that surface through the training. If employees do 
not feel comfortable with the trainer, they are less likely to absorb and apply the program content effectively.

Alternatively, corps members may feel very comfortable with the person but not receive adequate training if the facilitator's teaching skills, comfort level with group moderation, and navigation of difficult topics are inadequate. Corps staff vary widely in their natural or developed teaching skills. Thus, youth and conservation corps organizations seeking to implement prevention programming need to carefully consider which staff are most appropriate to lead trainings and to prioritize these skills in the development of job descriptions and hiring of future staff to ensure capacity at each site. Incorporating training and delivery of prevention curricula such as Adapted Team Awareness into job descriptions not only allows for organizations to assess these skills at the hiring stage but also frames this work as an essential part of the staff's roles and responsibilities. Given how overworked many corps staff are, commitment to successful delivery of such programs must be seen as a core aspect of their work rather than an added burden.

\section{Provide Credit for Time Spent in Training}

Another element that would better communicate Adapted Team Awareness as an essential component of the corps experience is for youth and conservation corps organizations to provide appropriate credit for corps members' time spent in the training. That is, as with other coursework or tasks undertaken, corps members might receive community service hours or have time spent in Adapted Team Awareness count as part of their working hours. This ensures that the training is presented as a valuable use of the site's time (not just from the corps members' perspective but from the staff's perspective).

\section{Continue to Apply Skills Learned in Adapted Team Awareness}

Finally, Adapted Team Awareness should be regarded not as a one-shot prevention intervention but as a skills training that can and should be applied across various contexts inside and outside the workplace. Following the training, it is important that corps staff continue to initiate and facilitate conversations with corps members on the topics and skills targeted by Adapted Team Awareness, such as stress, coping skills, communication skills, help-seeking behaviors, taking action, values, and policy information. These discussion opportunities can arise while on the job, around the campfire, at meal times, and in other appropriate workplace contexts. 


\section{References}

Coomes, M. D. (2004). Understanding the historical and cultural influences that shape generations. New Directions for Student Services, 106, 17-31.

Ennett, S. T., Ringwalt, C. L., Thorne, J., Rohrbach, L. A., Vincus, A., SimonsRudolph, A., et al. (2003). A comparison of current practice in school-based substance use prevention programs with meta-analysis findings. Prevention Science, 4(1), 1-14.

Kinchin, I. M. (2003). Investigating students' beliefs about their preferred role as learners. Educational Research, 46(3), 301-312.

Manuel, K. (2002). Teaching information literacy to Generation Y. Journal of Library Administration, 36(1-2), 195-217.

Raines, C. (2003). Connecting generations: The sourcebook for a new workplace. Menlo Park, CA: Crisp Publications, Inc. 


\section{LifeSkills Training Wellness Program: An Application for Young Adults in Supermarkets}

Christopher Williams,1 Jessica Samuolis, ${ }^{1}$ Kenneth W. Griffin, ${ }^{2}$ and Gilbert J. Botvin²

1National Health Promotion Associates, White Plains, NY;

2Weill Cornell Medical College, New York, NY

\section{Introduction}

To address the need for workplace substance use prevention programming, National Health Promotion Associates (NHPA) developed the LifeSkills Training Wellness Program (LST-WP) with funding from the Substance Abuse and Mental Health Services Administration's (SAMHSA's) Young Adults in the Workplace (YIW) grant program. LST-WP adapts and extends the highly effective, school-based LifeSkills Training (LST) model program (Botvin, 1998; Botvin et al., 1995) and provides comprehensive skills training for adolescent and young adult employees in communication, problem-solving, conflict resolution, drug resistance, and related life skills. Overall, the program is designed to be highly flexible to meet employee and manager needs across different worksites and industries. This chapter discusses the content and implementation of LST-WP and describes the target population of the NHPA YIW grant, the instructional techniques of LST-WP, and process evaluation tools for the program.

\section{Program Description}

\section{The LST Model Program}

The LST program was initially developed for middle schools and has since proven to be quite flexible. The LST middle school program is a broad-based, multicomponent competence enhancement intervention that teaches social skills, self-management skills, and drug resistance skills. The social skills component is designed to improve important interpersonal skills to help young 
people communicate and negotiate effectively and assertively, handle a variety of social interactions, and resolve interpersonal conflicts. The self-management component is designed to foster the development of decision-making and problem-solving skills and provides young people with skills for maintaining self-control and coping with anxiety, anger, and frustration. LST also impacts knowledge and attitudes concerning drug use, normative expectations, and skills for resisting drug use influences from peers and the media.

The overarching goals of the LST activities are to provide young people with the skills needed to resist negative influences from peers and the media, to reduce the internal psychological forces that may motivate substance use, and to boost overall resilience. LST is grounded in the principles of social learning theory (Bandura, 1977), which outlines the importance of modeling and reinforcement in shaping behavior. Problem behavior theory (Jessor \& Jessor, 1977) suggests that young people engage in risky behaviors, such as substance use, because they view these behaviors as functional for achieving goals (e.g., looking mature, becoming popular). Accordingly, problem behavior prevention strategies need to focus on improving an individual's psychosocial skills.

Over the past 25 years, more than 20 peer-reviewed articles containing analyses of 17 separate cohorts of students have demonstrated that the LST program is highly effective, typically reducing alcohol, tobacco, marijuana, and other illicit drug use by 50 percent or more. These studies (all randomized controlled trials) range from initial small-scale efficacy studies (Botvin \& Eng, 1980; Botvin et al., 1980; Botvin et al., 1983) to large-scale effectiveness trials with suburban white youth (Botvin et al., 1990; Botvin et al., 1995) and with urban minority youth (Botvin et al., 2001a, 2001b). In addition, the positive behavioral effects of LST have been shown to be durable, lasting until the end of high school (Botvin et al., 1995). Moreover, one recent study found that students who received LST in junior high school reported lower rates of HIV risk behavior when followed up with 10 years later as young adults (Griffin et al., 2006), demonstrating that the prevention effects of LST can last well beyond the high school years and can generalize to other risk behaviors. LST has also been shown to be effective in reducing other high-risk behaviors, including binge drinking (Botvin et al., 2001b) and risky driving behavior (Griffin et al., 2004). Furthermore, several independent research teams have shown positive behavioral effects of LST on a variety of substance use outcomes (Fraguela et al., 2003; Trudeau et al., 2003; Zollinger et al., 2003). 


\section{The LifeSkills Training Wellness Program (LST-WP)}

In light of LST's strong theoretical framework, track record of effectiveness, highly successful program characteristics, and versatility of use in a range of settings, the existing LST model program was an ideal candidate to be adapted to the workplace setting. LST-WP builds on the LST approach and is adapted for an older group of adolescents and young adults who are employed outside the home. LST-WP materials were developed to be appropriate for an older, diverse, employed target population; to be relevant to important transitions in adolescent and young adult employees' lives and careers; and to incorporate the contextual factors of the workplace. LST-WP maintains the core components, key skills, and interactive nature of the model intervention while being highly flexible to meet employee and manager needs across different worksites and industries. In addition to content to help build social and self-management skills in and outside of the workplace, LST-WP contains exercises and activities on time and financial management, risk-taking related to substance use, and building a safe and drug-free workplace.

The first three program sessions teach employees how to set realistic goals for their personal and professional lives. The next two sessions focus on interpersonal skills, emphasizing that success involves being able to function effectively in a variety of situations. The last three sessions focus on being organized at home and in the workplace. The eight sessions are described in detail in the LST-WP Session Content section of this chapter.

\section{LST-WP Logic Model}

A logic model has been developed to depict the principles and concepts underlying LST-WP (Figure 7.1). The essential program elements include eight program sessions taught in hourly increments or in a more compact format depending on individual worksite needs. The delivery format of LST-WP sessions is influenced by several worksite constraints, including available worksite space and time to implement the program. In addition, necessary program inputs include the program materials and resources. A number of intermediate outcomes result from proper and sufficient implementation of LST-WP. Employees learn effective goal-setting and steps toward reaching these goals using key skills and resources available to them. To achieve goals, employees learn how to make reasoned decisions and deal effectively with complex problems. Employees also learn how to deal with setbacks and difficulties by effectively managing emotional reactions to stress and anger. In addition to intermediate outcomes related to self-management skills, LST-WP 
also teaches employees to function effectively in a variety of interpersonal situations, to interact with others in positive ways by communicating clearly, and to resolve interpersonal conflicts effectively. Several intermediate outcomes are related to an employee's being organized in his or her personal life and in the workplace, including skills to effectively manage money and time, knowledge about the negative impact that substance use has on achieving goals, and knowledge of workplace policies related to substance use. Antecedent variables that may negatively impact program delivery and inputs include employee attrition, employee turnover, perceived stigma of participation, and scheduling conflicts.

Figure 7.1 LifeSkills Training Wellness Program logic model

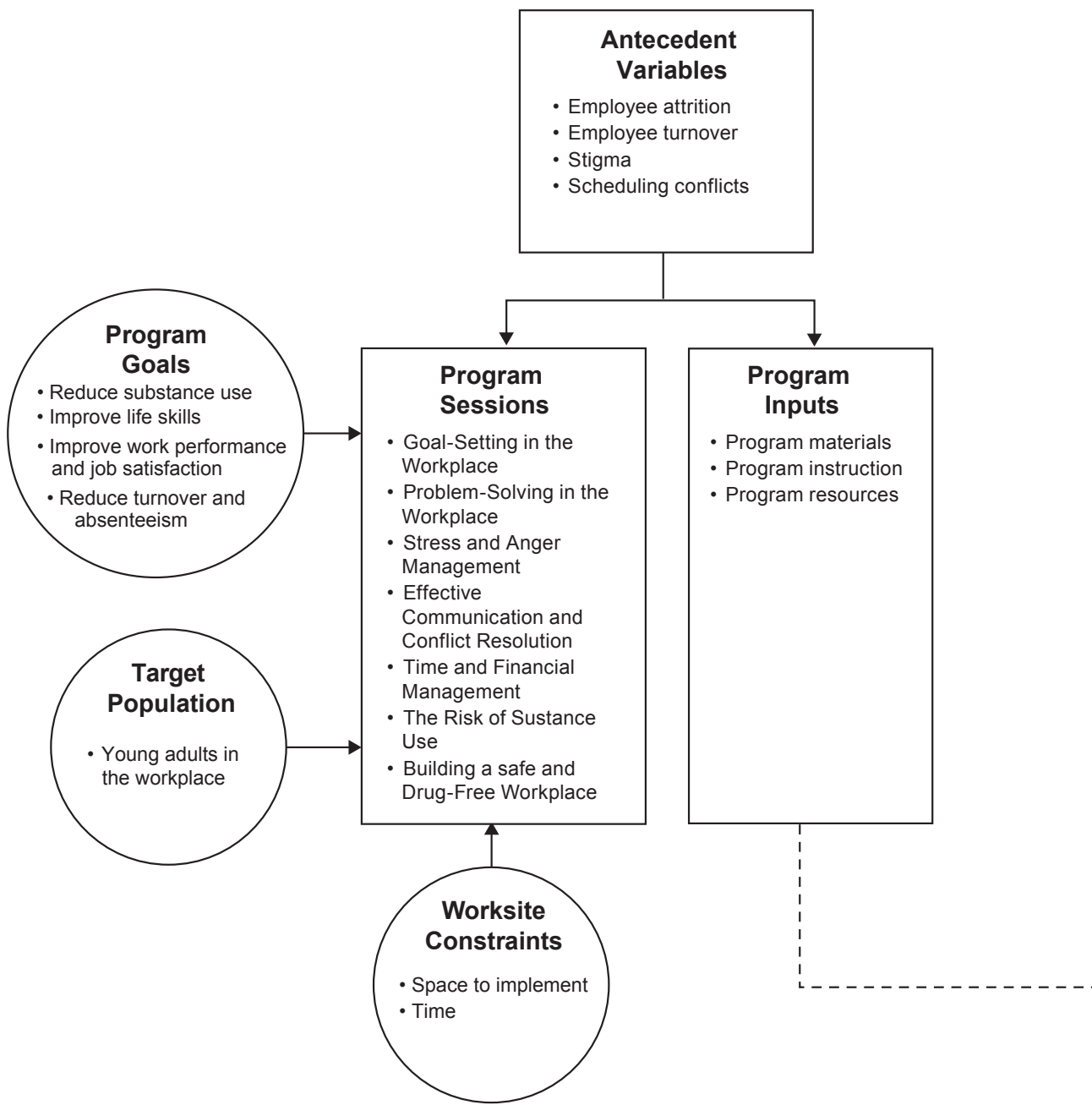


Intermediate outcomes serve to mediate the effects of LST-WP and impact the hypothesized long-term outcomes of the program, which include low rates of substance abuse, changes in mediators associated with decreased substance abuse, improved work performance, and improved life skills. Potential moderator variables that may impact intermediate and long-term outcomes include the use of other programs, such as worksite substance abuse programs and smoking cessation or stress management programs; community-level variables, such as changes in local employment patterns and poverty rates; family-level variables, such as domestic violence, divorce, or substance-using

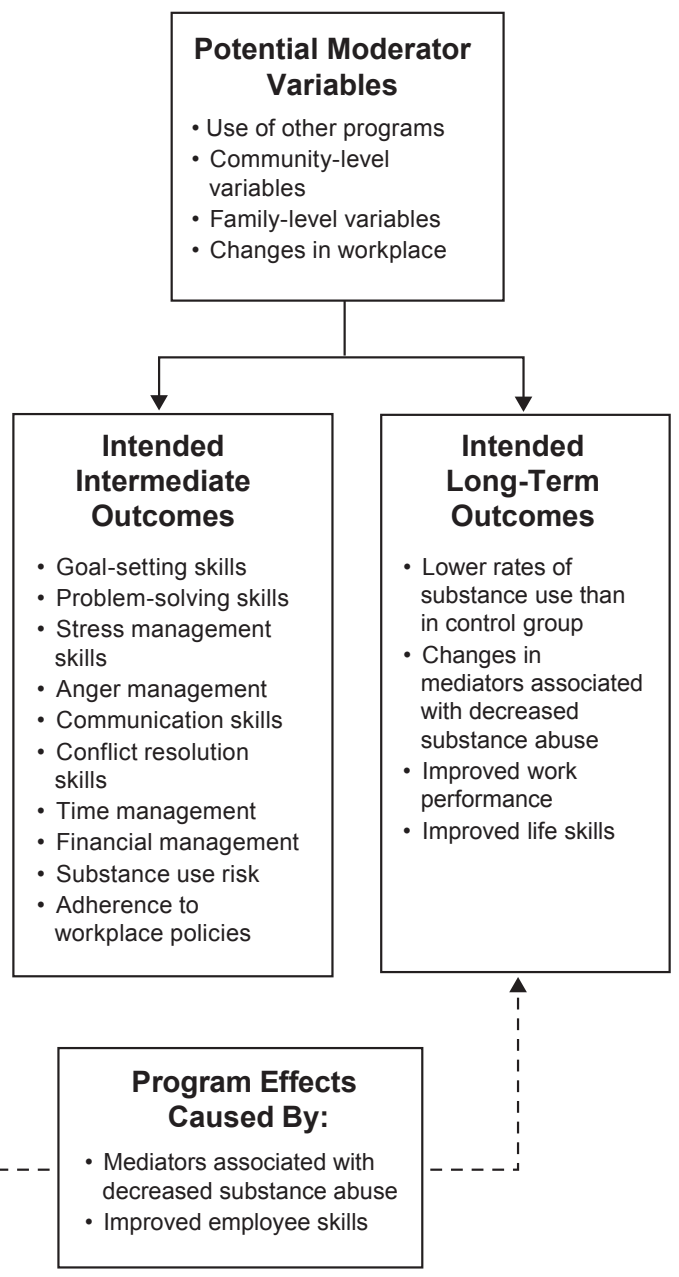


relatives; and changes in workplace policies related to substance use, such as the implementation of employee drug testing.

\section{LST-WP Session Content}

The eight LST-WP sessions are designed to be developmentally appropriate for diverse groups of adolescent and young adult employees and to be flexible in their implementation to meet the varied needs of different work settings. Table 7.1 summarizes the eight sessions.

\section{Table 7.1 LifeSkills Training Wellness Program sessions}

\begin{tabular}{|c|c|c|c|c|c|}
\hline$\stackrel{\longleftarrow}{\varpi}$ & 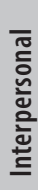 & 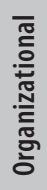 & LST-WP Session & $\begin{array}{l}\text { 능 } \\
\text { ऐo }\end{array}$ & $\stackrel{\dddot{\Xi}}{\leftrightarrows}$ \\
\hline$\bullet$ & & & 1. Goal-Setting in the Workplace (Got Goals....?) & $\bullet$ & \\
\hline$\bullet$ & & & $\begin{array}{l}\text { 2. Problem-Solving in the Workplace (What's the } \\
\text { Problem?) }\end{array}$ & $\bullet$ & • \\
\hline \multirow[t]{5}{*}{$\bullet$} & $\bullet$ & & 3. Stress and Anger Management (Can You Cope?) & $\bullet$ & $\bullet$ \\
\hline & $\bullet$ & $\bullet$ & $\begin{array}{l}4 \text { and 5. (two sessions) Effective Communication } \\
\text { and Conflict Resolution (Let's Talk About It) }\end{array}$ & $\bullet$ & $\bullet$ \\
\hline & $\bullet$ & $\bullet$ & $\begin{array}{l}\text { 6. Time and Financial Management (It's About } \\
\text { Time-and Money) }\end{array}$ & $\bullet$ & • \\
\hline & $\bullet$ & $\bullet$ & 7. The Risk of Substance Use (Risky Business) & $\bullet$ & $\bullet$ \\
\hline & & $\bullet$ & $\begin{array}{l}\text { 8. Building a Safe and Drug-Free Workplace } \\
\text { (Keeping It Safe) }\end{array}$ & $\bullet$ & \\
\hline
\end{tabular}

Each of the eight sessions contains the following four sections: Think About It, Figure It Out, Do It Now, and Make It Happen. Think About It serves as the introductory section and allows the participants to begin exploring the topic. In the Figure It Out section, the session topic is discussed further and the related skills are introduced. The participants then practice these skills in the Do It Now section. The Make It Happen section reviews the session topic and concepts and encourages participants to apply the skills outside of the program workshop. Key vocabulary and relevant tips are interspersed throughout each session.

The LST-WP materials include a Facilitator's Manual and an accompanying participant guide (LifeSkills Planner). In addition to the eight sessions, 
the LifeSkills Planner includes sections for quick tips, a calendar to track milestones, extra worksheets, resources, and selected site-specific workplace policies. Participants are encouraged to use their LifeSkills Planners to practice the skills introduced in the workshop and to use the resource section as a guide to find additional information on the program topics discussed.

Session 1: Goal-Setting in the Workplace. Session 1 teaches participants effective goal-setting, the value of short- and long-term goals, and steps toward reaching these goals using key skills and available resources.

Session 2: Problem-Solving in the Workplace. The problem-solving session is implemented early in the sequence, and program facilitators encourage the integration of the skills learned in this session throughout the remainder of the program. Workshop participants identify common problems that arise in the workplace and then identify factors that influence how people respond to these types of problems. Participants are then introduced to a step-by-step method for effective problem solving and practice applying the technique using the common workplace problems identified previously through group discussion.

Session 3: Stress and Anger Management. Facilitators use group discussion and interactive activities to discuss and practice the session goals. Participants identify the causes of stress and anger in the workplace and their personal lives, the physical symptoms of stress and anger, and common responses to stress and anger. In addition, participants examine personal triggers and the effects of unmanaged stress, and they explore how unmanaged stress in one part of life affects other parts of life. They also practice techniques for stress and anger management.

Sessions 4 and 5: Effective Communication and Conflict Resolution.

Sessions 4 and 5 include individual exercises, group discussion, and activities. Participants identify typical workplace misunderstandings and conflicts and consider their causes. They also explore the effects of misunderstandings and conflicts in the workplace and in one's personal life. Participants learn about verbal and nonverbal communication and are asked to consider the significance of both when communicating. Facilitators introduce specific steps for effective communication and conflict resolution to successfully move from conflict to resolution.

Session 6: Time and Financial Management. Session 6 includes group discussion, individual activities, and an interactive group activity. In this session, participants are asked to assess how much time they spend on various 
activities throughout the course of a typical day and consider whether these activities help bring them closer to achieving their personal goals. They are given strategies to help them use their time more efficiently. In an effort to align their financial habits with efforts to achieve their goals, participants also spend time tracking personal expenses and monies spent. The LifeSkills Planner includes worksheets for attendees to use when creating budgets and setting financial goals.

Session 7: The Risk of Substance Use. Session 7 is delivered toward the end of the workshop and includes group discussion, brainstorming, and large and small group activities. Facilitators encourage participants to use and build on many of their newly acquired skills and strategies to protect themselves against pressures and conditions that might make them susceptible to intrapersonal and interpersonal pressures to engage in risk behaviors. Participants define the terms risk and drug, identify the effects of substance use and abuse on work performance and the work environment, explore the effects of substance use and abuse on personal goals, examine and define the progression of substance use from abstinence to experimentation to social use to abuse to addiction, and examine personal risk factors for the progression of substance use and abuse.

Session 8: Building a Safe and Drug-Free Workplace. Implemented at the end of the workshop, Session 8 orients participants to company policies promoting workplace wellness. Participants are then engaged in discussion and a small group activity to explore how policies contribute to creating and maintaining workplace and personal health.

\section{LST-WP Instructional Techniques}

LST-WP is taught using cognitive-behavioral skills training, facilitated group discussion, demonstrations, and traditional didactic teaching methods. Most of the material in the program is taught by facilitating group discussion and through skills training, although lectures and conventional didactic teaching methods are appropriate for some of the material. Because the major emphasis of LST-WP is on teaching personal self-management skills, social skills, and drug resistance skills, the most important intervention method is skills training. The cognitive-behavioral skills in the program are taught using a combination of instruction, demonstration, behavioral rehearsal, feedback, social reinforcement, and extended practice in the form of behavioral homework assignments.

Instruction and Demonstration. The first step in the skills training process involves instruction and demonstration. Instruction involves explaining a 
particular skill to workshop participants in a careful step-by-step fashion, along with a clear explanation of when to use the skill. Demonstration involves showing attendees how to perform a particular skill. This is done by the program facilitator or by a participant who has already learned the skill being taught.

Behavioral Rehearsal. Once the skill has been explained and demonstrated by the LST-WP facilitator, participants are given the opportunity to practice the skill themselves through selected behavioral rehearsal scenarios. Participants take turns coming to the front of the room to role-play, using the skill being taught. The workshop can also be divided into small groups, with the program facilitator circulating from group to group to observe the participants practicing. The behavioral rehearsal scenarios are first described by the facilitator or a small group leader, and the exercises are kept brief so that as many participants as possible have a chance to participate.

Feedback. After participants rehearse the skills being taught, they are given feedback about the strengths and weaknesses of their skills performance. The facilitator conveys this information in a supportive manner so attendees understand which aspects of the skill they performed well and which need improvement. The facilitator's constructive feedback is designed to guide participants as they strive to improve and successively master the skills being taught.

Social Reinforcement. Because a primary objective of LST-WP is to reduce risk for substance use, the goal of the skills training is to improve the target skills and self-efficacy of each participant. Therefore, participants are assessed individually with respect to improvement over their own baseline levels. During and after the behavioral rehearsal exercises, the facilitator reinforces one or two positive elements of each participant's practice of the skill.

Extended Practice. The extended practice provides opportunities for additional practice of the target skills outside of the workshop to promote skill development and utilization. This is accomplished through behavioral homework assignments, which may include tasks such as repeating a calming self-statement throughout the day or using communicating-for-conflictresolution steps in a situation at work. In addition to providing opportunities for practice in general, extended practice facilitates the use of new skills in situations outside of the workshop and encourages attendees to use these skills at work and in their everyday lives. 


\section{LST-WP Materials}

The Facilitator's Manual provides instruction on strategies for interactive teaching and learning, step-by-step instructions for delivering each session, fully illustrated diagrams of all instructional materials, completed examples of all LifeSkills Planner worksheets, and a comprehensive directory of Web-based and other technical assistance resources for all content areas covered in the curriculum. The LifeSkills Planner contains worksheets, information needed to participate in the activities for each session, extra worksheets for participants to use after the workshop, and resources for all content areas covered in the curriculum.

The Facilitator's Manual and the LifeSkills Planner are organized by the specific sessions. The Facilitator's Manual consists of session materials, an introduction, and resource pages. The LifeSkills Planner consists of exercises and activities for each session to reinforce the knowledge, attitudes, and skills taught in the program. Each workshop participant receives a LifeSkills Planner, which serves as a daily organizational planner for work and personal use. Program facilitators use the Facilitator's Manual to conduct the workshops. Each section includes pages from the LifeSkills Planner. Sections are visibly separated with titled tabs. The session goals, materials needed, key vocabulary, and step-by-step instructions are presented in the beginning of each session. Points to make, relevant examples, and sidebars are included to reinforce key concepts and guide the facilitator through the activity. Reproducible resources are provided where necessary.

\section{LST-WP Implementation Flexibility}

LST-WP is designed to offer an optimal level of implementation flexibility. Facilitators can be either internal or external to a worksite and are equally appropriate to lead workshops when adequately trained. The program is well suited for various kinds of worksites. It is also well suited for young employees who are making their initial entry into the workforce or for employees who have more experience in balancing the tasks, concerns, and stressors of home and work life. In addition, LST-WP was designed specifically to allow flexibility in scheduling so that it could be adopted by employers of shift workers, seasonal workers, or traditional " 9 to 5 " workers.

Flexibility of Providers. The program can be implemented by a variety of providers/facilitators. Ideally, program facilitators would be trained by one of NHPA's expert trainers (see the following section, Program Implementation). NHPA, the training and technical support company for LST, has a large cadre 
of trainers available to train worksite staff to implement LST-WP with a high degree of fidelity. LST-WP can be implemented by staff internal to a given worksite. In large companies, these staff members are typically members of the human resources training department. NHPA's trainers are geographically dispersed to readily offer provider trainingand support services to companies throughout the country. For smaller companies or for those that prefer external facilitators, NHPA trainers can themselves serve as workshop facilitators.

Variety in Worksites and Employees. As part of the training and technical assistance that NHPA provides for LST program clients, we have repeatedly observed that the school-based LST has been effectively implemented in community-based settings, treatment centers, and after-school programs, attesting to the program's versatility. LST-WP can be incorporated easily into a variety of industries with different kinds of employees. The workshop activities are designed to be appropriate for laborers, individuals in administrative roles, and professional-level workers.

Flexibility of Scheduling. LST-WP is designed to offer worksites flexibility regarding how the program is scheduled into the workday. The program can be taught at a rate of one session per week over 8 weeks. Using this implementation strategy, for example, worksites can schedule in-service trainings so that employees can participate in the workshop. An interval between workshops is optimal-even up to 1 month apart-to allow attendees to practice newly acquired skills at home and in their specific work settings. LST-WP can also be programmed as modules or mini-courses so that the entire program is conducted on 1 day or on consecutive days. Both types of schedules have been found to be effective in evaluation studies of the LST school model, suggesting that either implementation strategy could be effective for LST-WP.

\section{Program Implementation}

LST-WP is designed as a self-contained and complete prevention curriculum, giving facilitators all of the necessary program materials in one package. LST-WP is distinguished by the breadth and quality of the implementation materials and the availability of provider training and technical assistance resources. As facilitators go through the decision-making process to adopt LST-WP for the first time or to re-adopt materials, they are encouraged to consult with specially trained staff members who have LST-WP expertise. 


\section{Training and Support Resources}

To ensure the successful implementation of LST-WP, training and technical assistance is provided by NHPA, which has an extensive 12-year history of providing training and technical support for the LST middle school program. NHPA offers professional trainings/workshops each year throughout the United States that take the form of 1-day in-service training workshops for teachers or prevention specialists. However, 2-day or 3-day training workshops are also available, depending on the implementation plan and the needs of a site. The provider-training workshops are informative, interactive, and fun, emphasizing the use of well-established skills training techniques, such as instruction, demonstration, feedback, reinforcement, and practice.

\section{Target Population}

The target population for the YIW initiative is young working adults aged 16 to 24. NHPA and a large supermarket chain collaborated to implement NHPA's LST-WP program. Twenty stores participated and had a combined workforce of nearly 5,000 employees, of which approximately 48 percent fell within the 16 to 24 target age range. The population within these 20 stores was 50 percent male and 84.3 percent white. Educational enrollment is not a consideration in defining the target population. Young adult employees in this supermarket chain typically work as cashiers, baggers, stockers, or clerks or in food preparation.

To support the YIW cross-site evaluation (see Chapter 8 for more information about the cross-site evaluation and the core survey measures), NHPA conducted a survey of LST-WP participants and a comparison sample of employees. Across three waves of data collection, 1,313 employees completed the baseline survey. Demographically, the survey respondents were similar to the target population in the stores. Slightly more than half (51.2 percent) of the survey respondents were male, 83.3 percent were white, and 75.8 percent were under age 21 at the time of their baseline survey.

\section{Process Evaluation Resources}

The implementation team conducted 53 workshops that were attended by 528 young employees. The process evaluation was designed to help determine whether the program was implemented as designed, assess receptivity to the intervention, and identify any events or factors that may have impacted program implementation or other related activities. Information obtained 
from a process evaluation will be meaningful in tracking the program dosage participants receive, informing the revision of program components or methods of program delivery, and facilitating the interpretation of outcome results.

Available process evaluation tools for LST-WP include a Fidelity Checklist, designed to enable the documentation of the programmatic components delivered and the assessment of fidelity of implementation. An Employee Feedback Tool to gauge participants' receptivity to the program is also available.

\section{Fidelity Checklist}

The Fidelity Checklist consists of a three-page questionnaire for each of the eight program sessions. Typically completed by an observer during program implementation, the checklist helps to track a program provider's adherence to the content and design of the program. Each questionnaire contains a series of yes/no items assessing whether the major objectives of the session and the related activities were covered during program implementation. Additionally, each checklist includes items in which the facilitator or observer is asked to estimate the percentage of time spent on lecture, discussion, demonstration, and practice. The checklist also includes an item on the total length of time of the session and an item regarding participants' responsiveness to the content. The average fidelity scores indicated that the majority of sessions adhered to the content and covered the objectives.

\section{Employee Feedback Tool}

Another process evaluation tool is the Employee Feedback Tool, which can be used to obtain participant feedback upon completion of program implementation. This feedback can be used to gauge receptivity to the program and to determine the extent to which participants believe the program and its related materials and activities are useful, interesting, and relevant. The four-page Employee Feedback Tool consists of open- and closed-ended items that assess the following: ease and frequency of use, reaction to the visual presentation of material and content, understanding of concepts presented, perceived utility/benefit of the program, and perceived appropriateness of program components/materials. The tool, which takes approximately 5 minutes to complete, is administered to workshop participants by the program facilitator at the end of each implementation workshop. To maintain anonymity, employees are instructed not to write their names on the forms. 
Results from the Employee Feedback Tool revealed that the LST-WP workshop was well received by the employees, with employees reporting that the program was highly engaging and interesting. The vast majority of participants reported they would be able to use LST-WP skills in their personal life and at work.

\section{Conclusions}

To maintain a productive and viable workforce, health and wellness and disease prevention must continue to be a public health priority. Increasingly, employers are dedicating resources and time to health and wellness programs, such as LST-WP, to foster a healthy, safe, and drug-free workforce, which is linked to lower absenteeism and tardiness, greater job satisfaction and performance, lower turnover, and improved productivity. Prevention efforts offer the opportunity to proactively promote health and wellness and help to reduce costly reactive approaches to substance use, such as drug testing and treatment.

LST-WP is a research-based, innovative health and wellness program for adolescents and young adults in the workplace that is designed to help companies reduce employee health-risk behaviors that impact productivity and profitability. The program empowers employees to successfully balance their work and personal lives by developing skills in essential areas: goal-setting, problem-solving, stress and anger management, effective communication and conflict resolution, time and financial management, management of risky behavior, and workplace safety. It is specially designed to offer an optimal level of flexibility for a variety of employees in a broad range of industries.

As new workplace prevention programs such as LST-WP are developed and tested, it will be critical that the most effective programs reach the employees who can benefit the most from them. To have a meaningful impact on an increasingly competitive workforce and commercial market, researchers, policy makers, and prevention practitioners should explore new ways to enhance the adoption and utilization of workplace prevention programs. A first step will be to ensure that employers are knowledgeable about such programs and receive the necessary training and technical assistance to implement these programs with fidelity and a focus toward long-term sustainability. 


\section{References}

Bandura, A. (1977). Social learning theory. Englewood Cliffs, NJ: Prentice Hall.

Botvin, G. J. (1998). LifeSkills training: Teacher's manual. White Plains, NY: Princeton Health Press.

Botvin, G. J., Baker, E., Dusenbury, L., Botvin, E. M., \& Diaz, T. (1995). Longterm follow-up results of a randomized drug abuse prevention trial in a white middle-class population. Journal of the American Medical Association, 273(14), 1106-1112.

Botvin, G. J., Baker, E., Dusenbury, L., Tortu, S., \& Botvin, E. M. (1990). Preventing adolescent drug abuse through a multimodal cognitivebehavioral approach: Results of a 3-year study. Journal of Consulting \& Clinical Psychology, 58(4), 437-446.

Botvin, G. J., \& Eng, A. (1980). A comprehensive school-based smoking prevention program. Journal of School Health, 50(4), 209-213.

Botvin, G. J., Eng, A., \& Williams, C. L. (1980). Preventing the onset of cigarette smoking through life skills training. Preventive Medicine, 9(1), 135-143.

Botvin, G. J., Griffin, K. W., Diaz, T., \& Ifill-Williams, M. (2001a). Drug abuse prevention among minority adolescents: Posttest and one-year follow-up of a school-based preventive intervention. Prevention Science, 2(1), 1-13.

Botvin, G. J., Griffin, K. W., Diaz, T., \& Ifill-Williams, M. (2001b). Preventing binge drinking during early adolescence: One- and two-year follow-up of a school-based preventive intervention. Psychology of Addictive Behaviors, 15(4), 360-365.

Botvin, G. J., Renick, N. L., \& Baker, E. (1983). The effects of scheduling format and booster sessions on a broad-spectrum psychosocial approach to smoking prevention. Journal of Behavioral Medicine, 6(4), 359-379.

Fraguela, J. A., Martin, A. L., \& Trinanes, E. A. (2003). Drug-abuse prevention in the school: Four-year follow-up of a programme. Psychology in Spain, $7(1), 29-38$.

Griffin, K. W., Botvin, G. J., \& Nichols, T. R. (2004). Long-term follow-up effects of a school-based drug abuse prevention program on adolescent risky driving. Prevention Science, 5(3), 207-212. 
Griffin, K. W., Botvin, G. J., \& Nichols, T. R. (2006). Effects of a school-based drug abuse prevention program for adolescents on HIV risk behavior in young adulthood. Prevention Science, 7(1), 103-112.

Jessor, R., \& Jessor, S. L. (1977). Problem behavior and psychosocial development: A longitudinal study of youth. New York: Academic Press.

Trudeau, L., Spoth, R., Lillehoj, C., Redmond, C., \& Wickrama, K. (2003). Effects of a preventive intervention on adolescent substance use initiation, expectancies, and refusal intentions. Prevention Science, 4(2), 109-122.

Zollinger, T. W., Saywell, R. M., Muegge, C. M., Wooldridge, J. S., Cummings, S. F., \& Caine, V. A. (2003). Impact of the life skills training curriculum on middle school students tobacco use in Marion County, Indiana, 1997-2000. Journal of School Health, 73(9), 338-346. 


\title{
The Young Adults in the Workplace Initiative: Cross-Site Evaluation Methods
}

\author{
Georgia T. Karuntzos, ${ }^{1}$ Jeremy Bray, ${ }^{1}$ Laurie Cluff, ${ }^{1}$ and \\ Deborah M. Galvin² \\ 1RTI International, Research Triangle Park, NC; \\ 2 Substance Abuse and Mental Health Services Administration, Center for Substance \\ Abuse Prevention, Division of Workplace Programs, Rockville, MD
}

\section{Introduction}

Cross-site evaluations have become a common methodology to provide the best evidence possible from studies examining complex social phenomena. Cross-site evaluations are designed to compare program characteristics across multiple venues, to use common data across sites, and to identify the relative effectiveness of programs and program characteristics (Sambrano et al., 2005; Sinacore \& Turpin, 1991; Straw \& Herrell, 2002). Unlike clinical trials, which test programs under ideal settings, cross-site (or multisite) evaluations often test the impact of different programmatic and design elements as they are implemented in real-world settings. Government agencies are increasingly turning to cross-site evaluations of the programs they sponsor to ensure accountability of the individuals and organizations they fund, to inform policy decisions, and to gain an understanding of how government-funded programs affect targeted populations.

This chapter provides an overview of the design and methods of the Young Adults in the Workplace (YIW) cross-site evaluation. By assessing program content and implementation processes, identifying diversity in the YIW interventions and populations, and using this diversity to examine the workplace and programmatic characteristics that mediate and moderate the effectiveness of various intervention components and strategies, the crosssite evaluation will provide the Substance Abuse and Mental Health Services Administration (SAMHSA) with knowledge to meet the objectives of the YIW initiative. 


\section{Overview of the YIW Initiative}

The YIW initiative includes several interrelated components that enable SAMHSA to integrate data across funded programs, allowing the agency to examine program effectiveness at the program and cross-site levels and to use expert knowledge to strengthen each component to best inform public policy at the national level. Chapter 1 provides a detailed description of the YIW initiative; here we provide a brief overview that establishes the framework for the cross-site evaluation.

As depicted in Figure 8.1, the YIW cross-site components include technical assistance to the grantees to strengthen program implementation and granteelevel evaluations, cross-site data collection to support a cross-site evaluation, consultation and knowledge exchange workshops to provide expert input at all levels of the evaluation, and knowledge dissemination to ensure the transfer of information from service to science. The cross-site data collection initiative is informed by SAMHSA's national outcome measures (NOMs), a set of outcome measures that SAMHSA discretionary grant recipients are required to collect and that SAMHSA uses to assess the performance of its prevention programs. The required adult NOMs items measure past-30-day alcohol and other drug

Figure 8.1 Young Adults in the Workplace initiative

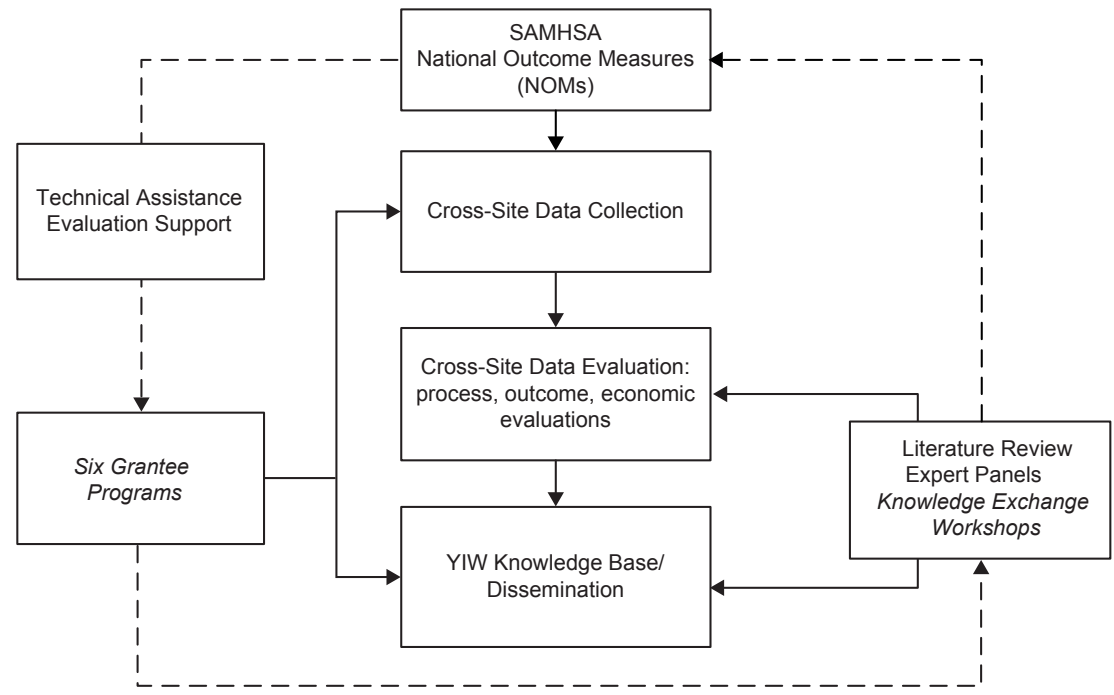

SAMHSA = Substance Abuse and Mental Health Services Administration; CSAP = Center for Substance Abuse Prevention; YIW = Young Adults in the Workplace. 
use, age of first use, perceived risk/harm of use, perception of workplace policy, workplace alcohol and other drug use, and family communication around drug use. The YIW Steering Committee, composed of the SAMHSA project officer, grantee representatives, and the cross-site evaluators, incorporated the NOMs items into a set of core cross-site measures. These measures were included in an employee survey administered by the grantees that generated the longitudinal data to be used for the cross-site evaluation. In addition, substantive and methodological input from subject matter experts and consultants was incorporated in all aspects of the evaluation to ensure its success. Together, these components generate the knowledge base that meets SAMHSA's needs and broadens the prevention field.

\section{YIW Cross-Site Evaluation}

The cross-site evaluation incorporates three interrelated studies that provide a comprehensive evaluation of the YIW initiative: a process study, an outcome study, and an economic study. Combined, these three studies provide a framework to understand what constitutes the YIW interventions, how they were implemented at the partnering worksites, what effects they had on employees, and what value they provided to employers. In the following sections, we discuss our rationale and approach for each of these studies.

\section{Process Study}

Over the past few decades, evaluators and health services researchers have learned that intervention effectiveness findings must be interpreted within the context of the environment in which the intervention was implemented and the actual (as opposed to the intended) implementation process (Karuntzos, 2004; Millar et al., 2001; Steckler \& Linnan, 2002; Yin, 1998). Historically, poorly implemented, poorly documented, or poorly understood interventions are among the most common reasons for misinterpreting the results of field trials. Consequently, many evaluation methodologists (Dennis, 1990; Fairweather \& Tornatzky, 1977; Scott \& Sechrest, 1989; Sechrest et al., 1979) have emphasized the importance of measuring the actual intervention received in terms of its timing, duration, intensity, content, and context.

For the YIW initiative, process data were collected prospectively by the grantees to inform the cross-site evaluation and aid in the interpretation of the 
cross-site findings. These data are primarily descriptive and will answer the following core evaluation questions:

- What prevention/early intervention programs were implemented?

- How the were programs implemented?

- What individual and contextual factors are related to program effectiveness?

In developing the YIW process measures, we emphasized the need for these measures to document (1) the underlying logic or theoretical models of the grantees' programs and (2) the actual implementation and delivery strategy. As part of the process study documentation, the grantees were asked to

- describe and document the development and evolution of their prevention and early intervention programs,

- document the interventions actually implemented,

- document the operational features and factors affecting their operation,

- delineate the strategies used in implementing the programs and any barriers to implementation,

- describe the contexts in which the programs were implemented,

- document the sociodemographic characteristics of the people served by the YIW programs and the types and amounts of services they received, and

- provide quantitative information related to how much of the interventions were received by the target populations.

The YIW process measures (shown in Table 8.1) provide the basis for combining the quantitative data by identifying common program features and suggest hypotheses to be tested in the outcome and economic studies. In the next sections, we present more information about program, participant, and worksite characteristics across the six grantees. Information about the programs was gathered from the grantee process studies. Some of the information about the participants is based on survey data collected by each grantee. We conclude with a section describing early process findings related to program implementation. 
Table 8.1 Process study measures collected by all YIW grantees

\begin{tabular}{|c|c|}
\hline Content & $\begin{array}{l}\text { - Program goals/objectives and if/how they evolved during Phase I } \\
\text { - Target population with whom the program is being implemented } \\
\text { - Components/key activities of the prevention/early intervention } \\
\text { program } \\
\text { - Historical initiation/implementation and program design changes for } \\
\text { working young adults aged } 16 \text { to } 24 \\
\text { - System access and mechanisms used to deliver the program } \\
\text { components } \\
\text { - Program outputs/products that result from the program }\end{array}$ \\
\hline Context & $\begin{array}{l}\text { - Socioeconomic context in which the program is implemented } \\
\text { - Antecedent variables or known factors outside of the program that } \\
\text { might affect the program outputs or put the program success at risk }\end{array}$ \\
\hline Utility & $\begin{array}{l}\text { - Intended intermediate outcomes } \\
\text { - Intended long-term outcomes }\end{array}$ \\
\hline $\begin{array}{l}\text { Adoption and } \\
\text { implementation }\end{array}$ & $\begin{array}{l}\text { - Available and/or required resources for supporting the program } \\
\text { during the study period and beyond } \\
\text { - Key stakeholders within and outside the worksite who will influence } \\
\text { program implementation during the study period and beyond } \\
\text { - Timeline for implementing the program } \\
\text { - Implementation steps }\end{array}$ \\
\hline Schedule & $\begin{array}{l}\text { - Timing and duration } \\
\text { - Participant groupsize and characteristics } \\
\text { - Staff size, characteristics, and level of effort }\end{array}$ \\
\hline Intensity & $\begin{array}{l}\text { - Exposure } \\
\text { - Dosage }\end{array}$ \\
\hline Lessons learned & \\
\hline
\end{tabular}

YIW = Young Adults in the Workplace.

\section{Program Characteristics}

To understand which prevention programs were implemented, we have organized the information provided in each grantee's individual process study into a table showing common intervention strategies and program types (Table 8.2). We reviewed grantee program descriptions and classified the six programs into four types: Health Promotion, Life Skills Training, Peer Intervention, and Team Training. We looked across the programs and further classified the program content into four main categories: Substance 
Use, General Health, Team Skills, and Life Skills. Finally, within each of these four broad categories, we specified more detailed components (e.g., problem solving, communication) and indicated in Table 8.2 which components are implemented within each program.

As expected, all six programs include alcohol and other drug components. All programs also include a stress component. The integration of substance use components within general health and health promotion messaging builds on research emphasizing the importance of blended messaging to engage participants and avoid the unintended stigma of prevention messaging in the workplace (Cook et al., 2003). Most programs also include content addressing communication as part of team skills and problem solving as part of life skills training, and most programs emphasize general desired work habits for young adults.

\section{Table 8.2 Program commonalities}

\begin{tabular}{|c|c|c|c|c|c|c|c|c|c|c|c|c|c|c|c|c|c|}
\hline \multirow[b]{2}{*}{$\begin{array}{l}\text { Program } \\
\text { Type }\end{array}$} & \multicolumn{3}{|c|}{$\begin{array}{c}\text { Substance } \\
\text { Use }\end{array}$} & \multicolumn{3}{|c|}{$\begin{array}{l}\text { General } \\
\text { Health }\end{array}$} & \multicolumn{3}{|c|}{$\begin{array}{l}\text { Team } \\
\text { Skills }\end{array}$} & \multicolumn{8}{|c|}{$\begin{array}{l}\text { Life } \\
\text { Skills }\end{array}$} \\
\hline & 气ั & 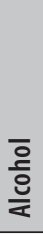 & $\begin{array}{l}\stackrel{0}{\pi} \\
\text { 응 }\end{array}$ & 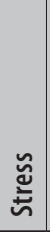 & 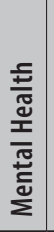 & 竞 & 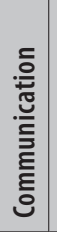 & 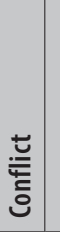 & 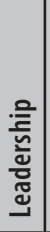 & 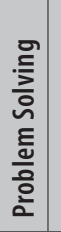 & 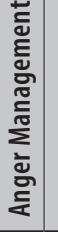 & 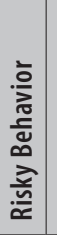 & 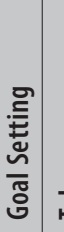 & 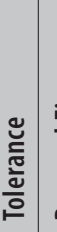 & 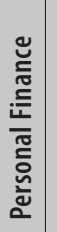 & $\stackrel{\Xi}{\underline{\underline{E}}}$ & \\
\hline $\begin{array}{l}\text { Health } \\
\text { Promotion } \\
\text { (Hospital) }\end{array}$ & $\bullet$ & • & & $\bullet$ & & $\bullet$ & & & & & • & & & & & & \\
\hline $\begin{array}{l}\text { Peer } \\
\text { Intervention } \\
\text { (Transportation) }\end{array}$ & $\bullet$ & • & $\bullet$ & $\bullet$ & $\bullet$ & & $\bullet$ & $\bullet$ & & $\bullet$ & & & $\bullet$ & & • & & • \\
\hline $\begin{array}{l}\text { Team Training } \\
\text { (Restaurant) }\end{array}$ & $\bullet$ & $\bullet$ & & $\bullet$ & & & $\bullet$ & & & $\bullet$ & & $\bullet$ & • & $\bullet$ & & & • \\
\hline $\begin{array}{l}\text { Team Training } \\
\text { (Electricians' } \\
\text { Union) }\end{array}$ & $\bullet$ & $\bullet$ & & $\bullet$ & & & $\bullet$ & $\bullet$ & • & $\bullet$ & $\bullet$ & $\bullet$ & & & & & $\bullet$ \\
\hline $\begin{array}{l}\text { Team Training } \\
\text { (Workforce } \\
\text { Development) }\end{array}$ & $\bullet$ & $\bullet$ & $\bullet$ & $\bullet$ & $\bullet$ & & $\bullet$ & & & & & $\bullet$ & & $\bullet$ & & & • \\
\hline $\begin{array}{l}\text { Life Skills } \\
\text { Training } \\
\text { (Supermarket } \\
\text { Chain) }\end{array}$ & $\bullet$ & $\bullet$ & $\bullet$ & $\bullet$ & & & $\bullet$ & $\bullet$ & & $\bullet$ & $\bullet$ & & & & $\bullet$ & $\bullet$ & \\
\hline
\end{tabular}




\section{Participant and Workship Characteristics}

To examine the participant and worksite characteristics, we used the baseline survey data collected from more than 3,000 respondents across approximately 160 worksites. The mean age of the respondents is 20.8 years, with 89 percent in the target age range of 16 to 24 and almost 66 percent under age 21 . Slightly more than half of the respondents (54 percent) are male, and nearly threequarters are white ( 74 percent); 17 percent are black, 2 percent are Asian, and 5 percent are mixed race. Roughly 13 percent indicated that they are of Hispanic ethnicity. Only 5 percent of the respondents are married, and 54 percent are currently in school. Just a fraction of these young respondents have a bachelor's degree (5 percent) or some graduate school (2 percent), although one-third have some postsecondary education. Thirty percent of respondents indicated that their highest level of education was a high school diploma, and 29 percent still have less than a high school diploma.

The baseline survey included NOM items measuring substance use and alcohol-related behaviors. The majority of respondents reported using cigarettes (64 percent), alcohol (83 percent), and marijuana (53 percent) during their lifetime, whereas a smaller percentage reported using other drugs (21 percent). The mean age at first use for respondents who had ever used cigarettes, alcohol, or marijuana was about 15 years of age for each substance. In terms of current use (within the 30 days before completing the survey), 38 percent reported that they had smoked cigarettes, 58 percent had drunk alcohol, 17 percent had used marijuana, and 4 percent had used other drugs. With regard to alcohol-related risky behaviors, 38 percent of respondents reported binge drinking within the past 30 days, and 17 percent reported driving under the influence of alcohol within the past year. A small percentage (4 percent) admitted to drinking at work during the past 30 days, which includes lunch hours and breaks.

The YIW baseline findings are similar to the 2007 National Survey on Drug Use and Health (NSDUH) results (SAMHSA, 2008) for young adults aged 18 to 25 . NSDUH results estimated that 36 percent of young adults in this age range smoked cigarettes, 16 percent used marijuana, 42 percent had engaged in binge drinking within the past 30 days, and 23 percent had driven under the influence of alcohol within the past year. The NSDUH subgroup is slightly older than the YIW target population of 16- to 24-year-olds, which could account for some of the higher alcohol-related percentages in the NSDUH estimates. 
When we analyze and interpret the employee survey data for the cross-site evaluation, we will consider several possible confounding variables that may help to explain the cross-site outcomes. Some of these potential confounding variables were highlighted by the grantees' process studies, including employee age, level of education, employee turnover, and the status of workplace drug testing policies.

\section{Program Implementation}

As described in Chapter 1, the YIW initiative proceeded in two phases. During the first phase (years 1 and 2 of the initiative), the grantees adapted evidencebased prevention programs to better meet the needs of young working adults. The grantees also piloted the adapted interventions to assure successful implementation during the second phase of the initiative. In the second phase, the grantees are implementing and evaluating the effectiveness of their interventions.

We examined the grantee process study reports across the two phases for themes related to contextual factors that influenced program implementation and outcomes. Preliminary process data across grantees revealed several important considerations related to program adaptation and program reach for young working adults. Procedurally, the grantees emphasized the importance of engaging both managers and young adults in the intervention tailoring process. A common contextual factor that workplace managers reinforced was the importance of social connectedness and peer influence on younger workers. To engage young adults, the grantees learned not to underestimate the importance of relevance and engagement in prevention messaging and methods. Both managers and young adult employees agreed that framing substance abuse prevention in the larger holistic context of health (both physical and emotional) is essential for message delivery and participant buy-in. Both groups also agreed that making the connection between health behaviors and tangible outcomes relevant to young adults (e.g., getting ahead at work or being at the top of your game) will make the messages more appealing to the target population. Other process findings revealed that supervisors and managers require training on issues related to young adults. On the other hand, in some industries (e.g., service organizations), supervisors are likely to be young adults themselves, suggesting the potential importance of supervisors as positive role models for younger employees.

The process data also provided some valuable insights into the ideal methods for delivering prevention messages to young adults, including using 
multimedia technology (e.g., Internet, message boards, podcasts) to deliver the message and incorporating skills training to build content knowledge and application. Program participants and supervisors recommended incorporating prevention efforts into mandatory trainings and orientations, allocating work time and resources to training and professional development, and providing program incentives for employees to maximize employee engagement and program reach.

In addition to recommendations for successful program implementation, grantee process studies also exposed barriers that needed to be overcome in implementing workplace prevention programs. These included alleviating employee fears that participation would be perceived negatively by direct supervisors, addressing manager concerns about lost productivity because of employee time away from work, securing full buy-in from all supervisors and managers prior to program implementation, and enhancing access to participants through internal communication channels. These early process findings have informed program adaptations and delivery across all six grant programs.

Additional process data collected by each grantee include program participation records documenting the number of sessions delivered, the number of participants reached within each session, and the resources used to deliver each session. We will use these additional process measures of reach (i.e., what percentage of the target population actually received the intervention) and dose (i.e., how much of the intervention was delivered) to aid the interpretation of the outcome findings. Conclusions related to the effectiveness of the programs will be informed by the extent to which the programs were implemented successfully across grantees. As noted earlier in this chapter, fully understanding the context and actual implementation of the interventions is important for accurately interpreting the outcome data. These data provide the foundation for the cross-site evaluation outcome study we describe next.

\section{Outcome Study}

Building on the process study, the outcome study provides information on the effect of the YIW interventions on the participants and the workplaces involved. The outcome study relies on the grantee-level randomization designs to generate the cross-site comparison groups. Randomization levels across grantees included worksite locations, departments, work shifts, classrooms, and staggered cohorts within a worksite. To the extent possible, the outcome 
study accounts for grantee-level group variation in our analytic approach. The outcome study also provides evidence on how specific workplace and programmatic characteristics identified by the process study relate to effectiveness. The cross-site outcome study questions are as follows:

1. Are there differences in outcomes for individuals who participate in substance abuse prevention/early intervention programs relative to individuals who do not?

2. What is the relative impact of specific content areas on the intended outcomes?

3. What is the relative effectiveness of the varying types/settings of prevention/early intervention programs?

4. What program content areas are most effective in which program types/ settings?

\section{Outcome Data}

To answer the cross-site outcome questions, the YIW Steering Committee adopted a set of core outcome measures that were collected through selfreport employee surveys across all grantees. These surveys were completed by the young working adults selected for study participation. The domains, brief descriptions, and references for the YIW core outcome measures are listed in Table 8.3. The SAMHSA NOMs address outcomes related to substance use behavior and perceptions of risk related to substance use. Additional core items assess workplace outcomes and individual and contextual factors that we hypothesize mediate or moderate program effectiveness. These measures include awareness of and willingness to use prevention and early intervention programs; job satisfaction; and measures of mental health, including risk taking, sensation seeking, psychological distress, and stress.

In addition to the self-report survey data, the cross-site evaluation uses worksite-level aggregate administrative data (e.g., demographic composition, injuries, absences) to validate the self-reported outcomes from the survey (e.g., prevalence of injuries at the worksite), to inform the interpretation of the outcome measures (e.g., significant changes at the workplace that could influence survey reports), and to check the extent to which the worksite survey sample is demographically representative of the worksite population. Grantees submitted administrative data biannually to correspond to the time frames of the survey data. 


\section{Table 8.3 YIW core measures}

\begin{tabular}{|c|c|c|}
\hline Domain(s) & Description & Reference \\
\hline Demographics & $\begin{array}{l}\text { Basic demographics (e.g., age, } \\
\text { gender, race) }\end{array}$ & SAMHSA, 2008 \\
\hline \multicolumn{3}{|l|}{ Workplace outcomes } \\
\hline \multirow[t]{2}{*}{$\begin{array}{l}\text { Absenteeism/ } \\
\text { presenteeism, injuries }\end{array}$} & $\begin{array}{l}\text { Work performance/quality in } \\
\text { past } 4 \text { weeks }\end{array}$ & $\begin{array}{l}\text { Kessler et al., 2003, 2004; } \\
\text { Wang et al., } 2003\end{array}$ \\
\hline & $\begin{array}{l}\text { Performance compared with } \\
\text { past and compared with } \\
\text { coworkers }\end{array}$ & \\
\hline Job satisfaction & $\begin{array}{l}\text { Satisfaction with job and kind } \\
\text { of job }\end{array}$ & Hackman \& Oldham, 1975 \\
\hline $\begin{array}{l}\text { Program implementation } \\
\text { and satisfaction }\end{array}$ & $\begin{array}{l}\text { Program awareness, willingness } \\
\text { to use, use, and satisfaction }\end{array}$ & \\
\hline Substance use & $\begin{array}{l}\text { Quantity and frequency of } \\
\text { substance use }\end{array}$ & SAMHSA, 2008 \\
\hline Perceptions of risk & $\begin{array}{l}\text { Perceptions of risk to physical } \\
\text { and other health, based on } \\
\text { frequency of substance use }\end{array}$ & SAMHSA, 2008 \\
\hline \multicolumn{3}{|l|}{ Mental health } \\
\hline $\begin{array}{l}\text { Risk taking/ sensation } \\
\text { seeking }\end{array}$ & $\begin{array}{l}\text { One scale measuring two } \\
\text { factors: impulsivity and } \\
\text { sensation seeking }\end{array}$ & $\begin{array}{l}\text { McDaniel \& Zuckerman, } \\
\text { 2003; Zuckerman, } 2002\end{array}$ \\
\hline Psychological distress & $\begin{array}{l}\text { Symptoms of depression plus } \\
\text { a question about resulting } \\
\text { impairment }\end{array}$ & $\begin{array}{l}\text { Corson et al., 2004; Kroenke } \\
\text { et al., 2001; Lowe et al., 2004; } \\
\text { Spitzer et al., } 1999\end{array}$ \\
\hline Stress & Perceived stress in past month & $\begin{array}{l}\text { Cohen \& Williamson, 1988; } \\
\text { Sheu et al., 2002; Siqueira } \\
\text { et al., 2000; Zaré et al., } 2004\end{array}$ \\
\hline
\end{tabular}

NOMs = National Outcome Measures; SAMHSA = Substance Abuse and Mental Health Services Administration; YIW = Young Adults in the Workplace.

\section{Outcome Study Analysis Plan}

Because the YIW initiative is a multisite, multiprotocol study, the cross-site evaluation uses analytic approaches that account for the variation in program components implemented across grantees. Although each prevention program included substance abuse prevention messaging as a core element, the overall program characteristics varied considerably across grantees. To account for this variation, our primary analysis plan uses and extends traditional dismantling designs for component analysis to determine how each set of components relates to program effectiveness. A dismantling strategy compares 
a full program to a version of the program where at least one component is removed, allowing for a distinction of the incremental impact of each program component. (MacKinnon et al., 2002; West \& Aiken, 1997). Because the grantees developed their prevention and early intervention programs independently, the YIW outcome study uses a dismantling design in which the critical intervention components to be tested are identified through the process studies after (ex post) program implementation. This ensures that the interventions being evaluated are truly feasible in the real world as compared to standard methods in which all aspects of the intervention are defined in advance (ex ante) and tightly controlled to ensure adherence to that definition. Although ex ante methods ensure the fidelity of the intervention, they provide little to no evidence on the practicality of the interventions in real-world settings.

The cross-site outcome study design hinges on the quality of the process data collected by each grantee and the meaningful cross-grantee comparison or combination of the intervention content. We based our comparisons on the commonality of topics within a substantive domain, the method of delivery, and the time spent on each topic. We collected detailed information through the grantee process and cost studies on the actual content and delivery time across interventions in the four domain areas identified in the commonality matrix shown in Table 8.2: Substance Use, General Health, Team Skills, and Life Skills.

The next step in our analysis plan tests the effect of these four content domains on the outcomes by using a hierarchical linear model or a generalized linear mixed model framework (Breslow \& Clayton, 1993). Because the grantees implemented a group randomized pre-post design and collected at least one baseline and two post-intervention data points at 6 and 12 months, the grantee-level designs and data structures suggest a cross-site multilevel or nested design in which the activities at one level are influenced by those at a higher level. For example, employees' behaviors are influenced by experience and attitudes of individual employees; by the amount and nature of the intervention that they receive; and by worksite characteristics and contextual elements, such as tolerance and policy. By observing individuals within groups and over time, we can incorporate all of these influences, each of which varies at a different level. Our modeling framework is an extension of the dismantling strategy that permits the tests of hypotheses at the intervention component, worksite, and individual levels. Appendix A provides additional technical information related to our modeling approach. 
By examining the relative contribution of the various content areas to the overall effectiveness of the YIW interventions, the YIW cross-site outcome analysis allows conclusions to be drawn about program effectiveness that are broader than any one grantee could make. The analysis framework also allows us to capitalize on demographic and programmatic differences across grantee populations to better examine what works best for whom. By integrating these findings with the findings from the process and economic studies, we can provide valuable information to worksites that are considering implementing programs similar to those implemented by the YIW grantees.

\section{Economic Study}

The third and final component of the cross-site evaluation is an economic study of the prevention and early intervention programs that provides information on the cost, cost- effectiveness, and cost-benefit ratio of the interventions. The cost-effectiveness analysis will compare the relative costs and outcomes (effects) related to the intervention, and the cost-benefit analysis will assign a monetary value (when appropriate) to the measures of effectiveness. Typically the cost-effectiveness analysis is expressed in terms of a ratio whose denominator is a gain in measure of effectiveness (e.g. substance use) and whose numerator is the cost associated with the gain. The economic study uses information obtained from the process and outcome studies to assess the value of the interventions to various stakeholders. The cross-site economic evaluation questions are as follows:

1. What resources are used in the delivery of the prevention and early intervention programs?

2. What resources are used in the delivery of specific content areas of the programs?

3. Do the costs of program content areas vary by program type or setting or other key program characteristics?

4. What is the cost-effectiveness or cost-benefit ratio of each program?

5. What is the cost-effectiveness or cost-benefit ratio of the various program content areas?

6. Are some program content areas more cost-effective in one program type or setting relative to another?

The economic study will be conducted primarily from the perspective of the workplace. That is, we will estimate how much it costs the workplace to deliver 
each intervention, and we will estimate how much workplaces save through improving workplace-related outcomes, such as absenteeism and productivity. In addition, because the cross-site evaluation plan is designed to dismantle the programs into content areas across grantees, we can combine cost and effectiveness data for similar content areas across workplaces to calculate the average cost, cost-effectiveness, and cost-benefit ratio of that content over all of the workplaces. Below we discuss our approach for the economic study.

\section{Cost Analysis}

A cost analysis is the first step in a full economic study of any intervention. Cost analyses provide the amount of resources used and dollar estimates and also identify the key drivers of cost, allowing decision makers to identify critical cost components of the intervention. YIW grantees collected cost data for their prevention/early intervention programs using customized cost instruments based on the Substance Abuse Services Cost Analysis Program (SASCAP) methodology developed at RTI International (Zarkin et al., 2004). Cross-site economists provide technical assistance to the grantees on the customization of cost instruments and on the resulting data collection. The instrument is divided into two parts: one part collects information on the allocation of resources across services, and the other part collects unit cost information, such as wages or space rental rates. Although grantees may have used the unit costs collected via SASCAP for their own site-level cost analyses, the cross-site cost analyses used standardized unit cost data so that any cost differences across grantees were driven by differential resource use and not by cost-of-living differences across the grantees' geographic locations.

The resource allocation part of the instrument was completed by a key stakeholder, typically the project director at each site. The project director provided the job description of personnel performing each intervention, the number of personnel performing the intervention, and the total number of hours each staff member spent performing the intervention in a typical week. An important feature of the YIW costing methodology is that the data are validated by extensive review and follow-up telephone interviews conducted by the cross-site evaluation team.

Once resource use and standardized unit cost data were collected, the costs of the prevention/early intervention programs and their content areas were calculated. Given the variation in interventions across grantee programs, we calculated costs as the average costs of the program. An average cost estimate provides financial information that is normalized to adjust for program size 
and/or dose level/exposure to the intervention. This adjustment factor will allow programs of different sizes to be compared and analyzed in a meaningful way.

When calculating average program cost, several alternative values can be used as the normalizing factor. One option is to calculate the average cost per eligible employee. This method will return the smallest average cost estimate because it spreads the total program cost over all employees who are eligible to use the program, regardless of whether they received services. Another option is to calculate the average cost per employee served. This method will return a larger average cost estimate than the first method because it only accounts for employees who received services. Both cost estimates provide meaningful data to inform program adoption. The YIW cost analysis calculates cost per employee served. The cost estimates provided in Table 8.4 present average cost per employee served across grantee programs.

The variation in total costs is driven primarily by the variations in the length of the interventions, the numbers of persons served, and the participant wages. As summarized earlier in this chapter and described in detail in Chapters 2 through 7 , the interventions implemented across grantee programs varied in the number of sessions delivered and in the length of each session. For example, ISA's interactive DVD included three modules, each lasting 45 minutes; National Health Promotion Associates' group workshops included eight content sessions for a total of 200 minutes; and Pacific Institute for Research and Evaluation's program included six modules delivered in about 915 minutes over 2 days. The three grantees implementing adaptations of Team Awareness ranged from Peer Assistance Services/OMNI Institute's program of six modules delivered in about 320 minutes to RMC Research Corporation's program of six modules delivered in two 240-minute sessions, to Organizational Wellness \& Learning Systems' program of nine modules delivered in about 435 minutes over 3 days.

The content was tailored to the target population and adapted for the workplace, which resulted in program delivery strategies that varied in approach and program length. The programs also varied in the size of the groups served within sessions. This variation was a function of the delivery approach (e.g., classroom versus small group interactive sessions) and the availability of employees to participate in the sessions based on workflow and work assignments. The cost variation in wages is primarily related to occupation, level of education or training, and industry of employees. 
Table 8.4 Estimated per-person cost of providing YIW intervention, by grantee

\begin{tabular}{lcccc} 
& \multicolumn{4}{c}{ Total Cost } \\
\cline { 2 - 5 } Grantee & $\begin{array}{c}\text { Excluding } \\
\text { incentives and } \\
\text { employee wages }\end{array}$ & $\begin{array}{c}\text { Including } \\
\text { employee } \\
\text { wages }\end{array}$ & $\begin{array}{c}\text { Including } \\
\text { incentives }\end{array}$ & $\begin{array}{c}\text { Including } \\
\text { incentives and } \\
\text { employee wages }\end{array}$ \\
\hline ISA & $\$ 0.14$ & $\$ 67.73$ & $\$ 25.14$ & $\$ 92.73$ \\
\hline NHPA & $\$ 16.86$ & $\$ 48.83$ & $\$ 16.86$ & $\$ 48.83$ \\
\hline OWLS & $\$ 47.31$ & $\$ 105.53$ & $\$ 67.31$ & $\$ 125.53$ \\
\hline PAS-OMNI & $\$ 57.28$ & $\$ 126.71$ & $\$ 57.28$ & $\$ 126.71$ \\
\hline PIRE & $\$ 51.82$ & $\$ 366.47$ & $\$ 51.82$ & $\$ 366.47$ \\
\hline RMC & $\$ 22.67$ & $\$ 81.15$ & $\$ 22.67$ & $\$ 81.15$ \\
\hline
\end{tabular}

ISA = ISA Associates, Inc; NHPA = National Health Promotion Associates; OWLS = Organizational Wellness \& Learning Systems; PAS-OMNI = Peer Assistance Services/OMNI Institute; PIRE = Pacific Institute for Research and Evaluation: RMC $=$ RMC Research Corporation.

The average program costs presented in Table 8.4 will be used as the cost component for the cost-benefit and cost-effectiveness analyses.

\section{Cost-Benefit and Cost-Effectiveness Analysis}

Two basic methods can be used to compare a program's benefits with its costs. The first method is a return on investment, in which the benefits are expressed as a percentage return to the investment represented by the program costs. The second method is a net benefit measure, in which costs are subtracted from benefits. We will conduct cost-benefit analyses using both methods. The outcomes that will be used for the cost-benefit analysis will primarily be workplace outcomes (e.g., absenteeism, productivity) because they can be assigned dollar values more readily, and they are more meaningful to workplaces that might consider adopting one of the YIW prevention programs. We will combine the cost of each content area and of the programs overall (see Table 8.4) with outcome data from the cross-site survey to obtain the change in cost for an incremental change in the outcome. The unit cost of the outcomes (e.g., employee wages, the cost of health care services) will come from literature reviews and administrative data from the workplace.

We will also calculate cost-effectiveness ratios for selected outcomes. The first step in calculating the cost-effectiveness ratios is to tabulate the costs and outcome measures for each intervention under study in increasing order of effectiveness (or cost). Starting with the intervention with the smallest 
effectiveness (or cost), cost-effectiveness ratios are then computed for each intervention relative to the next most effective option after eliminating intervention options that are dominated by other interventions (Siegel et al., 1996). An intervention may be dominated in either a simple sense (higher cost and lower effectiveness than another option) or in an extended sense (higher cost-effectiveness ratio than a more effective option). The cross-site evaluation team, along with the steering committee, will decide on appropriate outcomes to be used for the cost-benefit analysis and the cost-effectiveness analysis.

After we have completed the cost-effectiveness analysis, we will conduct sensitivity analyses. The objective of a sensitivity analysis is to assess whether the cost-effectiveness results are affected by changes in model parameters, such as unit cost estimates of the economic outcomes. We will perform oneway sensitivity analyses to examine the effect of changing one of the model parameters (e.g., cost per day absent), holding all other parameters constant. We will also perform n-way sensitivity analyses in which $\mathrm{n}$ parameters of the model are varied jointly, holding all other parameters constant. Given the policy and programmatic implications to workplaces of these study results, the sensitivity analysis will provide valuable information to decision makers regarding the robustness of our study.

\section{Next Steps for the YIW Initiative}

The findings from the YIW initiative will provide strong evidence of the effectiveness of the six YIW grantee programs to reduce substance use and improve the health and productivity of young working adults. The crosssite evaluation will add to this body of knowledge by generating evidence of program effectiveness through a rigorous cross-site analysis to identify practices and contextual factors that influence these practices across a variety of employment settings. Although these findings have the potential to significantly advance the workplace prevention field, more research is needed as the nature of the workplace and the American workforce continues to change.

Currently, SAMHSA's National Registry of Effective Programs and Practices includes 140 programs or practices, 54 of which are classified as prevention programs; only 4 of these are workplace-based. With supporting evidence, the current YIW grantees will add to the list of programs in the registry. For future studies, we can build on this foundation by considering a replication of the current YIW programs, or an expansion of this initiative with a new set of intervention programs, or some combination of program replication 
and expansion. As depicted in Figure 8.2, replication efforts consisting of new employers investigating the effectiveness of the current YIW interventions will deepen our understanding of the effect of these interventions in more divergent contexts, and strengthen our analytic power to test the robustness of cross-site findings. Expansion efforts consisting of new employers using different interventions will expand our commonality matrix and broaden our understanding of the effects of prevention messaging coupled with a wider set of content areas and delivery methods. Replication and expansion of the YIW initiative will allow for the pooling of data in meaningful ways to carry out evaluations that permit explicit and robust statistical testing of program effectiveness.

Replication of the YIW initiative will be informed by the findings from the current initiative. Therefore, the immediate next steps for the current

\section{Figure 8.2 YIW cohorts 1 and 2: analytic integration plan}

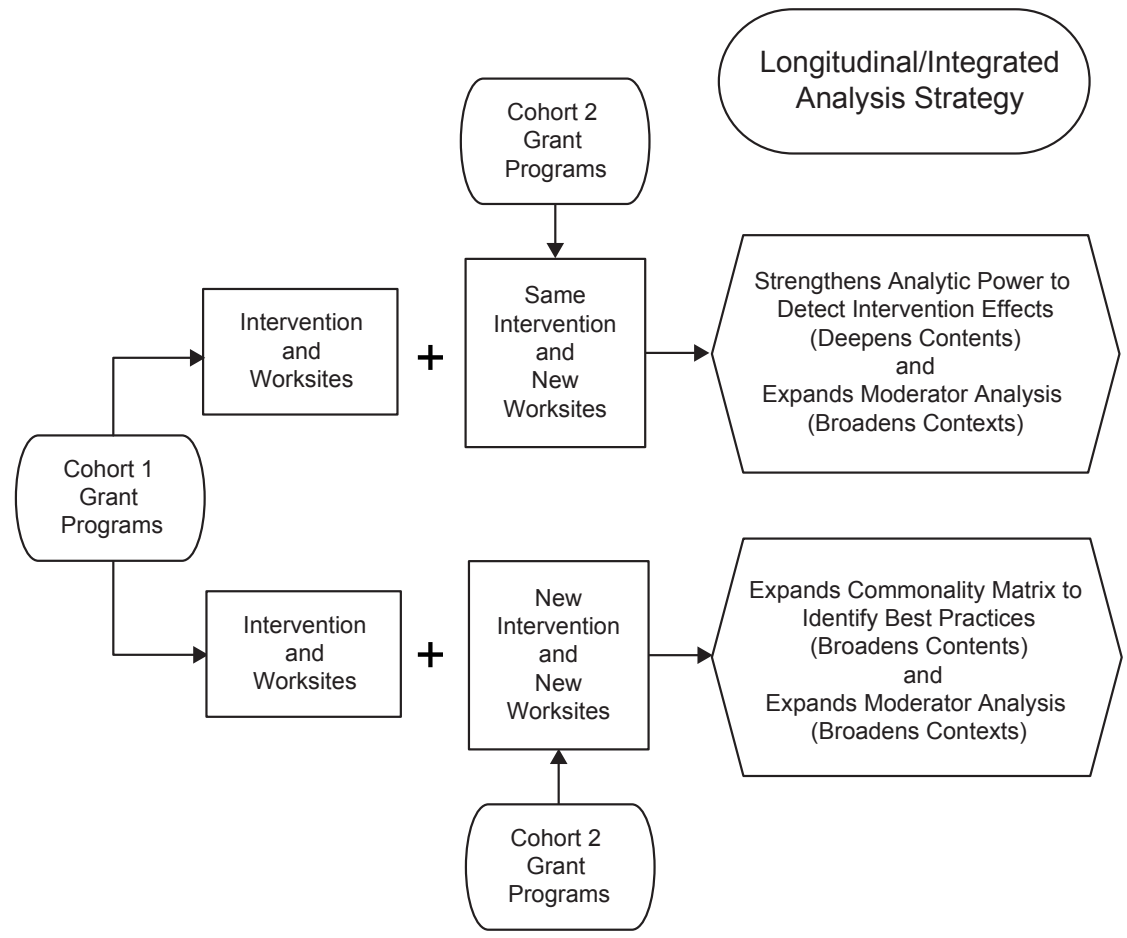


YIW initiative will be to complete the grantee and cross-site data analysis and disseminate the findings. In this volume, we provide a detailed description of the grantee programs and the methods for the cross-site evaluation. Subsequent peer-reviewed and professional publications will present the findings and recommendations for program dissemination and policy at the national level.

\section{References}

Breslow, N. E., \& Clayton, D. G. (1993). Approximate inference in generalized linear mixed models. Journal of the American Statistical Association, 88(421), 9-25.

Cohen, S., \& Williamson, G. (1988). Perceived stress in a probability sample of the United States. In S. Spacapan \& S. Oskamp (Eds.), The social psychology of health (pp. 31-67). Newbury Park, CA: Sage.

Cook, R. F., Back, A. S., Trudeau, J., \& McPherson, T. (2003). Integrating substance abuse prevention into health promotion programs in the workplace: A social-cognitive intervention targeting the mainstream user. In J. B. Bennett, \& W. E. K. Lehman (Eds.), Preventing workplace substance abuse: Beyond drug testing to wellness (pp. 97-133). Washington, DC: American Psychological Association.

Corson, K., Gerrity, M. S., \& Dobscha, S. K. (2004). Screening for depression and suicidality in a VA primary care setting: 2 items are better than 1 item. The American Journal of Managed Care, 10(11), 839-845.

Dennis, M. L. (1990). Assessing the validity of randomized field experiments: An example from drug abuse treatment research. Evaluation Review, 14(4), 347-373.

Fairweather, G. W., \& Tornatzky, L. G. (1977). Experimental methods for social policy research. New York: Pergamon Press.

Hackman, J. R., \& Oldham, G. R. (1975). Development of the job diagnostic survey. Journal of Applied Psychology, 60(2), 159-170.

Karuntzos, G. T. (2004). The logic model. In M. S. Lewis-Beck, A. Bryman, \& T. F. Liao (Eds.), The Sage encyclopedia of social science research methods (Vol. 3) (pp. 484-485). Thousand Oaks, CA: Sage. 
Kessler, R. C., Barber, C., Beck, A., Berglund, P., Cleary, P. D., McKenas, D., et al. (2003). The World Health Organization Health and Work Performance Questionnaire (HPQ). Journal of Occupational and Environmental Medicine, 45(2), 156-174.

Kessler, R. C., Ames, M., Hymel, P. A., Loeppke, R., McKenas, D. K., Richling, D. E., et al. (2004). Using the World Health Organization Health and Work Performance Questionnaire (HPQ) to evaluate the indirect workplace costs of illness. Journal of Occupational and Environmental Medicine, 26(6), S23-S37.

Kroenke, K., Spitzer, R. L., \& Williams, J. B. W. (2001). The PHQ-9: Validity of a brief depression severity measure. Journal of General Internal Medicine, 16(9), 606-613.

Lowe, B., Spitzer, R. L., Grafe, K., Kroenke, K., Quenter, A., Zipfel, S., et al. (2004). Comparative validity of three screening questionnaires for DSMIV depressive disorders and physicians' diagnoses. Journal of Affective Disorders, 78(2), 131-140.

MacKinnon, D. P., Taborga, M. P., \& Morgan-Lopez, A. A. (2002). Mediation designs for tobacco prevention research. Drug and Alcohol Dependence, 68, S69-S83.

McDaniel, S. R., \& Zuckerman, M. (2003). The relationship of impulsive sensation seeking and gender to interest and participation in gambling activities. Personality and Individual Differences, 35(6), 1385-1400.

Millar, A., Simeone, R. S., \& Carnevale, J. T. (2001). Logic models: A systems tool for performance management. Evaluation and Program Planning, 24(1), $73-81$.

Sambrano, S., Springer, J. F., Sale, E., Kasim, R., \& Hermann, J. (2005). Understanding prevention effectiveness in real-world settings: The national cross-site evaluation of high risk youth programs. American Journal of Drug and Alcohol Abuse, 31(3), 491-513.

Scott, A. G., \& Sechrest, L. (1989). Strength of theory and theory of strength. Evaluation and Program Planning, 12(4), 329-336.

Sechrest, L., White, S. O., \& Brown, E. D. (1979). The rehabilitation of criminal offenders: Problems and prospects. Washington, DC: National Academy of Sciences. 
Sheu, S., Lin, H., \& Hwang, S. (2002). Perceived stress and physio-psychosocial status of nursing students during their initial period of clinical practice: The effect of coping skills. International Journal of Nursing Studies, 39, 165-175.

Siegel, J. E., Weinstein, M. C., \& Torrance, G. W. (1996). Reporting costeffectiveness studies and results. In M. R. Gold, J. E. Siegel, \& M. C. Weinstein (Eds.), Cost-effectiveness in health and medicine (pp. 276-303). New York: Oxford University Press.

Sinacore, J. M., \& Turpin, R. S. (Eds.). (1991). Multisite evaluations (new directions for program evaluation) San Francisco, CA: Jossey-Bass.

Siqueira, L., Diab, M., Bodian, C., \& Rolnitzky, L. (2000). Adolescents becoming smokers: The roles of stress and coping methods. Journal of Adolescent Health, 27(6), 399-408.

Spitzer, R. L., Kroenke, K., Williams, J. B. W., and the Patient Health Questionnaire Primary Care Study Group (1999). Validation and utility of a self-report version of PRIME-MD. The Journal of the American Medical Association, 282(18), 1737-1744.

Steckler, A., \& Linnan, L. (Eds.) (2002). Process evaluation for public health interventions and research. San Francisco, CA: Jossey-Bass.

Straw, R. B., \& Herrell, J. M. (2002). A framework for understanding and improving multisite evaluations. New Directions for Evaluation, 94, 5-15.

Substance Abuse and Mental Health Services Administration (SAMHSA) (2008). Results from the 2007 National Survey on Drug Use and Health: National findings (Office of Applied Studies, NSDUH Series H-34, DHHS Publication No. SMA 08-4343). Rockville, MD: SAMHSA.

Wang, P. S., Beck, A., Berglund, P., Leutzinger, J.A., Pronk, N., Richling, D., et al. (2003). Chronic medical conditions and work performance in the health and work performance questionnaire calibration surveys. Journal of Occupational and Environmental Medicine, 45, 1303-1311.

West, S. G., \& Aiken, L. S. (1997). Towards understanding individual effects in multiple component prevention programs: Design and analysis strategies. In K. Bryant, M. Windle, \& S. West (Eds.), The science of prevention: Methodological advances from alcohol and substance abuse research (pp. 167-209). Washington, DC: American Psychological Association. 
Yin, R. K. (1998). The abridged version of case study research: Design and method. In L. Bickman \& D. J. Rog (Eds.), Handbook of applied social research methods (pp. 229-259). London: Sage.

Zaré, S. M., Galanko, J., Behrns, K. E., Korunda, M. J., Boyle, L. M., Farley, D. R., et al. (2004). Psychological well-being of surgery residents before the 80-hour work week: A multiinstitutional study. Journal of the American College of Surgeons, 198(4), 633-640.

Zarkin, G. A., Dunlap, L. J., \& Homsi, G. (2004). The substance abuse services cost analysis program (SASCAP): A new method for estimating drug treatment services costs. Evaluation and Program Planning, 27(1), 35-43.

Zuckerman, M. (2002). Genetics of sensation seeking. In J. Benjamin, R. P. Ebstein, \& R. H. Belmaker (Eds.), Molecular genetics and the human personality. Washington, DC: American Psychiatric Publishing. 


\section{Appendix: Additional Information about the Outcome Study Analysis}

Guided by the grantees' evaluation models of their workplace prevention and early intervention programs, our analysis framework is shown in Equation 1 (assuming only two content areas):

$$
\begin{aligned}
& E\left(y_{j i t} \mid \mathbf{z}_{j i t}, \mathbf{x}_{j i t}, \xi_{j}, \eta_{j i}\right)=f\left(\beta_{0 j i}+\beta_{1 j} S U_{j i t}+\beta_{2} L S_{j i t}+\mathbf{x}_{j i t}^{\prime} \beta\right) \\
& \beta_{0 j i}=\beta_{0}+\xi_{0 j}+\eta_{0 j i} \\
& \beta_{1 j}=\beta_{1}+\alpha_{1} L S_{j i t}+\xi_{1 j}
\end{aligned}
$$

where $y_{j i t}$ is the outcome for person $i$ at worksite $j$ in time $t, \mathbf{x}_{j i t}$ is a vector of observed characteristics of person $i$ and characteristics of worksite $j$ in time $t, S U_{j i t}$ and $L S_{j i t}$ are the time in hours spent delivering substance use/abuse messages and for teaching life skills to person $i$ at worksite $j$ in time $t, \eta_{0 j i}$ is the person-level random intercept that represents unobserved time-invariant heterogeneity, and $\left(\xi_{0 j}, \xi_{1 j}\right)$ are the worksite random intercept and random slope that allow the estimation of the worksite-specific effect of substance use/abuse messages. $S U_{j i t}$ and $L S_{j i t}$ are enumerated during the process study. $f$ is a known link function that depends on the distribution of the outcome under investigation. For example, if the outcome is whether a person consumes alcohol, then the link function can be the logit function that leads to a random effect logistic regression; if the outcome is a person's ranking of degree of approval of the frequency of tobacco, alcohol, and marijuana use in five categories-strongly approve, somewhat approve, neither approve or disapprove, somewhat disapprove, and strongly disapprove-then the link function can be either the logit link or the probit link that leads to an ordered logistic or probit regression analysis with random effects.

Equation 1 hypothesizes that the effect of delivering substance use/abuse messages on employee outcomes is worksite-specific and is moderated by life skills messaging. The flexibility of the model lies in the fact that it also permits testing of equal treatment effects across all worksites. The primary coefficient of interest, $\beta_{1}$, measures the average treatment effect per hour of substance use content $\left(S U_{j i t}\right)$ across all grantees. The worksite-specific intervention effect will be estimated by $\xi_{1 j}$. In addition, the coefficient $\alpha_{1}$ measures the moderating effect of an additional hour of life skills content $\left(L S_{j i t}\right)$ on the effect of substance use/abuse messaging content $\left(\mathrm{SU}_{\mathrm{jit}}\right)$. 



\section{Contributors}

Charles C. Aden, MS, Organizational Wellness \& Learning Systems, Ft. Worth, Texas

Joel B. Bennett, PhD, Organizational Wellness \& Learning Systems, Ft. Worth, Texas

Douglas W. Billings, PhD, ISA Associates, Inc., Alexandria, Virginia

Gilbert J. Botvin, PhD, Weill Cornell Medical College, New York, New York

Jeremy W. Bray, PhD, RTI International, Research Triangle Park, North Carolina

Laurie A. Cluff, PhD, RTI International, Research Triangle Park, North Carolina

Royer F. Cook, PhD, ISA Associates, Inc., Alexandria, Virginia

Jean Denious, $\mathrm{PhD}$, OMNI Institute, Denver, Colorado

Eric Einspruch, PhD, RMC Research Corporation, Portland, Oregon

Deborah M. Galvin, PhD, Substance Abuse and Mental Health Services Administration, Center for Substance Abuse Prevention, Division of Workplace Programs, Rockville, Maryland

Kenneth W. Griffin, PhD, Weill Cornell Medical College, White Plains, New York

Rebekah K. Hersch, PhD, ISA Associates, Inc., Alexandria, Virginia

Jennifer Hooks, MA, OMNI Institute, Denver, Colorado

Daniel Hughes, PhD, Mount Sinai Medical Center, New York, New York

Kelly Jarvis, PhD, RMC Research Corporation, Portland, Oregon

Georgia T. Karuntzos, PhD, RTI International, Research Triangle Park, North Carolina

Caitlin Kozicki, MA, LPC, CAC III, CEAP, Peer Assistance Services, Denver, Colorado
Samantha L. Leaf, PhD, ISA Associates, Inc., Alexandria, Virginia

Ted Miller, PhD, Pacific Institute for Research and Evaluation, Calverton, Maryland

Johannes Norling, BA, University of Michigan, Ann Arbor, Michigan

Chris O'Neill, RN, DMin, Oregon Nurses Foundation, Tualatin, Oregon

Paméla Raya-Carlton, EdD, RMC Research Corporation, Portland, Oregon

Nick Reese, MA, OMNI Institute, Denver, Colorado

Brie Reimann, BA, Peer Assistance Services, Denver, Colorado

Chandra Ring, BA, OMNI Institute, Denver, Colorado

Jessica Samuolis, $\mathrm{PhD}$, National Health Promotion Associates, White Plains, New York

William Schlenger, Abt Associates, Durham, North Carolina, and RTI International, Research Triangle Park, North Carolina

Rebecca Spicer, MPH, PhD, Pacific Institute for Research and Evaluation, Calverton, Maryland

Cori Stott, MA, Peer Assistance Services, Denver, Colorado

Kelly Vander Ley, PhD, RMC Research Corporation, Portland, Oregon

Christopher Williams, PhD, National Health Promotion Associates, White Plains, New York

Eduard Zaloshnja, PhD, Pacific Institute for Research and Evaluation, Calverton, Maryland 


